Florida International University FIU Digital Commons

\title{
Video Modeling for Teaching Imitation to Young Children With Autism: A Treatment Comparison and Analysis of Potential Predictors of Success
}

Logan S. McDowell

Florida International University, lsmcdowe@fiu.edu

DOI: 10.25148 /etd.FIDC000124

Follow this and additional works at: https:// digitalcommons.fiu.edu/etd

Part of the Applied Behavior Analysis Commons, and the Developmental Psychology Commons

\section{Recommended Citation}

McDowell, Logan S., "Video Modeling for Teaching Imitation to Young Children With Autism: A Treatment Comparison and Analysis of Potential Predictors of Success" (2015). FIU Electronic Theses and Dissertations. 2178.

https://digitalcommons.fiu.edu/etd/2178 


\section{FLORIDA INTERNATIONAL UNIVERSITY}

Miami, Florida

\section{VIDEO MODELING FOR TEACHING IMITATION TO YOUNG CHILDREN WITH AUTISM: A TREATMENT COMPARISON AND ANALYSIS OF POTENTIAL PREDICTORS OF SUCCESS}

A dissertation submitted in partial fulfillment of the requirements for the degree of DOCTOR OF PHILOSOPHY

in

PSYCHOLOGY

by

Logan McDowell

2015 
To: Dean Michael R. Heithaus

College of Arts and Sciences

This dissertation, written by Logan McDowell, and entitled Video Modeling for Teaching Imitation to Young Children with Autism: A Treatment Comparison and Analysis of Potential Predictors of Success, having been approved in respect to style and intellectual content, is referred to you for judgment.

We have read this dissertation and recommend that it be approved.

Jonathan Comer

Leslie Frazier

Kyle Bennett

Anibal Gutierrez, Major Professor

Date of Defense: June 5, 2015

The dissertation of Logan McDowell is approved.

$\begin{array}{r}\hline \begin{array}{r}\text { Dean Michael R. Heithaus } \\ \text { College of Arts and Sciences }\end{array} \\ \hline \begin{array}{r}\text { Dean Lakshmi N. Reddi } \\ \text { University Graduate School }\end{array}\end{array}$

Florida International University, 2015 
(C) Copyright 2015 by Logan McDowell

All rights reserved. 


\section{DEDICATION}

This dissertation is dedicated to my family. Mom, Dad, and André: I would never have been able to come this far without your consistent, unwavering love and support. Thank you for everything. 


\section{ACKNOWLEDGMENTS}

I would like to thank the members of my committee for all of their support and assistance in completing this dissertation. To Dr. Anibal Gutierrez, thank you for all that you have taught me over these past four years. You have consistently gone above and beyond the expectations of a mentor. Your guidance, support, and knowledge have helped me make it through a bumpy and yet ultimately immeasurably fulfilling journey. I will always be grateful for your mentorship. I would also like to thank Dr. Kyle Bennett for believing in me, sharing my interests, and providing me with knowledge, encouragement, and irreplaceable research experience. To Dr. Jon Comer, thank you for agreeing to participate in the final stretch of my graduate career, I truly appreciate your time and effort, as well as the differing perspective that you have contributed over the past year. Finally, I would specifically like to thank Dr. Leslie Frazier, who has consistently been there when I most needed her, brought sanity when there seemed to be none left, truly supported my research even though it may, at times, have strayed from her area of expertise, and above all else has always cared deeply about the success of all

of her students. Without all of your support I do not know that I would have been able to make it this far. Thank you. 


\section{ABSTRACT OF THE DISSERTATION \\ VIDEO MODELING FOR TEACHING IMITATION TO YOUNG CHILDREN WITH \\ AUTISM: A TREATMENT COMPARISON AND ANALYSIS OF POTENTIAL \\ PREDICTORS OF SUCCESS \\ by}

Logan McDowell

Florida International University, 2015

Miami, Florida

Professor Anibal Gutierrez, Major Professor

Imitation is a prerequisite for the development of several important abilities.

Children with Autism Spectrum Disorder (ASD) exhibit a distinct deficit in imitation. There has been a considerable amount of research into the most effective ways to teach this crucial skill. Unfortunately, there are drawbacks to many prevalent teaching strategies including difficulty with implementation and lack of generalization. The present study sought to determine whether video modeling (VM) might function as a successful alternative for teaching imitation to young children with ASD.

The literature on VM has demonstrated that it can be a highly effective technique for teaching a variety of skills to individuals with ASD. Additionally, VM has been identified as easy to implement and has lead to improved generalization when compared to other treatments. However, there are still a number of questions about when, and for whom, VM is most effective. The current study begins to answer some of these questions by analyzing a treatment comparison between VM and live modeling (LM). Eight children were taught to imitate two equivalent behaviors each, one using VM and the 
other using LM. The trials to criterion required to learn the behaviors were then compared.

Results indicated that there was a significant difference between the two treatment types, and that six of the participants were more successful with VM. Neither social skills nor technological literacy were significant predictors of treatment success. However, pretreatment imitative abilities were shown to significantly predict success. Those children with the fewest imitative abilities were shown to be more successful with the VM technique, while those children with more imitative abilities were more successful with LM. An additional analysis was conducted to evaluate the predictive relationship between social skills and imitation. Results indicated that social skills significantly predict imitative abilities. These results could have widespread implications for imitation training, as they verify the relationship between social skills and imitation, demonstrate that VM can be an effective treatment for teaching young children with ASD to imitate, and further indicate that a pre-treatment imitation assessment may help to identify the most effective and efficient treatment for each child. 


\section{TABLE OF CONTENTS}

CHAPTER

PAGE

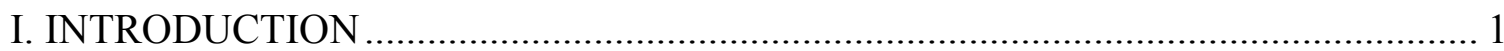

Autism Spectrum Disorders: A review of the literature ........................................... 2

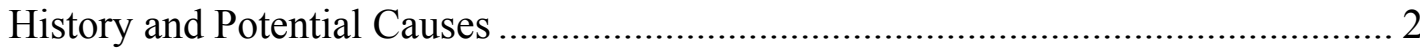

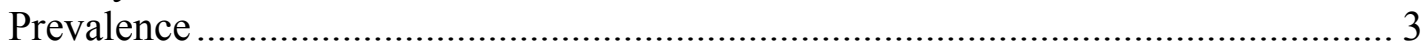

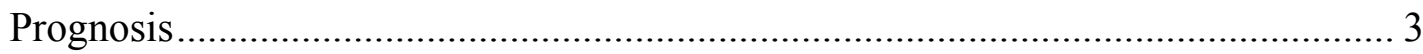

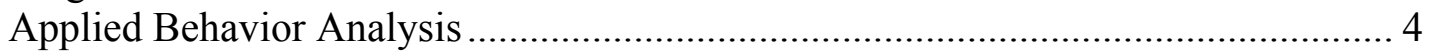

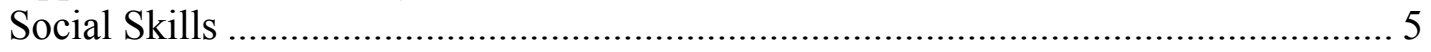

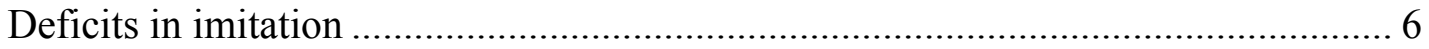

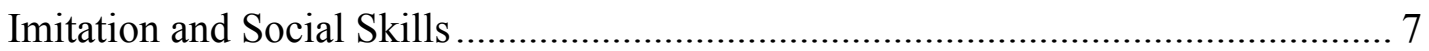

II. THEORETICAL PERSPECTIVE _.................................................................... 9

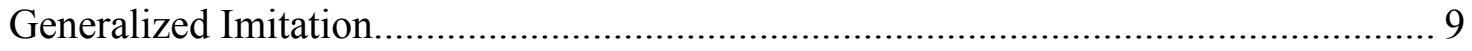

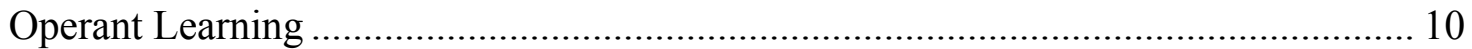

Unit of analysis: The Three Term Contingency ......................................................... 12

Applied Behavior Analysis: Intervention .............................................................. 13

Discrete Trial Training ........................................................................................ 14

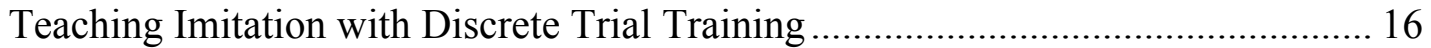

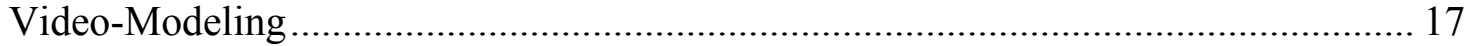

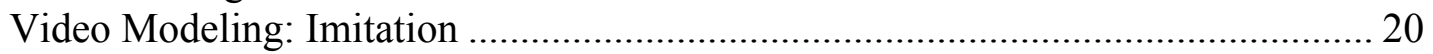

Video Modeling: Unresolved Questions........................................................... 23

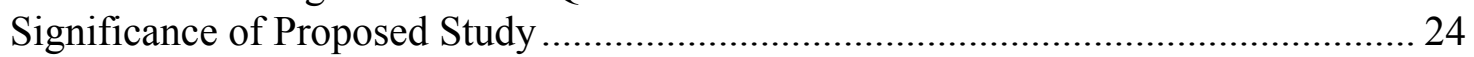

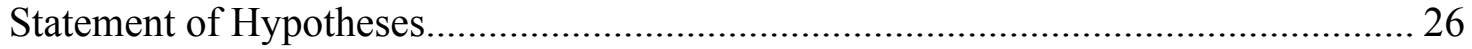

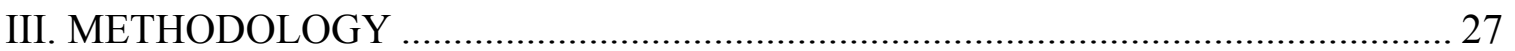

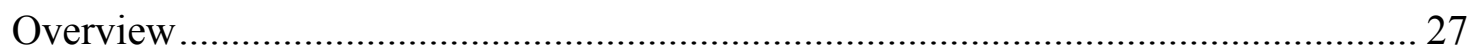

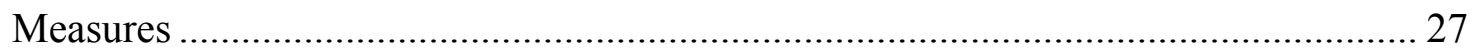

Autism Diagnostic Observation Schedule: Second Edition (ADOS-2) .................... 27

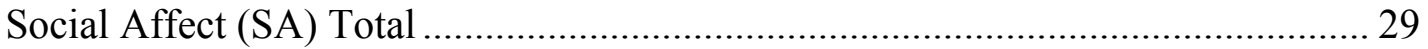

Motor Imitation Scale (MIS) .................................................................... 31

Parent and Family Technology Survey .......................................................... 32

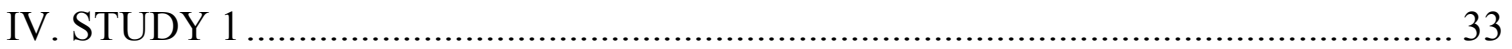

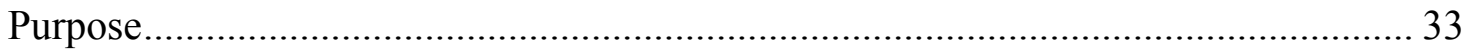

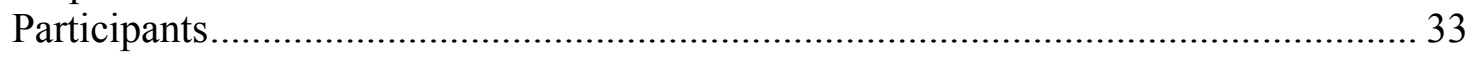

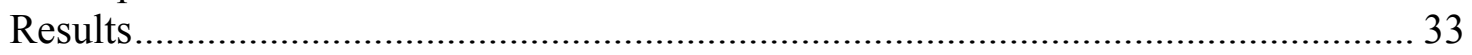

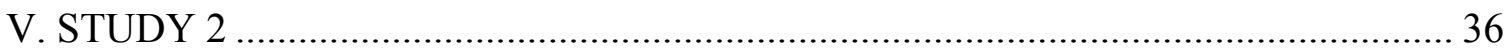

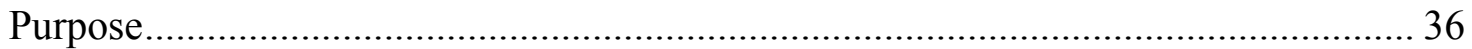

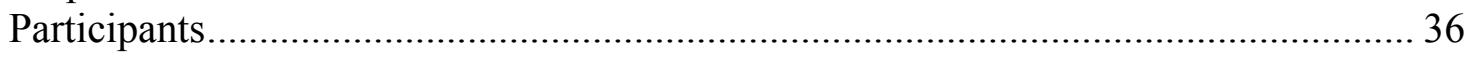




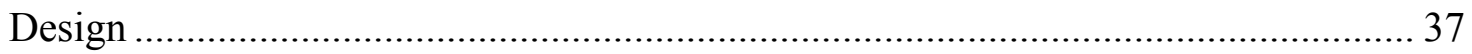

Alternating Treatments Design .................................................................... 37

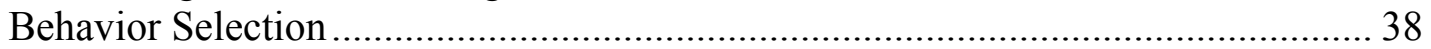

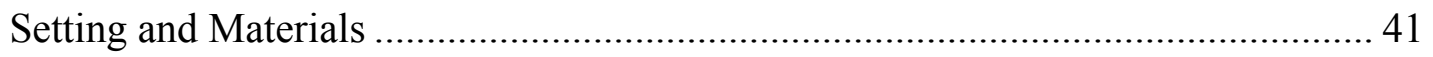

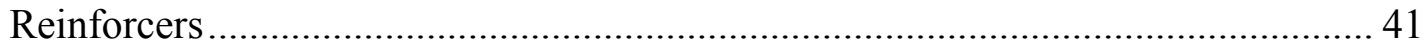

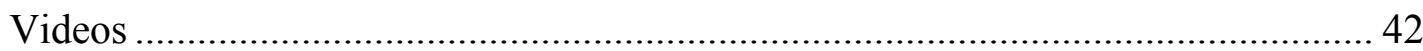

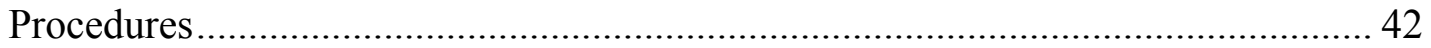

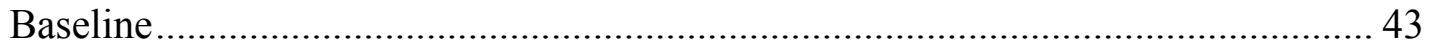

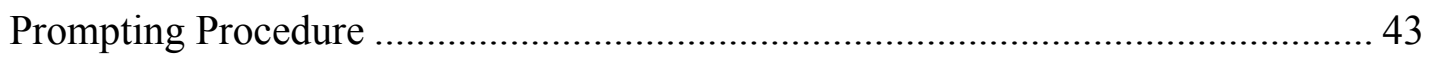

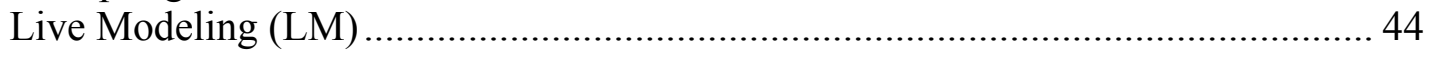

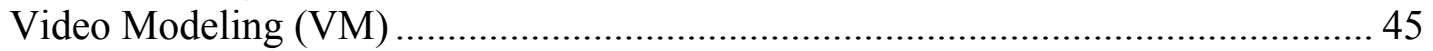

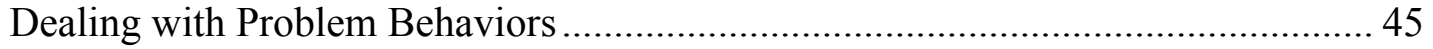

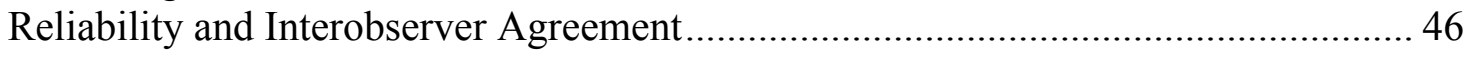

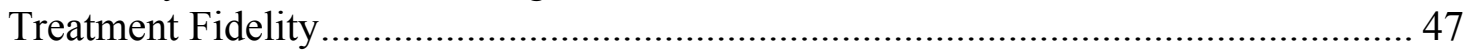

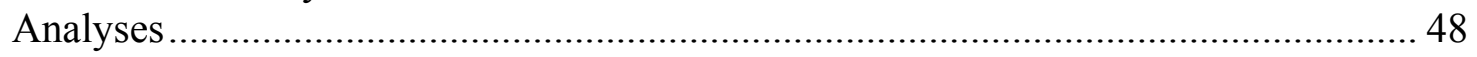

Individual Participant Characteristics and Results ............................................... 49

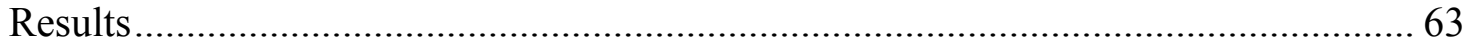

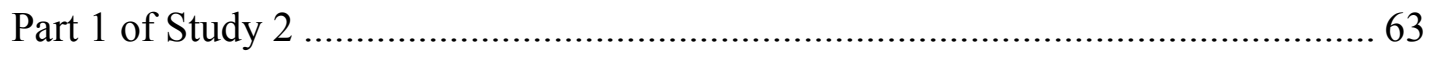

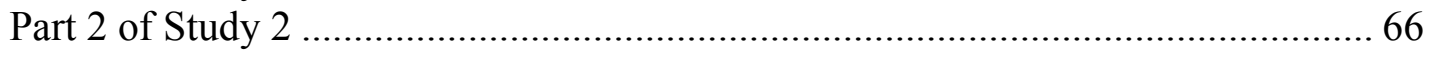

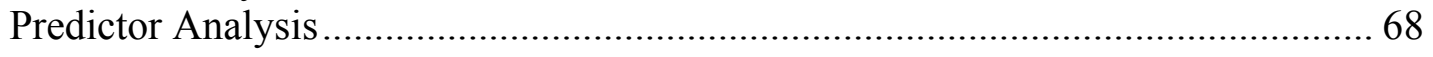

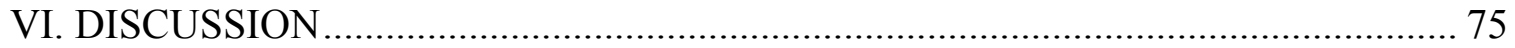

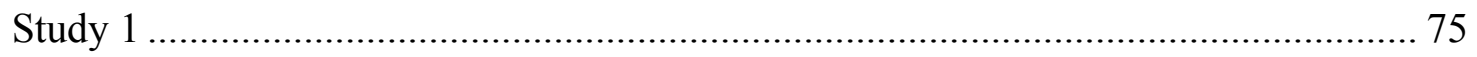

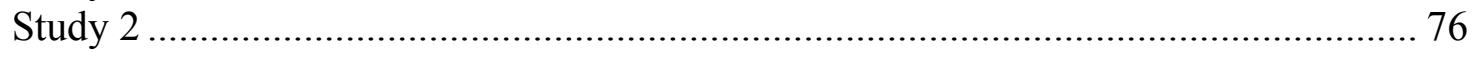

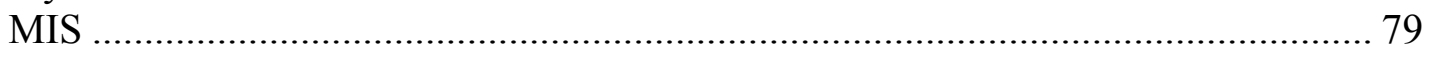

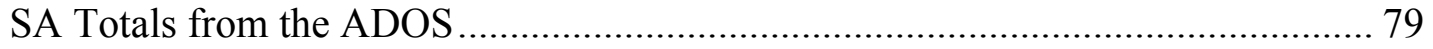

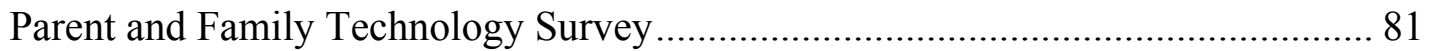

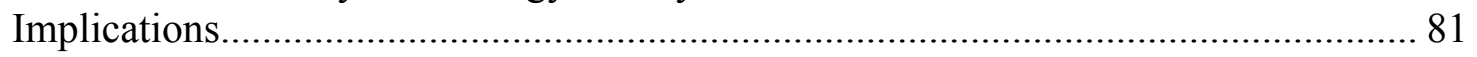

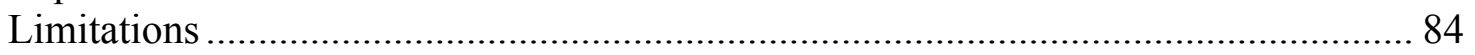

Future Directions ............................................................................................ 86

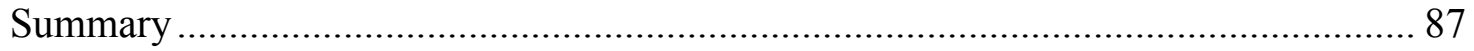

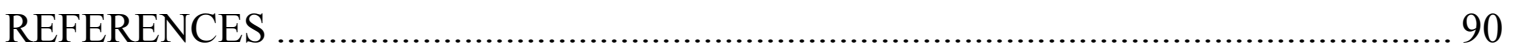

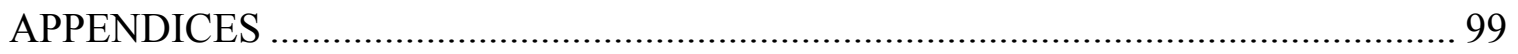

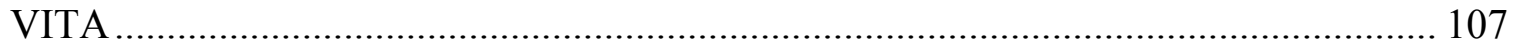




\section{LIST OF FIGURES}

FIGURE

PAGE

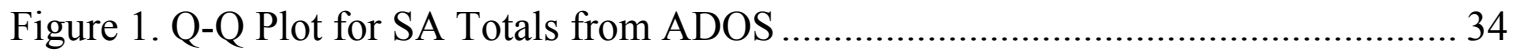

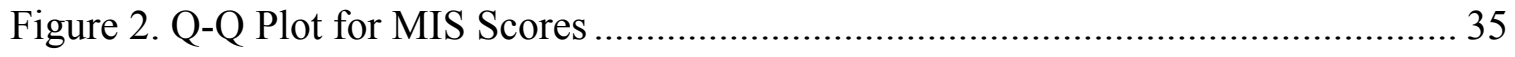

Figure 3. Sample Imitation Schedule ................................................................. 38

Figure 4. Line Graph of Treatment Mastery and Trials to Criterion Chart for Scott ....... 55

Figure 5. Line Graph of Treatment Mastery and Trials to Criterion Chart for Edgar ...... 56

Figure 6. Line Graph of Treatment Mastery and Trials to Criterion Chart for Fiona....... 57

Figure 7. Line Graph of Treatment Mastery and Trials to Criterion Chart for Pedro ...... 58

Figure 8. Line Graph of Treatment Mastery and Trials to criterion Chart for Samantha. 59

Figure 9. Line Graph of Treatment Mastery and Trials to Criterion Chart for Adam...... 60

Figure 10. Line Graph of Treatment Mastery and Trials to criterion Chart for Arnie ..... 61

Figure 11. Line Graph of Treatment Mastery and Trials to Criterion Chart for Leo ....... 62

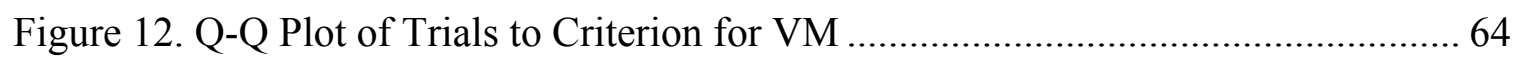

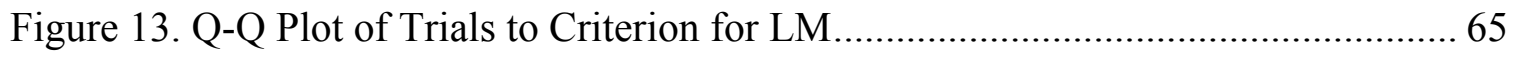

Figure 14. Trials to Criterion for Each Participant and Treatment Type ........................ 67

Figure 15. Differences in Trials to Criterion Between Treatments ............................... 68

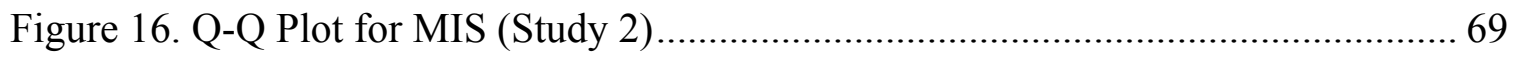

Figure 17. Q-Q Plot for Parent and Family Technology Survey ................................ 70

Figure 18. Graph of Each Participant's MIS Score ............................................... 71

Figure 19. Graph of Each Participant's SA Total from the ADOS .............................. 73

Figure 20. Graph of Each Participant's Parent and Family Technology Survey Score .... 74 


\section{ABBREVIATIONS AND ACRONYMS}

ABA

ADOS

APA

ASD

BAAR

$\mathrm{CCF}$

$\mathrm{CDC}$

DSM-V

DTT

FIU

IOA

LM

MIS

Mullen

PBS

PVM

SA

$\mathrm{S}^{\mathrm{D}}$

$\mathrm{S}^{\mathrm{P}}$

VM

VSM
Applied Behavior Analysis

Autism Diagnostic Observation Schedule

American Psychiatric Association

Autism Spectrum Disorder

Behavioral Analysis Autism Research Lab

Center for Children and Families

Center for Disease Control

Diagnostic and Statistical Manual of Mental Disorders

Discrete Trial Training

Florida International University

Inter-Observer Agreement

Live Modeling

Motor Imitation Scale

Mullen Scales of Early Learning

Public Broadcasting Services

Point of View Video Modeling

Social Affect

Discriminative Stimulus

Discriminative Stimulus for Punishment

Video Modeling

Video Self-Modeling 


\section{INTRODUCTION}

Autism Spectrum Disorder (ASD) is comprised of a series of neurodevelopmental disorders characterized by pervasive deficits in social communication and social interaction, and the presence of restricted, repetitive or stereotyped behaviors. The Diagnostic and Statistical Manual of Mental Disorders (DSM-V; American Psychiatric Association [APA], 2013) further specifies that these deficits must be present across contexts, not accounted for by general developmental delays, present in childhood, and when combined, must limit or impair everyday functioning.

The present study focused specifically on what the DSM-V describes as deficits in social communication and interaction. These deficits can be further grouped into three subcategories including: (a) deficits in social-emotional reciprocity, (b) deficits in nonverbal communication, and (c) deficits in developing, maintaining, and understanding relationships. The present study concentrated on how these deficits in social communication relate to the substantial deficiency in imitation often seen in individuals diagnosed with ASD. In an effort to further explore the relationship between these social and imitative deficits, scores on social skills assessments were compared to scores on imitation assessments to determine whether social skills significantly predicted imitation skills within the sample. Additionally the present study explored the utility of social skills, imitation skills, and technological literacy as potential predictors of the effectiveness of a video modeling-based intervention. In combination, the results of these explorations will contribute new information to the body of literature on techniques for improving imitation in young children with autism and, in addition will contribute to the relatively new body of literature on the use of video-modeling as an intervention 
technique for treating individuals with autism through its potential to provide new insight into when and for whom this methodology may be most appropriately employed.

Autism Spectrum Disorders: A review of the literature

\section{History and Potential Causes}

Autism, as first described by Kanner (1943), referred to an emotional disorder characterized by obsessiveness, stereotypy, and an innate inability to form usual affective relationships. Since that time research in ASD has expanded the field's knowledge of the traits, characteristics, and likely outcomes for individuals diagnosed with the disorder. Autism is known to be a chronic, persistent developmental disorder characterized by deficits in social skills, communication, and the presence of restrictive, repetitive, and stereotyped behaviors or patterns of behavior (APA, 2013). While the causes of ASD remain unknown, it is recognized that $\mathrm{ASD}$ is not the result of poor parenting skills as first proposed by Kanner (1943), nor is it the result of poor reactions to vaccinations (Madsen, 2004). Instead, ASD is likely related to abnormal brain development that is argued to be the result of the interrelated impact of environmental and inherited factors (Herbert, 2010; Lickliter \& Honeycutt, 2013). Evidence for the presence of a genetic factor in the development of ASD was first demonstrated by Folstein and Rutter (1977) who conducted a traditional twin study and found that four out of 11 pairs of monozygotic twins were concordant for ASD as opposed to zero out of 10 sets of dizygotic twins. The Folstein and Rutter study has been followed in recent years by several others, which indicate the presence of a genetic determinant in the development of ASD. However, the discordance between some sets of monozygotic twins confirms that the basis of ASD is not 100\% genetic (Folstein \& Rutter, 1977). Instead it is 
theorized that environmental factors such as toxins, illness, trauma, and other pre- and post-natal factors may play a role in the development of ASD (Herbert, 2010).

Prevalence

Most recent estimates place the prevalence of ASD at approximately 1 in 68 individuals with a larger proportion being male than female (Centers for Disease Control and Prevention [CDC], 2013). According to the CDC, currently 1 in 42 males are diagnosed with ASD, as compared to 1 in 189 females (CDC, 2013). These numbers represent a more than 16-fold increase in the number of individuals diagnosed with ASD over the last 30 years. The increase in diagnosis is likely the result of a combination of factors including broader recognition of the symptomatology and early diagnosis. Regardless of the cause, this has resulted in an increase in the number of individuals requiring treatment and accommodations (Hattier \& Matson, 2012).

Prognosis

While traditionally the prognosis for individuals diagnosed with ASD was considered relatively poor, with as many as $25 \%$ of individuals remaining mute for their entire lives (Hattier \& Matson, 2012), recent findings related to neuroplasticity and the impact of early intervention indicate that significant gains in adaptive skills are possible (Dawson \& Bernier, 2013). According to a systematic review of the existing literature conducted in 2013, outcomes for adolescents and adults diagnosed with autism vary significantly with some individuals leading relatively independent lives, while others continued to rely largely on outside support (Magiati, Tay, \& Howlin, 2014). Although diagnoses tended to remain relatively stable, the degree of severity and presence of symptoms varied. Some studies reported relatively stable data, while others indicated 
deterioration in symptamology over time. The literature further indicated that childhood IQ and early language abilities were the most likely predictors of future outcomes (Magiati, Tay, \& Howlin, 2014). Overall, the prognosis for individuals with ASD has improved in recent years with a growing number of adults living independently (APA, 2013). Improved outcomes may be in part the result of the prevalence of behaviorallybased interventions which are effective in increasing the social and communicative abilities of individuals with ASD and improving their chances of leading independent lives (Dawson, et al. 2002). Additionally, research has demonstrated that when behavioral interventions are implemented intensively and in early childhood, a significant percentage of individuals diagnosed with ASD can become indistinguishable from their typically-developing peers (Lovaas, 1974; Virtues-Ortega, Rodríguez, \& Yu, 2013). Applied Behavior Analysis

Applied behavior analysis (ABA) refers to a psychological discipline wherein the principles of human behavior, as derived through the experimental analysis of behavior as proposed by B.F. Skinner, Albert Watson, and Edward Thorndike, are applied to improving the lives of individuals through intervention with socially significant behaviors (Cooper, Heron \& Heward, 2003). While a variety of therapeutic options are available to individuals with ASD, ABA has been frequently cited since the 1980's as one of the most effective methods for treating individuals with ASD (Rosenwasser \& Axelrod, 2001). Interventions relying on $\mathrm{ABA}$ approaches use direct experimentation and analysis to design and implement behavioral techniques which can both increase adaptive behaviors and decrease maladaptive behaviors in individuals with a variety of diagnoses. One basic tenet of $\mathrm{ABA}$ is that specific, observable behaviors are the focus of analysis and that each 
person must be addressed as an individual rather than as a member of a diagnostic category or group. However, ABA is frequently and successfully implemented with individuals with a diagnosis of ASD, and when implemented in a comprehensive fashion, has been shown to be effective in improving intellectual functioning, language development, daily living skills, and social functioning (Virtues-Ortega, 2010).

There has been an increased focus in recent years on the importance of early diagnosis and intervention in the treatment of ASD (Virtues-Ortega, 2010). Early intensive behavioral intervention programs are a particular type of ABA intervention in which young children receive between 25 and 40 hours per week of treatment in the acquisition of verbal behavior, pre-academics, imitation, and other essential skills either at home or in a school setting (Kaale, Fagerland, Martinsen, \& Smith, 2014; Lovaas, 2003). The results of a recent meta-analytic study involving 344 children with ASD indicated that groups who received early intensive behavioral intervention were more successful in tests of IQ, non-verbal IQ, expressive and receptive language, and adaptive behaviors than counterparts who did not receive this treatment (Peters-Scheffer, Didden, Korzilius, \& Sturmey, 2010).

\section{Social Skills}

One of the skill sets frequently targeted in early intervention programs is social interaction (Kaale, Fagerland, Martinsen, \& Smith, 2014). Individuals with autism tend to display a series of deficits in social communication and interaction that are pervasive and present across contexts (APA, 2013). While these deficits vary across individuals and may manifest in a number of different behavioral outcomes and extremes, they are often identified as one of the most salient traits of individuals with ASD. Individuals with ASD 
tend to be described as aloof because of the perception that they do not engage with their environments in the typical or expected fashion, and tend to show a lack of positive affect when interacting with others (Radley, et al., 2014; Kasari, et al., 1990). Several behavioral responses have been identified as related to this social abnormality in individuals with ASD including: unusual interactions with others, lack of interest in interaction with others, unusual eye contact or gaze, and lack of joint attention or the ability to share focus with another person on an object or individual (Mundy, Sigman, Kasari, \& Yirmiya, 1990). One additional behavioral deficit present in children with autism, which is highly pervasive and has been posited to relate directly to atypical development of other social skills, is a deficit in imitation (Ingersoll, 2008).

\section{Deficits in imitation}

Imitation refers to the immediate or delayed reproduction of a response with point-to-point similarity to that of a model (Cooper, Heron \& Heward, 2003; Gewirtz, 1969). Over the past several decades, research has consistently demonstrated a severe and distinct deficit in imitative abilities in children and adults diagnosed with ASD (Dawson \& Adams, 1984). The deficit is apparent not only when compared to typically developing individuals but also in comparison to individuals with a variety of other intellectual and developmental disabilities including Down syndrome (Dawson \& Adams, 1984). Deficits in imitation within the ASD population are so pronounced that several researchers have suggested it be included in the diagnostic criteria for ASD (Charman et al. 1997;

Ingersoll, 2008; Rogers and Pennington, 1991; Smith \& Byson 1994; Williams, Whiten \& Singh, 2004; Young, et al., 2011). 
Between the ages of 12 and 24 months, typically developing infants begin to demonstrate a variety of imitative and imitation-based behaviors, including deferred imitation and synchronic imitation (Nadel \& Fonatine, 1989). Synchronic imitation is typically present during play and refers to an infant demonstrating preference for engaging with similar objects to those that another person is engaging with and performing similar actions on or with those objects (Nadel \& Fonatine, 1989). Deferred imitation tends to emerge earlier than synchronic imitation and refers to the reproduction of a demonstrated behavior following the passage of an interval of time (Meltzoff \& Gopnick, 1993). According to Neilsen and Dissanayake (2003), deferred imitation has been demonstrated as early as 6-9 months of age in typically developing infants, while synchronic imitation tends to emerge halfway through the second year of life. Distinct deficits in imitative abilities in children with ASD have been demonstrated as early as 24 months, although it has been theorized that differences in imitative abilities may be present significantly earlier in infancy than the second year (MacDuff, Krantz \& McClannahan, 2001).

\section{Imitation and Social Skills}

Research has demonstrated that imitation plays a crucial role in the development of typical social behavior (Rogers \& Vismara, 2008). It has been argued that the acquisition of many aspects of typical social interaction relies heavily on a child's ability to imitate the actions of others (Ledford \& Wolery, 2010). Deficits in imitation directly relate to impaired learning abilities, cognitive functioning, communication, and specifically, impairments in social behaviors like play and joint attention for individuals with ASD (Ingersoll, 2008). Imitation skills are highly correlated with joint attention and 
have been previously included as a necessary component of the acquisition of joint attention during the course of typical development (Carpenter, Pennington \& Rogers, 2002). Joint attention refers to the ability to share and direct the attention of others through gaze and other communicative behaviors and has been directly tied to improved outcomes for individuals with ASD (Carpenter, Pennington \& Rogers, 2002).

Additionally, researchers have postulated that imitation may be directly linked to the development of a theory of mind, or the ability to discern the presence of mental states in others, which allows for much of our social development (Meltzoff \& Gopnick, 1993). A deficit in imitation could precipitously lead to an abnormal or non-existent theory of mind, which has been posited as one potential cause of abnormal social behaviors in individuals with ASD (Neilsen \& Dissanayake, 2003; Baron-Cohen, 2001).

It has been suggested that imitation serves two primary functions during the course of early development: (a) A learning function by which individuals can acquire new responses not previously present in their behavioral repertoire, and (b) A social function through which infants can interact with others in their environment without the need for more advanced verbal and motor behaviors (Ingersoll, 2008). Early in infancy one of the primary means through which an infant interacts with a caregiver is through reciprocal imitation in which the caregiver imitates the actions of the infant, and on occasion the infant imitates the actions of the caregiver (Ingersoll, 2008). Reciprocal imitation serves to introduce the infant to positive social interactions and other positive emotional responses such as smiles (Ingersoll, 2008). As the infant ages, these interactions become more vocal and eventually develop into a back-and-forth, call-andresponse vocal imitation between caregiver and child that has been shown to be an 
important precursor to typical language development (Locke, 2001). Finally, as the child becomes a toddler and begins to spend increasing periods of time with peers, play-based imitation of peers' actions with particular objects is one of the first means of pre-verbal social interaction with same-age others. In sum, the ability to imitate the actions of others in early childhood introduces infants and toddlers to a variety of reinforcing social interactions, which are often absent in individuals diagnosed with ASD. It is therefore posited that this lack of early imitative ability may be directly tied to, and possibly responsible for, some of the social deficits identified in individuals with ASD (Meltzoff \& Gopnick, 1994). Additionally, imitation has been correlated with a variety of other important social behaviors in the autism literature including language, play, and peer-play (Carpenter, Pennington, \& Rogers, 2002; Ingersoll \& Schreibman, 2006; Stone \& Yoder, 2001).

\section{THEORETICAL PERSPECTIVE}

\section{Generalized Imitation}

In the behavioral literature, generalized imitation refers to a functionally equivalent class of responses that are intermittently reinforced throughout the course of a child's early development and beyond (Gewirtz, 1969; Horne \& Erjavec, 2007). A functionally equivalent class of responses is a group of behaviors that reliably evoke the same or similar reinforcing consequences (Cooper, Heron, \& Heward, 2003). Gewirtz (1969) states that from a very early age, infants gain access to these reinforcers as a consequence of imitating the behavior of the persons around them; at first these persons are primarily the child's caregivers but they come to encompass peers, teachers, and other significant individuals. The first instance of imitation is hypothesized to have been the 
result of either random chance, during which a child happens to produce the same behavior as a model, or through direct training. Direct training would involve the use of shaping procedures to intentionally encourage the child to imitate a model by providing reinforcement for progressive approximations of the ultimate target behavior (Gewirtz, 1969). Fading procedures would then be implemented to decrease the presence of external prompts in favor of the natural discriminative stimuli present in the environment. For example, the process of teaching imitation may include first praising an infant for picking up his hands when he sees his mother clap, then only providing praise when the infant puts his hands together, and finally providing praise only when the infant claps his hands immediately after witnessing his mother do so. Instances beyond the first imitative response may then come under control of a functional response class that includes a variety of topographically distinct behaviors (clapping when the child sees his mother clap, stomping when he sees his father stomp, etc.), which are reinforced intermittently by a variety of different individuals within the child's environment.

In the field of $\mathrm{ABA}$, it is assumed that children who do not imitate the actions of others lack this generalized imitative repertoire (Horne \& Erjavec, 2007). Therefore, teaching generalized imitation is frequently targeted as one of the first behavior acquisition programs for children with ASD who present with limited or no imitative repertoires and are receiving ABA treatment (Rogers \& Vismara, 2008).

\section{Operant Learning}

Applied behavior analytic interventions used to increase imitative behaviors in children with autism are derived from the basic principles of behaviorism, or the philosophy of a science of behavior (Cooper, Heron, \& Heward, 2003). Behavior analysis involves the 
pursuit of the prediction, control, and description of human behavior. John B. Watson first introduced these concepts in the early 1900's. Watson promoted an exclusive focus on concrete and observable behaviors, and a step away from psychology's previous focus on unobservable, under-the-skin factors. He claimed that most, if not all of human development, was caused by interactions with environmental factors rather than innate knowledge or abilities (Watson, 1925). Watson focused primarily on the process of respondent conditioning, also known as Pavlovian conditioning, after Ivan Pavlov a Russian physiologist who is largely responsible for introducing the world to this type of behavioral conditioning (Pavlov, 1977).

Respondent conditioning relies on the presence of basic human reflexes through which certain unconditioned stimuli such as the presence of appetizing food will reliably elicit specific responses, such as the production of an increased amount of saliva, without the need for any prior learning to occur. Through the process of respondent conditioning, these unconditioned stimuli (food) are repeatedly paired with neutral stimuli (a bell ringing) eventually resulting in them becoming conditioned stimuli (a bell ringing) able to reliably elicit a conditioned response (salivation). The respondent conditioning paradigm is one way in which early behaviorists came to be able to predict and control behavior. A second way, more commonly implemented in ABA treatment, is through the use of operant conditioning techniques.

Operant conditioning, as described by B.F. Skinner (1938) refers to the process by which specific consequences, when repeatedly presented immediately following a particular behavior, result in an increased or decreased frequency of that behavior being produced (Cooper, Heron, \& Heward, 2003). Unlike respondent conditioning, which 
relies on behaviors being elicited in the presence of an antecedent stimulus, operant behavior is controlled by consequential stimuli or the impact of the particular behavior on the individual's environment.

Unit of analysis: The Three Term Contingency

Operant conditioning relies on establishing and controlling the relationship between an antecedent stimulus that precedes the production of a response, the response itself, and the consequential stimulus that follows the response. Within the field of ABA, these are typically referred to as the antecedent, behavior, and consequence, or the threeterm contingency (Cooper, Heron \& Heward, 2003). The ability to impact behavior relies not only the identification of the stimuli themselves but also on the relationship that they share with the behavior in question. In order to control behavior one must be able to identify a functional relationship, or one in which a specific antecedent predictably evokes a particular response as a result of a particular consequence having been previously delivered in the presence of that antecedent stimuli (Glenn, Ellis, \& Greenspoon, 1992). Given that the antecedent stimulus reliably evokes a response, it is referred to as a discriminative stimulus $\left(\mathrm{S}^{\mathrm{D}}\right)$, or a stimulus that in the past has signaled the availability of a particular consequence contingent upon the performance of a particular behavior. This terminology, however, is only appropriate given that the consequential stimulus in question is reinforcing. A reinforcing stimulus is one which, when provided contingent upon a specific behavior, increases the likelihood that that behavior will be produced in the future (Cooper, Heron \& Heward, 2003). Therefore, the three-term contingency in operant conditioning refers to: a discriminative antecedent stimulus $\left(\mathrm{S}^{\mathrm{D}}\right)$, followed by a target behavioral response, followed immediately by a reinforcing 
consequential stimulus. If the consequential stimulus was not reinforcing but instead was a punisher, or a stimulus which when presented contingent upon the performance of a particular behavior decreased that future likelihood of the behavior occurring, then the antecedent stimulus would be referred to as a discriminative stimulus for punishment $\left(\mathrm{S}^{\mathrm{P}}\right)$. The present study will focus primarily on procedures to increase specific behaviors and will therefore rely exclusively on reinforcing, rather than punishing, consequences.

Applied Behavior Analysis: Intervention

Applied behavior analysis (ABA) is a clinical area of psychology in which operant conditioning techniques are used to improve socially significant behaviors (Baer, Wolf \& Risley, 1968). Ayllon and Michael (1959) were among the first to employ these techniques in their efforts to improve and modify the behaviors of individuals living in a psychiatric institution. Since that time, ABA interventions have been used to treat individuals with a variety of disabilities as well as non-disabled individuals in need of behavioral modification (Blundell, Shepherd, Dean \& Adams, 2003; Correia \& Benson, 2006; Ghaderi, 2011; Kroeger \& Nelson, 2006). The first recorded instance of ABA interventions being applied to the treatment of individuals with autism was the work conducted by Ferster (1961). Ferster demonstrated, through a series of studies, that the principles of reinforcement and operant conditioning could be applied to successfully impact the behavior of children with ASD (Ferster, 1961; Ferster \& Demyer, 1961). Applied behavior analytic therapy has since become a basic recommendation in the treatment plans of the majority of individuals with autism (Peters-Scheffer, Didden, Korzilius, \& Sturmey, 2010). Applied behavior analysis is characterized by several basic principles put forth by Baer, Wolf, and Risley (1968) that guide the interventions 
developed and implemented within the field. These tenets are that interventions should be: applied, behavioral, analytic, technological, conceptually systematic, effective, and generalizable (Baer, Wolf, \& Risley, 1968). There are a number of different empirically validated intervention techniques that are employed within the field of ABA, including: direct instruction (Celik \& Vuran, 2014), incidental teaching (Casey, McWilliam \& Sims, 2012), and discrete trial training (Hall, Hustyi, Hammond, Hirt \& Reiss, 2014). The proposed study will involve the implementation of discrete trial training procedures.

\section{Discrete Trial Training}

Discrete trial training (DTT) refers to a teaching strategy in which an independent teaching unit or trial is presented to the learner in a clear and discrete format. Each trial is made up of five components: a discriminative stimulus, a prompt, a target response (which is always defined in clear observable terms), a consequence, and an inter-trial interval or pause between trials (Smith, 2001). In DTT, a therapist, teacher, or other instructor delivers the $\mathrm{S}^{\mathrm{D}}$ and awaits the child's response. If the child produces the correct response, the therapist provides access to a reinforcer, if the child does not produce the correct response the therapist prompts the child to do so and then provides access to the reinforcer contingent upon the eventual production of the correct response (Green, 2001). DTT is considered to be one of the most effective intervention techniques for teaching new skills to children with ASD (Smith, 2001). Through the presentation of discrete trials, children with ASD are given the opportunity to learn skills that typically developing children gain through interactions with their environments such as play, conversation, modeling, as well as myriad other behaviors which children with ASD do not typically engage in. 
Prompting is an essential part of the structure of DTT when working with children with autism (Green, 2001). Often children with autism do not respond as consistently to naturally occurring antecedent stimuli, such as verbal instructions, as typically developing peers. Because of this impaired responding it is frequently necessary to incorporate additional, more effective antecedent stimuli into therapeutic techniques to encourage the occurrence of the target behaviors (MacDuff et al., 2001). These additional stimuli, or prompts, are than faded over time as learning progresses, in an effort to transfer stimulus control to the naturally occurring $\mathrm{S}^{\mathrm{D}}$.

Prompting can be implemented and faded according to multiple schedules dependent upon the needs of each individual. Two typical prompting schedules are referred to as least-to-most prompting and most-to-least prompting (MacDuff et al., 2001). These schedules dictate the order of presentation of a variety of either increasingly or decreasingly intrusive prompting levels. Four common prompting levels or strategies are: (a) verbal prompts, such as "clap your hands" - which are considered to be the least intrusive level of prompting, (b) gestural prompts, such as the therapist pointing from one of the child's hands to the other, (c) modeling prompts, such as the therapist demonstrating clapping using their own hands, and (d) physical prompts, such as physically guiding the child to clap his hands - which are considered to be the most intrusive level of prompting.

In a least-to-most prompting hierarchy, following the presentation of the $\mathrm{S}^{\mathrm{D}}$ and the non-performance of the target behavior, the therapist would begin by providing the least intrusive prompt level, or a verbal prompt. If the child continued to not produce the target behavior, the therapist would then provide the next most intrusive level of 
prompting, or a gestural prompt. The progression continues until the child produces the appropriate response, at which point the therapist would provide access to a reinforcer. Least-to-most prompting is considered preferable in some instances as it is less likely to encourage prompt dependence, or a situation in which the child comes to depend on a particular prompt in order to produce a response. Prompt dependence can increase the level of difficulty associated with fading that prompt level (MacDuff et al., 2001).

In a most-to-least prompting hierarchy the therapist begins by prompting the child with the most effective prompt level, or the least intrusive prompt level at which the child will reliably produce the target response. Most-to-least prompting is also referred to as an errorless learning technique because it prevents the child from making an error when prompts are provided immediately following the presentation of the $\mathrm{S}^{\mathrm{D}}$. Alternatively, a delay can be imposed between the presentation of the $\mathrm{S}^{\mathrm{D}}$ and the implementation of the effective prompt level. Doing so increases the potential for the child to produce an incorrect response but also allows the child an opportunity to produce an unprompted correct response. Most-to-least prompting and errorless learning techniques are frequently considered ideal when working with young children with autism because they reduce the potential for the child to become frustrated as a result of making repeated errors (MacDuff et al., 2001).

\section{Teaching Imitation with Discrete Trial Training}

Previous research has demonstrated that DTT is an effective methodology for teaching initial imitative repertoires to children with ASD (Brown et al., 2008). Imitation training typically begins with simple tasks such as one-step motor imitation and progresses toward more difficult or complex tasks, such as vocal imitation, as more skills 
are acquired (Ingersoll, Schreibmen, \& Tran, 2003). The most basic imitative responses are thought to be those involving the use of an object, which can be seen by the child and produces a sound when it is manipulated, for example, shaking a rattle (Ingersoll, Schreibmen, \& Tran, 2003). Removing any type of sensory feedback increases the difficulty involved in imitating the response, as does increasing the number of steps required. To continue with the previous example, removing the contents of the rattle so that it no longer made a sound would increase the degree of difficulty involved in imitating shaking the rattle. Additionally, if the child were required to remove the rattle from a box prior to shaking it, the response would be considered more difficult than simply shaking a rattle that was already in front of them, as it would involve a larger number of steps.

When implementing DTT to teach imitation, the model typically sits directly across from the child in order to increase the likelihood of the child orienting toward the model, and then begins by providing an $\mathrm{S}^{\mathrm{D}}$ to the child. During imitation training this $\mathrm{S}^{\mathrm{D}}$ is often a compound stimulus such as a combination of the verbal phrase "do this" and the action to be imitated, for example pushing a toy car. The model then provides reinforcement for correct responding. These procedures usually include manual prompting and shaping techniques to encourage the child to produce the correct response. These techniques are then systematically faded over time (Tsiouri, Simmons, \& Paul, 2011).

\section{Video-Modeling}

In addition to discrete-trial training, a number of other ABA-based intervention strategies are available for individuals with ASD (Bui, Moore, \& Anderson, 2013). One 
technique that has received an increasing amount of attention and momentum over the last few decades is video-modeling (VM; Paterson \& Arco, 2007). Video modeling generally refers to a series of techniques that rely on the presentation of a video for instructional purposes, and has been used to teach a variety of different behaviors to individuals with ASD, as well as with other developmental delays or disabilities. There are three subtypes of VM, including: (a) video self-modeling (VSM), (b) video-modeling (VM), and (c) point-of-view video modeling (PVM; Shukla-Mehta, Miller, \& Callahan, 2010). Both VM and VSM follow a series of predictable steps in which: (a) an individual is instructed to watch a video, (b) a video is presented in which the target skill is modeled by an adult, peer, or, in the case of VSM, the individual himself, (c) an instructor provides prompts and reinforcers for attending to relevant stimuli, and (d) the person finally imitates the modeled behavior when presented with the opportunity to do so (Bellini \& Akullian, 2007). Point-of-view modeling varies from the other two modalities in that, rather than watching an individual perform the target behavior from the vantage point of someone sitting near that person, the perspective taken allows the viewer to assume the vantage point of the model. Point-of-view modeling is thought to be potentially beneficial as it allows the child to see a picture of the final project as well as to view the materials and steps of the behavior as they would if they were performing it themselves (Hine \& Wolery, 2006).

Video modeling techniques date as far back as the 1970s and are derived from the idea of learning through observation (Shukla-Mehta, Miller, \& Callahan, 2010). Video models have been used successfully to teach a variety of skills both through the presentation of the video alone, and as a component of an intervention package involving 
prompting and reinforcement. While these techniques have been used with a diverse group of individuals with differing skill sets, there has been a particular focus in recent literature on the use of VM for individuals with ASD (Shulka-Mehta, Miller, \& Callahan, 2010). These techniques are seen as particularly effective for individuals with ASD as the video itself may help compensate for a tendency toward stimulus over-selectivity (Maione \& Mirenda, 2010). Stimulus over-selectivity refers to a propensity for individuals with ASD to over-selectively focus on irrelevant stimuli, for example a shiny door handle, at the expense of potentially important stimuli in the external environment (Reed, 2011). The use of a video-based presentation modality in VM procedures allows for the narrowing in of the individual's focus on the video itself, while simultaneously helping to prevent them from over-selectively focusing on unrelated stimuli (Cardon \& Azuma, 2012).

According to a recent meta-analysis by Bellini, Peters, Benner, and Hopf (2007), VM and VSM may be considered successful evidenced-based practices for the treatment of communication, social skills, daily living skills, and other functional behavioral skills in individuals with ASD. However, the variability in treatment implementation and variety of treatment types have prevented this claim from being substantiated. For example, it is noteworthy that in the majority of studies cited, 19 out of 23, VM and VSM were combined with other strategies including prompting and reinforcement. The presence of these additional components may therefore lead to a certain amount of ambiguity regarding which parts of the treatment were most crucial. Despite these limitations, additional support for the effectiveness of VM-based interventions for teaching social, academic, and other functional skills to individuals with autism can be 
found in a study by McCoy and Hermansen (2007), in which the researchers analyzed the impact of the various types of VM techniques. In the McCoy and Hermansen (2007)

study, the authors found that all three types of VM were effective in increasing the behaviors targeted, with the least amount of evidence for PVM owing to its status as a relatively new type of intervention. Overall, there is substantial evidence within the literature for the utility of VM as an intervention for individuals with ASD, although variability in its implementation has precluded researchers' ability to determine which aspect or type of VM may be most effective.

\section{Video Modeling: Imitation}

Imitation, or generalized imitation, is one of the many skills that VM interventions have been used to teach (McCoy \& Hermansen, 2007). Typically, imitation is taught to young children with ASD using highly structured DTT techniques in which a model sits directly across from the child and performs the behavior to be imitated. In addition to DTT, there are a variety of VM imitation training techniques that have been implemented that vary in their similarity to this DTT model. Some researchers have directly replicated the steps of a DTT style intervention (Cardon, 2012), while others have used differing techniques such as the inclusion of the therapist verbally describing features of a video deemed critical for imitation as a component of the treatment package (Kleeberger \& Mirenda, 2010). Similarly, while some procedures have relied on prompting and reinforcement as integral parts of their intervention package, others have relied on the presentation of the video alone (Cardon \& Wilcox, 2010). Each of these techniques has been demonstrated to increase the imitative skills of participants, although the majority of successful interventions for teaching imitation skills have required to use 
of prompting, reinforcement, or other additional components beyond the video itself (Cardon, 2012; Kleeberger \& Mirenda, 2010; McDowell, Gutierrez \& Bennett, in press). While each of these studies focused on increasing basic motor imitation skills, they varied in the imitation tasks targeted. For example, a portion of the available studies focused on improving imitation of basic toy play activities, while others focused on imitating simple finger play games commonly seen in a pre-school setting, and a final study demonstrated that children who were unable to learn more complicated tasks through video instruction could be taught to do so through a chaining procedure after learning how to imitate more basic one-step actions using VM (Cardon, 2012; Cardon \& Wilcox, 2010; Kleeberger \& Mirenda, 2010; Tereshko, MacDonald \& Ahearn, 2009). According to much of the literature on imitation, traditional DTT has not been shown to be effective at increasing generalization of imitative skills for individuals with ASD without the inclusion of additional programmatic generalization training (Young, Krantz, McClannahan, \& Poulson, 1994)). One of the primary goals of imitation training is generalization. Generalization can be broken down into two types: response generalization and stimulus generalization (Cooper, Heron \& Heward, 2003). Response generalization refers to the process by which a particular response is taught, and, without additional training, multiple functionally similar responses occur (Cooper, Heron \& Heward, 2003). An example of response generalization would be if a child is taught to say, "hi" and begins to spontaneously say, "hello" and, "hey" as well. Conversely, stimulus generalization refers to the process by which a behavior is paired with a particular $\mathrm{S}^{\mathrm{D}}$ during training, but comes to be evoked by myriad stimuli within the same class as the original $\mathrm{S}^{\mathrm{D}}$. For example, after being taught to label a picture of a ball, a child 
may also be able to label an actual ball and a video of a ball (Cooper, Heron \& Heward, 2003). In an applied setting, the term generalization usually refers to the likelihood that a behavior trained in a particular setting and with a particular teacher will occur in different settings and with different individuals. Generalization is particularly important when teaching individuals to imitate, as one of the main functions of imitation is to be able to learn new behaviors from a variety of individuals and in a variety of settings.

Traditionally, in order to facilitate generalization, several procedures have been incorporated into $\mathrm{ABA}$ treatment including: (a) train and hope, (b) sequential modification, (c) introduce to natural maintaining consequences, (d) train sufficient exemplars, (e) train loosely, (f) use indiscriminable contingencies, and (g) program common stimuli (Stokes \& Baer, 1977). Conversely, VM interventions for imitation may be more likely to encourage generalization than DTT as watching a video presentation can be seen as more flexible and therefore a better example of "training loosely" than traditional DTT. Additionally, VM provides a potentially more efficient way of training with multiple exemplars, and VM may be more likely to provide children with access to naturally occurring reinforcers such as the intrinsic-reinforcement that may be related to watching videos (Charlop-Christy \& Daneshvar, 2003; Kleeberger \& Mirenda, 2010). Other benefits of teaching imitation skills using VM include the consistency of the model presented, and the portability of the video itself (Kleeberger \& Mirenda, 2010).

Traditional DTT is notoriously difficult to teach to parents and caregivers, and according to the literature available, delivers mixed results owing to the complicated nature of the technique itself (Dawson \& Adams, 1984). Video modeling however, may provide a simpler, streamlined intervention technique for teaching imitation and, in at least one 
previous study, was effectively implemented by parents in the home setting and lead to increases in imitative responses for all participants (Cardon, 2012).

\section{Video Modeling: Unresolved Questions}

While VM procedures are widely used and have received increasing amounts of positive attention in recent years in regards to their effectiveness when implemented with individuals with ASD, certain questions about their effectiveness and appropriateness remain. Although the majority of reports indicate that VM has been a successful intervention technique, there has been some degree of disagreement about their effectiveness. For example, a recent study by Rayner (2011) demonstrated that VM interventions were not effective for teaching an adolescent with autism a variety of basic tasks in the absence of a pre-existing imitative repertoire. However, other studies have indicated that VSM may be an ineffective intervention technique for children under the age of four both with and without a diagnosis of ASD (Buggey, 2011, Buggey et al., 2011, Buggey \& Ogle, 2012), although it is notable that in these studies the only VM technique implemented was VSM. Conversely, there have been studies using VM with both peer and adult models that have demonstrated successful results with children as young as 24 months (Cardon, 2012; Cardon \& Wilcox, 2011; McDowell, 2013). These results may suggest a degree of individual variability in the effectiveness of VM-based interventions which has lead researchers to question what other potential factors or skills may impact the successful implementation of VM. Delano (2007) points to several potential factors including: attention, language skills, visual processing, and rates of problem behaviors. While others have considered the impact of interest in, or ability to watch, television for a period of time (Nikopoulos \& Keenan, 2003). One basic question 
with regard to the use of VM is: to what extent does a child need to be able to imitate the behavior of a model for VM interventions to be effective? While certain studies have demonstrated that generalized imitation may function as a pre-requisite skill for the use of VM, other studies have shown the VM can be used to teach early imitation, and that this instruction can then lead to VM being a successful method for teaching complex skills (Cardon, 2012; Kleeberger \& Mirenda, 2010; Rayner, 2011; Tereshko, MacDonald \& Ahearn, 2009). These mixed results demonstrate the potential impact of individual differences on success with a VM based intervention and clearly establish the need for further research into what individual variables may function as predictors of success. As Rayner, Denholm, and Sigfoos (2008) point out, the field of VM currently "lacks predictive tools, measures, or indicators that: (1) have been empirically evaluated to predict success with [VM] and (2) are suitable for use in conjunction with the various procedural types and for a range of target behaviors."

\section{Significance of Study}

Imitation has been shown to be directly correlated with a variety of essential skills including language, cognitive abilities, and social skills such as joint attention and play (Rogers \& Vismara, 2008). Children with autism tend to display a severe deficit in imitative abilities compared to both typical peers and those with other developmental delays (Dawson \& Adams, 1984). The impairment in imitation may directly contribute to the deficit in, or atypical development of, social skills that is considered to be a hallmark of children diagnosed with ASD (Meltzoff \& Gopnick, 1994). There have been decades worth of research into a variety of intervention modalities for increasing the imitative repertoires of children diagnosed with autism which have highlighted specific techniques 
such as DTT as being particularly effective (Ledford \& Wolery, 2010). However, issues,such as difficulties related to generalization to novel persons, environments, and behaviors persist (Krantz, McClannahan, \& Poulson, 1994). Additionally, the large variety of symptomatology seen in children with autism may contribute to the difficulty in attempting to create a one-size-fits-all intervention technique (Schreibman, Dufek \& Cunningham, 2011).

Recently, there has been a push towards the use of VM for children with ASD (Shulka-Mehta, Miller \& Callahan, 2010). Video modeling has been highlighted as particularly appropriate for treating children with ASD because of several factors including ease of implementation and a tendency towards stimulus over-selectivity within this population (Reed, 2011). Video modeling has been used to treat a variety of skills including play, social communication, and in recent years, has been implemented as an intervention for treating a lack of generalized imitation (Lydon, Healy \& Leader, 2011; Maione \& Mirenda, 2006; Cardon, 2012). Although the majority of studies using VM have reported positive findings, questions remain within the field about what factors may influence its proper and successful implementation. These questions include whether age is an important variable when instituting a VM-based intervention, whether prompting and reinforcement are essential components of a successful treatment package, and what individual variables may impact success with VM (Rayner, Denholm \& Sigfoos, 2008). The present study will begin to address some of these questions by contributing to the literature examining potential predictors of success with VM in young children with ASD, and may help to further efforts to individualize and streamline intervention 
techniques based on specific child characteristics including imitation, social skills, and technological literacy.

\section{Statement of Hypotheses}

The following hypotheses have been developed based on the basis of previous findings about the relationship between social skills and imitation in children with ASD, the effectiveness of VM interventions with the current population, and the relationship between imitation skills and VM interventions:

Hypothesis 1: Social affect (SA) scores from the Autism Diagnostic Observation Schedule (ADOS-2; Lord et al., 2012) will significantly predict imitation scores on the Motor Imitation Scale (MIS; Stone, Ousley \& Litteford, 1997).

Hypothesis 2: Children with the fewest imitative abilities (as indicated by MIS scores) will be more successful with the video modeling intervention than with the live modeling (LM) intervention.

Hypothesis 3: Children whose parents and families are more technologically literate will be more successful with the VM intervention than with the LM intervention.

Hypothesis 4: Children who have more advanced social skills as determined by their SA score on the ADOS will be more successful with the LM intervention than with the VM intervention. 


\section{METHODOLOGY}

Overview

The present work consists of two studies, the second of which was divided into two parts. The first study involved an analysis of preexisting data from prior participants in various research projects conducted by the behavior analysis autism research lab (BAAR) at Florida International University (FIU), to determine whether SA totals from the ADOS (Lord et al., 2012) significantly predicted imitation abilities as demonstrated through results on the MIS (Stone, Ousley \& Litteford, 1997). For the second study, a subset of participants from the first study participated in an intervention comparison designed to determine whether they were more successful with a VM or LM intervention for teaching imitation. The data from the second study were then further analyzed in an effort to identify potential predictors of success with the VM modality including social skills, imitative abilities, and technological literacy.

Measures

Autism Diagnostic Observation Schedule: Second Edition (ADOS-2)

The Autism Diagnostic Observation Schedule (ADOS-2; Lord et al., 2012) is a semi-structured play-based assessment designed to aid in observing and recording the social and communicative behaviors of individuals suspected of having ASD. The ADOS is a diagnostic tool, which is frequently considered the gold standard in the field as it relies on direct observation rather than reports from parents, caregivers, or teachers (Lord et al., 2012; Sikora, Hall, Hartley, Gerrad-Morris \& Cagle, 2008). The ADOS is separated into modules that are specific to the age and expressive language abilities of the individual. The toddler module and module 1 are both administered to pre-verbal 
children, or those whose language is limited to occasional 1 to 2 word utterances. The toddler module is used for children aged 12-30 months, while module 1 is appropriate for children older than 30 months who do not yet exhibit the use of consistent phrase speech. For the purposes of the ADOS, phrase speech refers to non-echoed, flexible, three-word phrases that include the use of a verb (Lord et al., 2014). Module 2 is administered to children of any age who are not yet verbally fluent, but do engage in phrase speech. Algorithms for this module are separated into children under age 5 and children aged 5 or older. Finally modules 3 and 4 are both appropriate for verbally fluent individuals with module 3 catering to older children and adolescents and module 4 being more appropriate for older adolescents and adults based on the activities involved in the administration. The present study included only individuals who participated in the toddler module and module 1 , as the young age of the sample combined with the requirement of low levels of imitation decreased the likelihood that children would have advanced or age appropriate expressive language abilities.

The administration of the ADOS involves the presentation of a series of activities in a casual, play-based environment. Administration of each task is standardized to provide structure to the interaction between the participant and administrator, however tasks are not necessarily provided in a particular order. Each activity is designed to encourage the participant to demonstrate social, communicative, and behavioral characteristics that may aid diagnosis. Administrators are provided with instructions on how to deliver tasks, which include a hierarchy of social presses. These social processes vary from relatively unobtrusive (i.e.,"Baby is hungry"), to more explicit (i.e., "Feed the 
baby") and are used to encourage the child to participate in the various activities involved in the ADOS.

Scoring of the ADOS-2 evaluates five areas: (1) language and communication, (2) reciprocal social interaction, (3) play and imagination, (4) stereotyped behaviors and restricted interests, and (5) other behaviors. Behavioral and language indicators are typically coded on a 3-point scale in which " 0 " implies no evidence of abnormal behavior, "1" implies some unusual aspects of behavior or slight abnormality, "2" implies definite abnormality, and " 3 " implies that behavior appears markedly abnormal. A score of " 3 " is generally only assigned if the abnormalities observed are so severe that they interfere with the administration of the assessment, and when input into the final algorithm calculation are coded as scores of " 2 ". Social Affect (SA) Total

The final score for the ADOS uses an algorithm which can be broken down into two different analyses: (1) social affect, and (2) restricted and repetitive behaviors. These two totals are then combined to produce the overall total that is used for diagnostic classification purposes. The current study focused specifically on SA scores as they more appropriately represent the social behaviors that have been previously linked to a deficiency in imitation. Additionally, because of the young age of the target sample and the requisite deficit in imitation, the all participants fell into either the toddler module or module 1 categories. However, in order to facilitate a comparison between participants, all ADOS assessments were coded as module 1 . The toddler module is the most recent addition to the ADOS assessment and was not present prior to the ADOS-2 (Lord et al., 2012). Because a portion of the current assessments were conducted prior to the creation 
of this more recent version, several younger participants were administered module 1 assessments, although they would have been administered toddler modules given the current standards. For this reason, and in order to facilitate comparison, all participants both under and over 30 months of age were administered the ADOS module 1 based on their expressive language abilities. Thus, all analyses will be focused on that module.

The SA total is composed of scores on a subset of structured activities within the ADOS. Three of these fall under the category of communication, while the remaining scores fall under reciprocal social interaction. The three communication categories include: (1) frequency of spontaneous vocalizations directed to others, (2) pointing, and (3) gestures. The categories under the heading of reciprocal social interaction include: (1) unusual eye contact, (2) facial expressions directed to others, (3) integration of gaze and other behaviors during social overtures, (4) shared enjoyment in interaction, (5) showing, (6) spontaneous initiation of join attention, (7) response to join attention, and (8) quality of social overtures. Finally, a subset of the above scores are used to calculate the final SA total based on whether the child demonstrated few to no words, or some words.

\section{Mullen Scales of Early Learning}

The Mullen Scales of Early Learning Assessment (Mullen, 1995) is designed to provide an assessment of early cognitive abilities in children from birth through 68 months. The Mullen is broken down into five scales: (1) gross motor, (2) fine motor, (3) visual reception, (4) receptive language, and (5) expressive language. Of these five scales, all are appropriate for children up to age 68 months except for the gross motor scale, which is only appropriate for children under 33 months. Each scale consists of a series of age appropriate tasks presented through the use of a standardized manual, toy 
kit, and protocol (Bradley-Johnson, 2001). Administration typically ranges from 15 to 30 minutes for children aged birth to 3 years, with children diagnosed with ASD typically taking less time to complete the assessment than typically developing children (Akshoomoff, 2006). Each scale on the Mullen is coded as a subtest and T scores ( $M=$ $50, S D=10$ ), percentile ranks, and age equivalents are available for each. The combination of these subtest scores is then converted into an "Early Learning Composite" score $(M=50, S D=15)$. The Early Learning Composite score is representative of a descriptive category that indicates whether the child's cognitive capacity can be considered: very low, low, below average, average, or above average. For the purposes of the current study the Mullen was used to provide additional descriptive information about participants cognitive abilities.

Motor Imitation Scale (MIS)

The MIS was originally designed by Stone, Ousley, and Littleford (1997) and is indicated for the assessment of imitation skills present in very young children. The assessment is designed to coincide loosely with the sequence of imitation originally outlined by Jean Piaget (1962) and specifically caters toward imitative skills present in typically developing children at around 22 months old. The MIS is presented in an unstructured, playful environment and involves the presentation of 16 one-step motor actions. Each action is introduced by the administrator with the instruction, "do this" or,"do what I do," without naming the target object or action. Actions are broken down into meaningful actions or those that a child would likely have seen prior to the assessment, such as pushing a toy car, and meaningless actions that he or she is less likely to have encountered previously, such as walking a hairbrush across a table. The 
distinction between meaningful and not was incorporated to account for the potential effect of social meaning on imitative responses. Additionally, one half of the assessment is dedicated to motor actions without objects, such as clapping or waving, and the other half is dedicated to motor actions with objects, such as walking a toy dog or shaking a noisemaker.

Each of the 16 items is scored on 3-point scale from 0 to 2: "0" meaning no attempt at imitation, "1" meaning burgeoning imitation, and " 2 " meaning successful point-to-point imitation of the model. Each action is presented a minimum of three times and a maximum of nine times, and the highest score on each item is used to calculate the total. Scores on the assessment can therefore range from 0 to 32 . For the current study, a score at or below 16 was considered a sufficient indication of low levels of pretreatment imitation.

\section{Parent and Family Technology Survey}

A parent and family technology survey was developed for the purposes of the present study and derived from the Public Broadcasting Service (PBS) KIDS Parent Survey: Family Technology at Home. The original survey was sponsored by PBS Lab as part of their Ready To Learn Study, an initiative funded by a federal grant from the department of education and designed to evaluate the effectiveness of a variety of learning resources on the PBS KIDS lab website. The present survey was designed to be completed by a designated parent or caregiver. It included four categories: (1) technology at home, (2) your use of technology, (3) making decisions about technology use, and (4) your child's use of technology. There are several questions within each category. A variety of response forms are included such as scale responses with options from "every 
day" to "never," and "strongly disagree" to "strongly agree," and multiple-choice responses in which, the responder is asked to select all that apply. A subset of these responses were used to calculate an overall technological literacy score for each participant's family. The scores range from 0 to 138, with 138 representing the highest degree of technological literacy.

\section{STUDY 1}

Purpose

Study 1 was designed to further explore the relationship between social skills and imitation by determining whether SA totals from the ADOS would significantly predict MIS scores when looking specifically at children with a diagnosis of ASD.

\section{Participants}

Data for study 1 were drawn from previous and current participants in the various research projects conducted by the BAAR at FIU. Participants included 31 children between the ages of 2 and 5 years who were previously diagnosed with ASD $(M=2.97$, $S D=1.05)$. The sample consisted of 5 females and 26 males. The majority of the sample was comprised of Hispanic-Americans (93.5\%). Only those participants who had completed both an ADOS and an MIS assessment were included. No other inclusion criteria were applied.

\section{Results}

Prior to conducting further analyses, Q-Q plots and K-S tests were used to examine the underlying structure of the data and determine whether or not it exhibited a normal distribution. Results indicated that both the SA Totals from the ADOS and MIS scores demonstrated normality $(D>0.05)$. Visual inspection of Q-Q plots for each factor 
confirmed the results of the K-S test (See Figures $1 \& 2$ ). The ADOS scores ranged from 7 to 21 , with a mean of $15.1(S D=4.0)$, while MIS scores showed a range of 2 to $32(\bar{x}=$ $13.84, S D=8.72)$.

Correlational analyses among the ADOS and MIS variables revealed a significant relationship $(r=0.70, n=31, p<0.001)$. A linear regression was conducted to evaluate a potential predictive relationship. Results indicated that MIS scores significantly predict SA Totals from the ADOS $F(1,29)=28.41, p<0.001$ (see Table 1). These results demonstrate that motor imitation skills were a significant predictor of social skills within this sample.

Figure 1. Q-Q Plot for SA Totals from ADOS

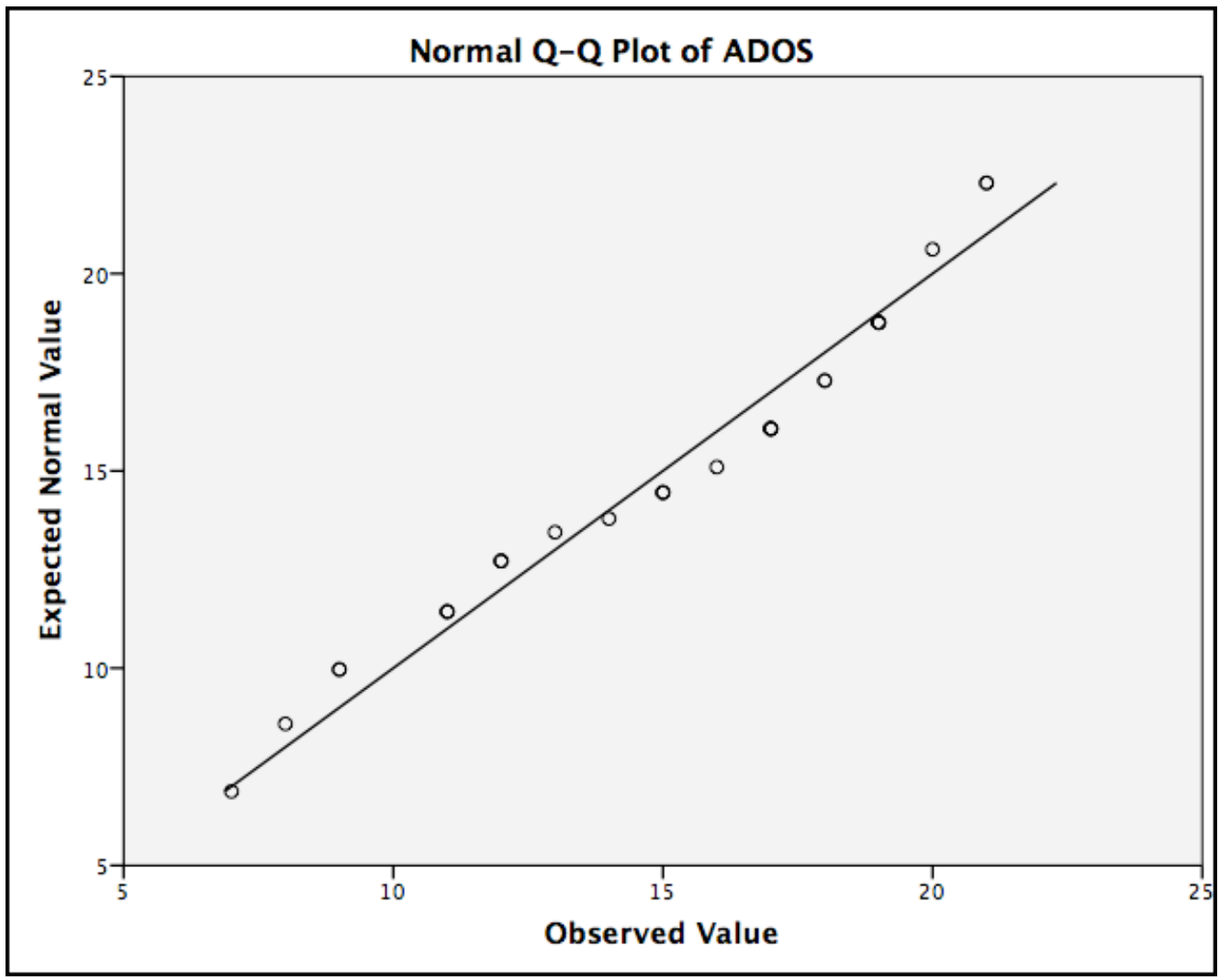


Figure 2. Q-Q Plot for MIS Scores

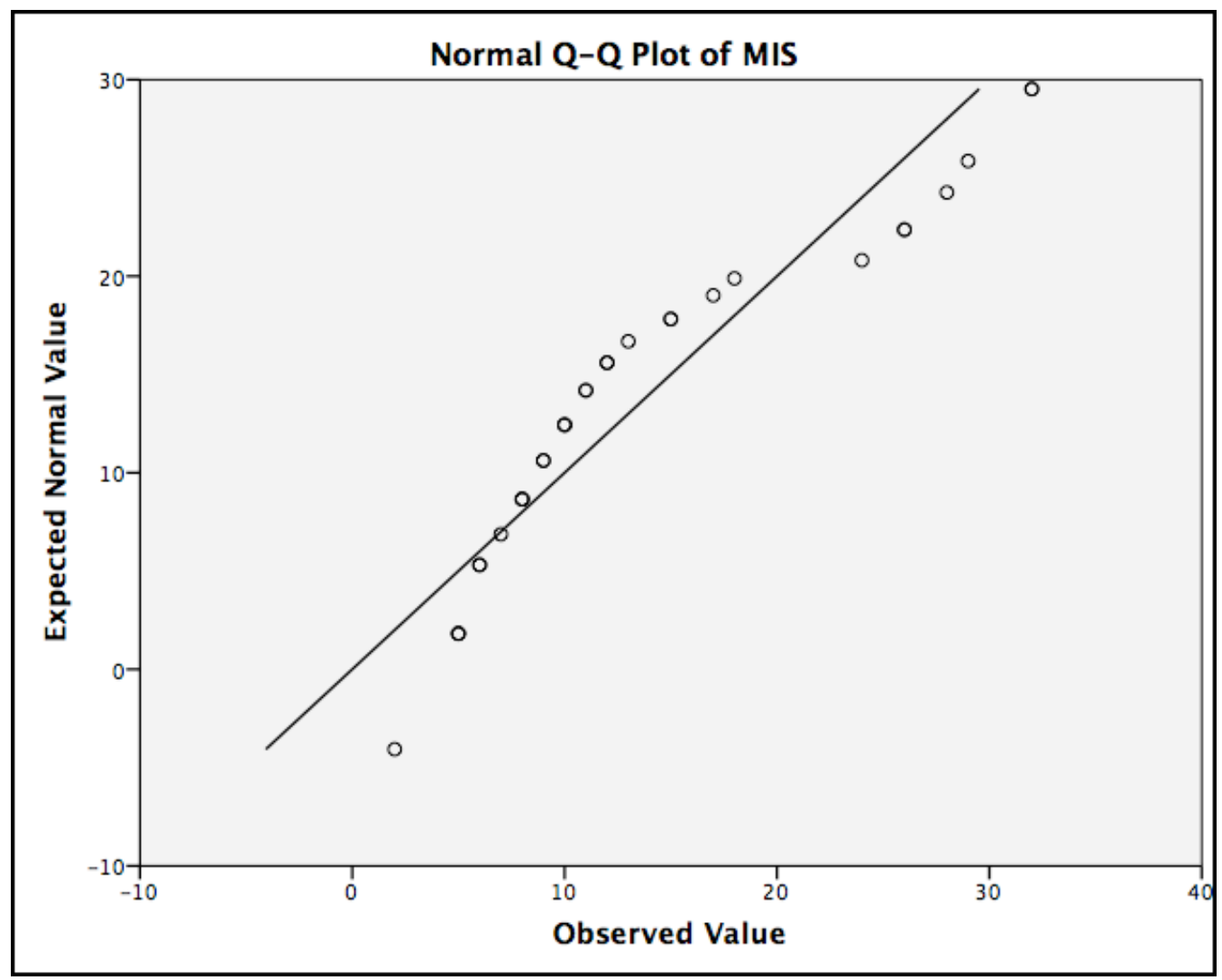

Table 1. ANOVA for Predictve Validity of ADOS Scores in Relation to MIS Scores

\begin{tabular}{llll}
\hline Model & $\mathrm{F}$ & $\mathrm{df}$ & $\mathrm{p}$ \\
\hline Regression & 28.41 & 1,29 & $* *<.001$ \\
\hline
\end{tabular}




\section{STUDY 2}

\section{Purpose}

Study 2 was designed to a) determine whether there was a significant difference in the effectiveness of VM and LM interventions for individual children, and b) to determine what individual differences may have contributed to participants achieving more success with one treatment model or the other. The study involved the implementation of a treatment comparison phase in which individuals were exposed to both VM and LM treatments. Resultant data were then compared to determine which treatment was more effective for each individual. Following this, predictive analyses were conducted to determine what factors might have lead individuals to be more successful with VM or LM.

\section{Participants}

Participants for the second study included eight children between the ages of 24 months and 62 months with a previously demonstrated diagnosis of ASD $(M=38.5, S D$ $=12.35)$. The sample contained six males $(75 \%)$ and two females $(25 \%)$. All eight participants identified as Hispanic. Participants were identified through participation in existing studies or treatment programs being conducted by the BAAR lab at FIU. These treatment programs included the Early Intensive Behavioral Intervention program (EIBI) and the Summer-Treatment Program for Autism Spectrum Disorders (STP-ASD). All diagnoses were confirmed via an ADOS conducted by a research reliable experimenter. Additional inclusion criteria involved a score at or below a 16 out of a total of 32 points 
$(<50 \%)$ on the MIS, which was considered a sufficient indication of low levels of pretreatment imitation.

\section{Design}

\section{Alternating Treatments Design}

An adapted alternating treatments design consisting of baseline and comparison phases was implemented in which participants were exposed to both VM and LM treatment conditions. The alternating treatments design was first described by Barlow and Hayes (1979) and refers to an experimental design in which two treatments are presented concurrently or simultaneously within one individual. In the present study, each participant was randomly assigned two equivalent behaviors, one to be treated using the VM technique and the other using the LM technique. Sessions were conducted at least twice per day, with a minimum of three VM sessions and three LM sessions conducted each day until criterion was reached in one or both treatment conditions. A minimum of one hour was required between treatment presentations. The order of presentation was randomized each day so that VM preceded LM on a subset of days, and followed LM on the remaining days (See Figure 3). The randomization process was implemented in an effort to control for potential carry-over or order effects (Gast, 2010). 
Figure 3. Sample Imitation Schedule

\begin{tabular}{|c|c|c|c|c|c|c|c|c|}
\hline \multicolumn{9}{|c|}{ IMITATION SCHEDULE - WEEK 1} \\
\hline & Child 1 & Child 2 & Child 3 & Child 4 & Child 5 & Child 6 & Child 7 & Child 8 \\
\hline \multirow{2}{*}{ Day 1} & Live & Video & Video & Live & Video & Live & Video & Live \\
\hline & Video & Live & Live & Video & Live & Video & Live & Video \\
\hline \multirow{2}{*}{ Day 2} & Video & Live & Live & Video & Video & Live & Live & Video \\
\hline & Live & Video & Video & Live & Live & Video & Video & Live \\
\hline \multirow{2}{*}{ Day 3} & Video & Live & Live & Video & Video & Live & Live & Video \\
\hline & Live & Video & Video & Live & Live & Video & Video & Live \\
\hline \multirow{2}{*}{ Day 4} & Video & Live & Live & Video & Live & Video & Live & Video \\
\hline & Live & Video & Video & Live & Video & Live & Video & Live \\
\hline \multirow{2}{*}{ Day 5} & Video & Live & Video & Live & Video & Live & Video & Live \\
\hline & Live & Video & Live & Video & Live & Video & Live & Video \\
\hline \multicolumn{9}{|c|}{ IMITATION SCHEDULE - WEEK 2} \\
\hline & Child 1 & Child 2 & Child 3 & Child 4 & Child 5 & Child 6 & Child 7 & Child 8 \\
\hline \multirow{2}{*}{ Day 1} & Live & Video & Live & Video & Video & Live & Video & Live \\
\hline & Video & Live & Video & Live & Live & Video & Live & Video \\
\hline \multirow{2}{*}{ Day 2} & Live & Video & Live & Video & Live & Video & Live & Video \\
\hline & Video & Live & Video & Live & Video & Live & Video & Live \\
\hline \multirow{2}{*}{ Day 3} & Video & Live & Live & Video & Video & Live & Live & Video \\
\hline & Live & Video & Video & Live & Live & Video & Video & Live \\
\hline \multirow{2}{*}{ Day 4} & Live & Video & Live & Video & Live & Video & Live & Video \\
\hline & Video & Live & Video & Live & Video & Live & Video & Live \\
\hline \multirow{2}{*}{ Day 5} & Live & Video & Video & Live & Live & Video & Live & Video \\
\hline & Video & Live & Live & Video & Video & Live & Video & Live \\
\hline
\end{tabular}

\section{Behavior Selection}

In order to compare VM to LM directly as a treatment modality for increasing imitation using an alternating treatments design, behavioral equivalency must be demonstrated between the tasks in the two treatment conditions (Barlow \& Hayes, 1979). For the purposes of the present study behavioral equivalency was determined on the basis of the following criteria: (a) all actions incorporated the use of an object, (b) all actions supplied the performer with visual feedback, meaning the performer was able to see the action as they performed it, (c) all actions required the same number of steps, and (d) a logical analysis was conducted by the researchers (Ingersoll, Schreibmen, \& Tran, 2003; Wolery et al., 2010). 
All participants had one behavior randomly assigned to the LM treatment condition and one behavior randomly assigned to the VM treatment condition. A list of equivalent behaviors was used to determine which behaviors were assigned to each treatment condition (See Table 2). Behaviors were presented in an identical order to all participants. If, as a result of treatment randomization a child was assigned to the VM condition first, the first behavior on the list would be placed into the VM treatment condition and the second behavior on the list would be placed into the LM treatment condition, for that child. Conversely, if the child were randomly assigned to LM first, the first behavior on the list would be placed into the LM treatment condition and the second behavior would be placed into the VM treatment condition. In this way, behaviors were randomly distributed across participants and treatment conditions (See Table 3).

Table 2. List of Target Behaviors

Behavior

Shakes Clapper

Drags Rake

Rolls Ball

Squeezes Horn

Flips Disk 
Table 3. Distribution of Behaviors Across Participants and Treatments

\begin{tabular}{llc}
\hline Participant Name & Behavior & Treatment \\
\hline Adam & Shakes Clapper & VM \\
Adam & Rolls Ball & LM \\
Fiona & Rolls Ball & VM \\
Fiona & Shakes Clapper & LM \\
Scott & Shakes Clapper & VM \\
Scott & Rolls Ball & LM \\
Edgar & Rolls Ball & VM \\
Edgar & Flips Disk & LM \\
Arnie & Rolls Ball & VM \\
Arnie & Shakes Clapper & LM \\
Leo & Shakes Clapper & VM \\
Leo & Rolls Ball & LM \\
Pedro & Squeezes Horn & VM \\
Pedro & Shakes Clapper & LM \\
Samantha & Rolls Ball & VM \\
Samantha & Drags Rake & LM \\
\hline
\end{tabular}




\section{Setting and Materials}

All sessions were conducted at the Center for Children and Families (CCF) at FIU's Modesto Maidique campus. Sessions were conducted in dedicated session rooms containing small child-sized tables and chairs as well as other toys and objects commonly seen in a preschool classroom. A video camera was used to record all sessions for subsequent coding of inter-observer agreement (IOA) and treatment fidelity. Additional materials included pens and data sheets used by the therapists to record data during sessions.

Each behavior targeted for treatment involved the use of an object. These objects included small toys that were deemed appropriate play objects for preschool-aged children. Objects included: (a) a toy shaker, (b) a ball, (c) a toy disk, (d) a small, handheld toy rake, and (e) a toy horn.

\section{Reinforcers}

Previous research has demonstrated a variety of ways to identify preferred items for use as reinforcers during behavioral acquisition trials (Carr, Nicolson, \& Higbee, 2000; DeLeon \& Iwata, 1996). For the present study potential reinforcers were identified during brief informal preference assessments conducted at the outset of, and as needed throughout the training sessions (Davis, Dacus, Strickland, Machalicek \& Coviello, 2013). During these preference assessments therapists presented a small variety of approximately 2 to 5 items to the child, including toys, food, and videos, that had been previously identified as preferred. The therapist then allowed the child to indicate either through gesture, vocalization, or other response which items they would prefer to interact 
with. These items were then delivered as reinforcers during subsequent trials following both independent and prompted productions of the target behavior.

\section{Videos}

Videos for the VM treatment condition were recorded and played using an $\mathrm{iPad}^{\mathrm{TM}}$. All videos were recorded in a quiet session room. Each video featured the same research assistant sitting at a table in front of a white wall. During the video the research assistant said, "do this" and presented the target behavior. The research assistant wore the same clothes and presented the phrase, "do this" is a neutral voice and with a neutral facial expression for all videos. Videos were approximately 3 to 5 seconds long.

\section{Procedures}

Sessions consisted of the presentation of five discrete trials. Each trial consisted of the presentation of the $\mathrm{S}^{\mathrm{D}}$, followed by either the independent or prompted performance of the target behavior, and the immediate presentation of a reinforcer. At least three sessions were conducted per day for each treatment type (VM and LM) with at least one hour between treatment presentations. The routine continued until the behavior in either or both treatment conditions was mastered. Unprompted responses that demonstrated point-to-point correspondence with the modeled behavior were recorded as "independent" and all other responses were recorded as "prompted." The target behavior was considered learned once a mastery criterion of at least $80 \%$ correct responding across two consecutive sessions was reached. Reinforcers were delivered following the production of both prompted and independent responses. 


\section{Baseline}

Baseline sessions were conducted prior to intervention for both treatment conditions and included the presentation of 15 baseline trials or 3 sessions. Baseline trials were conducted in an identical manner to treatment trials without the inclusion of prompting or reinforcement. Baseline trials for LM consisted of a therapist sitting across from the child, presenting the $\mathrm{S}^{\mathrm{D}}$, "do this," modeling the target behavior and handing the object used while performing the behavior to the child. The therapist then recorded whether or not the child imitated the behavior correctly and then moved to the next trial. Baseline trials for VM were conducted in a similar manner with the only difference being the medium through which the modeled behavior was presented. During VM baseline sessions the therapist sat next to the child on the floor and played a video for the child in which a model said, "do this" and modeled the target behavior. The therapist then handed the object used in the video to the child and recorded whether or not the child correctly imitated the modeled behavior. If the child successfully imitated the modeled behavior during baseline sessions, that behavior was not used during the treatment condition. In order for a behavior to move to treatment, the child must not have engaged in correct imitation during any of the baseline trials.

\section{Prompting Procedure}

Following the baseline condition, the treatment condition began for both interventions. Both LM and VM procedures incorporated a delayed most-to-least prompting procedure, which took place over a number of phases (MacDuff et al., 2001). In each phase the child was given the opportunity to respond independently following the presentation of the $\mathrm{S}^{\mathrm{D}}$. If the child did not respond within 3 seconds or responded 
incorrectly, the appropriate prompting level was implemented. Therapists were instructed to prompt immediately when the child began to produce an incorrect response or a response that did not display formal similarity to the behavior of the model, in order to prevent the child from having the opportunity to make an error. During the first phase, full physical guidance was provided during which the therapist provided hand-over-hand guidance to ensure that the child engaged in the target response. The therapist then provided the child with an appropriate reinforcer. If the child successfully engaged in imitating any part of the response, the therapist continued to phase two. Phase two involved partial physical guidance. In phase two, the therapist used a brief touch of the child's hand or arm to prompt the response. The child received reinforcement after each instance in which he / she produced the target response, both prompted and unprompted. Live Modeling (LM)

During LM sessions, the therapist sat directly across from the child at a small child-sized table. A camera was set up near or on the table to record the child's responses. The therapist had the object being used during treatment as well as a variety of preferred items to use as reinforcers. Once seated the therapist attempted to get the child's attention, presented the $S^{\mathrm{D}}$, "do this" and modeled the target behavior. The therapist then passed the object used during modeling to the child. If the child responded correctly and independently within 3 seconds of receiving the object, the therapist provided praise and access to a reinforcer and recorded the trial as independent. If the child did not respond within 3 seconds, or began to respond incorrectly, the therapist provided a prompt followed by access to a reinforcer contingent upon the performance of the target 
behavior. All correct responses, both prompted and unprompted, were followed by access to a reinforcer.

\section{Video Modeling (VM)}

The VM sessions were alternated with LM sessions according to a randomized schedule each day. During VM sessions, the therapist sat next to the child at a small table and placed an $\mathrm{iPad}^{\mathrm{TM}}$ against the wall across the table from the child. The appropriate video was displayed on the $\mathrm{iPad}^{\mathrm{TM}}$ screen. Again, a video camera was placed on or near the table to record the child's responses. The therapist then directed the child's attention to the screen and pressed play on the $\mathrm{iPad}^{\mathrm{TM}}$. The video was composed of a model sitting at a similar table and providing the $\mathrm{S}^{\mathrm{D}}$, "do this," prior to modeling the appropriate action. Once the video was complete the therapist provided the child with the same object used in the video. The therapist then waited 3 seconds for the child to respond. If the child responded correctly, the therapist provided praise and an appropriate reinforcer. If the child did not respond or responded incorrectly, the therapist followed the prompting procedure described earlier. Reinforcement was again provided for both prompted and independent correct responses.

Dealing with Problem Behaviors

Sessions were only conducted when participants were exhibiting behaviors that were conducive to learning. As aforementioned, prior to presenting the $S^{D}$ or playing the video, the therapist directed the child's attention to the relevant stimulus. If the child was engaging in problem behavior in the form of tantrums, crying, screaming, or other behaviors that would have detracted from their ability to attend and may have interfered with learning, sessions were paused until the child calmed down, sat quietly, and the 
therapist determined that they were ready to work. Additionally, the use of a most-toleast prompting strategy was intended to decrease the number of errors that the child had the opportunity to make, and increase the frequency of access to reinforcers (MacDuff et al., 2001). The purpose of the most-to-least prompting procedure was to decrease the potential for frustration and therefore the amount of problem behavior displayed during sessions (Lovaas, 2003). Had the problem behaviors exhibited posed a danger to either the child or therapist, sessions would have been suspended until the behavior could have been dealt with appropriately; however, this did not occur during the course of data collection.

\section{Reliability and Interobserver Agreement}

Interobserver agreement (IOA) refers to the degree to which two independent observers agree on the measurement of a target event (Cooper, Heron \& Heward 2003). Interobserver agreement is one of the most common ways of assessing reliability and validity in behavioral research (Watkins \& Pacheco, 2000). There are multiple methods available for calculating the degree of IOA, each of which relies on the following criteria to maintain validity of the measurement: (a) observers must use the same measurement system, (b) observers must measure the same events, and (c) observers must be independent.

For the current work, at least two independent observers collected data for each participant for a total of $48.6 \%$ of sessions across participants, treatment conditions, and phases (baseline and treatment). All observers were trained on data collection procedures prior to participation. Trial-by-trial IOA was calculated as it is considered an appropriate method for calculating agreement between two observers when the object being 
measured is the occurrence or non-occurrence of discrete trial behaviors. The unprompted occurrence of the target behavior was recorded as "I" for independent, and any other response including the prompted occurrence of the target response was recorded as "P" for prompted. Trial-by-trial IOA was calculated by dividing the number of trials during which the two observers agreed by the total number of trials, and multiplying the outcome by 100 . Results indicated an overall agreement rate of $95.9 \%$ (range: $80 \%$ $100 \%$ ) on trial-by-trial reliability.

\section{Treatment Fidelity}

Treatment fidelity or treatment integrity refers to the degree of consistency in the application of the treatment or independent variable (Cooper, Heron \& Heward, 2003). To assess the validity of claims about the effectiveness or impact of an intervention it is essential to assess whether or not the treatment of interest is being implemented in the manner in which it was intended. Treatment fidelity data allow the researcher to assess essential aspects of treatment implementation including adherence to prescribed procedures, and competence of the implementers (Forsberg et al., 2014). The resultant conclusions are then used to supplement any claims made about the impact of the treatment.

The present study included an analysis of treatment fidelity. All sessions were videotaped for later coding. Treatment fidelity data were recorded for $20 \%$ of sessions across all phases, treatment conditions, and participants. Coding involved a trained observer collecting data on whether or not the therapist implemented the following series of steps during the course of each trial: (a) directs the child's attention to the relevant stimulus (either the video display or therapist dependent upon treatment condition), (b) 
presents the $\mathrm{S}^{\mathrm{D}}$ for the LM treatment or presses play on the video for the VM treatment, (c) allows up to 3 seconds for the child to respond independently, (d) provides the appropriate prompt for any incorrect responses or no responses, and (e) provides an appropriate reinforcer immediately following the production of the target response. A percentage of correct steps were calculated by dividing the number of completed steps by the number of planned steps, and multiplying by 100 . Trials in which $80 \%$ or more of the treatment steps were correctly implemented were considered successful. Overall treatment fidelity was then calculated by dividing the number of successful trials by the number of trials coded, and multiplying by 100 . Results indicated an overall rate of $100 \%$ correctly implemented trials.

\section{Analyses}

Data were collected and analyzed using a variety of methods, including: visual analysis of graphs (Cooper, Heron \& Heward, 2003), descriptive statistics, parametric statistical analyses, and non-parametric tests. The use of the visual analysis of graphs as a means of describing relationships is paramount in behavioral literature. Graphs are considered to be the primary means within the field of behavior analysis of displaying and interpreting relationships between relevant variables (Cooper, Heron \& Heward, 2003). Visual analysis generally involves the detection of range, variability, and trends within the relevant data set. A variety of benefits related to the reliance on graphic analysis have been put forth in the literature including: (a) immediate access to an ongoing visual record, (b) the ability to explore variations within the data as they occur, (c) visual analysis can be considered a more conservative method of analyzing the significance of behavior change, and (d) graphs may encourage independent 
interpretations of the meaning and significance of behavior change (Cooper, Heron \& Heward, 2003). Additionally, while parametric statistical analyses are considered one of the main vehicles by which relationships may be detected in broader psychological research, they require that a variety of assumptions be met including the use of normally distributed data and the homogeneity of variance within the data set. It is often difficult to meet these assumptions when conducting research with a small sample size $(<30)$, and as Cooper et al. (2003) point out, the majority of behavior analytic research is typically conducted with four to eight participants. Thus, many researchers use non-parametric statistical analyses in addition to graphical analysis, as non-parametric tests require that fewer assumptions be met. Although these tests are characterized by lower statistical power, behavior analysts have recently begun including them in their research owing to their appropriateness with small sample sizes (Davidson, 1999; Maharaj, 2014).

Individual Participant Characteristics and Results

The names of all participants have been changed to ensure confidentiality. The first participant, Scott, was a 42-month-old boy with a diagnosis of ASD. Results on the Mullen Scales of Early Learning Assessment (Mullen) indicated that Scott had an early learning composite score of 49 , or a descriptive category of "very low." Scott received a pretreatment SA total score of 19 on the ADOS, and an MIS score of 6 . Additionally Scott scored a 118 on his Parent and Family Technology Survey. During the treatment comparison condition, Scott was taught to imitate shaking a toy clapper using the VM technique, and rolling a ball using the LM technique. Baseline data were stable and exhibited no trend for either intervention. During the treatment comparison phase, Scott's responding was variable for the first 23 sessions in the VM treatment condition followed 
by a steep increase towards criterion (See Figure 4). In the LM treatment condition data were relatively stable for the first 73 sessions, again followed by a steep rise toward mastery. For Scott, VM required 115 trials to criterion, and LM required 365 trials to criterion (See Figure 4). He was therefore grouped into the category of children who were more successful with the VM technique.

The second participant, Edgar, was a 26-month-old boy with a diagnosis of ASD. Results on the Mullen indicated that Edgar had an early learning composite score of 54, or a descriptive category of "very low." Edgar received a pretreatment SA total score of 14 on the ADOS, and an MIS score of 5. Additionally, Edgar scored a 79 on his Parent and Family Technology Survey. During the treatment comparison condition Edgar was taught to imitate rolling a ball using the VM technique, and flipping a toy disk using the LM technique. Baseline data were stable and exhibited no trend for either intervention. During the treatment comparison phase, Edgar's responding quickly accelerated toward mastery in the VM treatment condition with the first 10 sessions. In the LM treatment condition data were variable for the remaining 75 sessions (See Figure 5). Furthermore, VM required 50 trials to criterion for Edgar, and LM required 375 total trials (See Figure 5). However, Edgar did not acquire the behavior placed into the LM condition during the course of treatment. He was therefore grouped into the category of children who were more successful with the VM technique.

The third participant, Fiona, was a 40-month-old girl with a diagnosis of ASD. Results on the Mullen indicated that Fiona had an early learning composite score of 49, or a descriptive category of "very low." She received a pretreatment SA total score of 16 on the ADOS, and an MIS score of 7. Additionally, Fiona scored a 107 on her Parent and 
Family Technology Survey. During the treatment comparison condition Fiona was taught to imitate rolling a ball using the VM technique, and shaking a toy clapper using the LM technique. Baseline data were stable and exhibited no trend for either intervention. During the treatment comparison phase, Fiona's responding was stable for the first two sessions in the VM treatment condition, followed by a steep increase towards criterion after seven sessions. In the LM treatment condition data were stable with no trend for the full 87 sessions (See Figure 6). For Fiona, VM required 35 trials to criterion, and LM required 435 total trials (See Figure 6). Like Edgar, Fiona did not learn the behavior placed into the LM treatment condition during the prescribed period. She was therefore grouped, along with Scott and Edgar, into the category of children who were more successful with the VM technique.

Pedro, the fourth participant, was a 25-month-old boy with a diagnosis of ASD. Results on the Mullen indicated that Pedro had an early learning composite score of 49, or a descriptive category of "very low." Pedro received a pretreatment SA Total score of 18 on the ADOS, and an MIS score of 8. Unfortunately, scores on Pedro's Parent and Family Technology Survey were never received. During treatment comparison Pedro was taught to imitate squeezing a toy horn using the VM technique, and shaking a toy clapper using the LM technique. Baseline data were stable and exhibited no trend for either intervention. During the treatment comparison phase, Pedro's responding was stable for the first six sessions in the VM treatment condition, followed by some variability, and a steep increase towards criterion after 13 sessions. In the LM treatment condition data were relatively stable for all 99 sessions, with two small increases occurring at sessions 34 and 41 (See Figure 7). For Pedro, VM required 65 trials to criterion, and LM required 
495 total trials (See Figure 7). Pedro, like Fiona and Edgar, only acquired the behavior placed into the VM condition during the treatment period. He was therefore also grouped into the category of children who were more successful with the VM technique.

The fifth participant, Samantha, was a 29-month-old girl with a diagnosis of ASD. Results on the Mullen indicated that Samantha had an early learning composite score of 49 , or a descriptive category of "very low." Samantha received a pretreatment SA total score of 19 on the ADOS, and an MIS score of 9. Additionally Samantha scored a 91 on her Parent and Family Technology Survey. During the treatment comparison condition Samantha was taught to imitate rolling a ball using the VM technique and scratching a toy rake using the LM technique. Baseline data were stable and exhibited no trend for either intervention. During the treatment comparison phase, Samantha's responding was highly variable for both intervention types. Data from the VM condition demonstrated an increasing trend leading to mastery after 26 sessions. The LM condition while more variable, also eventually led to mastery after 52 sessions (See Figure 8). As with the previous participants, VM required 130 trials to criterion for Samantha, and LM required 260 trials to criterion. She was therefore grouped into the category of children who were more successful with the VM technique (See Figure 8).

Adam, the sixth participant, was a 62-month-old boy with a diagnosis of ASD. Results on the Mullen indicated that Adam had an early learning composite score of 49, or a descriptive category of "very low." Although Adam was the oldest participant he demonstrated a skill set comparable to those of his fellow participants. Specifically, he was non-verbal and demonstrated relatively little receptive communication. Adam received a pretreatment SA total score of 19 on the ADOS, and an MIS score of 10. 
Additionally Adam scored a 99 on his Parent and Family Technology Survey. During the treatment comparison condition, Adam was taught to imitate shaking a toy clapper using the VM technique, and rolling a ball using the LM technique. Baseline data were stable and exhibited no trend for either intervention. During the treatment comparison phase, Adam's responding began to increase after only three sessions in the VM condition, and reached mastery after five. In the LM treatment condition data were relatively stable for the first 55 sessions, followed by an increasing trend toward mastery, which he achieved after 66 sessions (See Figure 9). For Adam, VM required 25 trials to criterion, and LM required 330 trials to criterion (See Figure 9). He was therefore grouped into the category of children who were more successful with the VM technique along with all participants previously discussed.

The seventh participant, Arnie, was a 45-month-old boy with a diagnosis of ASD. Results on the Mullen indicated that Arnie had an early learning composite score of 50, or a descriptive category of "very low." Arnie received a pretreatment SA total score of 17 on the ADOS, and an MIS score of 12. Additionally, Arnie scored a 103 on his Parent and Family Technology Survey. During the treatment comparison condition Arnie was taught to imitate rolling a ball using the VM technique, and shaking a toy clapper using the LM technique. Baseline data were stable and exhibited no trend for either intervention. During the treatment comparison phase, Arnie's responding was variable for the first 35 sessions in the LM treatment condition followed by an increasing trend towards criterion after 42 sessions. In the VM treatment condition data were relatively stable for the first 41 sessions, followed by some variability, and an eventual steep rise toward mastery after 60 sessions (See Figure 10). For Arnie, VM required 300 trials to 
criterion, and LM required 210 trials to criterion, thereby distinguishing him from his fellow participants and placing him into the category of children who were more successful with the LM technique (See Figure 10).

The final participant, Leo, was a 40-month-old boy with a diagnosis of ASD. Results on the Mullen indicated that Leo had an early learning composite score of 49, or a descriptive category of "very low." Like Arnie, Leo received a pretreatment SA total score of 17 on the ADOS, however he also received an MIS score of 15, the highest of any of the participants. Additionally, Leo scored a 96 on his Parent and Family Technology Survey. During the treatment comparison condition Leo was taught to imitate rolling a ball using the VM technique, and shaking a toy clapper using the LM technique. Baseline data were stable and exhibited no trend for either intervention. During the treatment comparison phase, Leo's responding was stable for the first 12 sessions in the VM treatment condition followed by some variability and an eventual increase towards criterion after 27 sessions. In the LM treatment condition data were similarly stable for the first 12 sessions, again followed by some variability and an increasing trend toward mastery after 18 sessions (See Figure 11). For Leo, VM required 135 trials to criterion, and LM required 90 trials to criterion (See Figure 11). He was therefore, like Arnie, grouped into the category of children who were more successful with the LM technique. 
Figure 4. Line Graph of Treatment Mastery and Trials to Criterion Chart for Scott
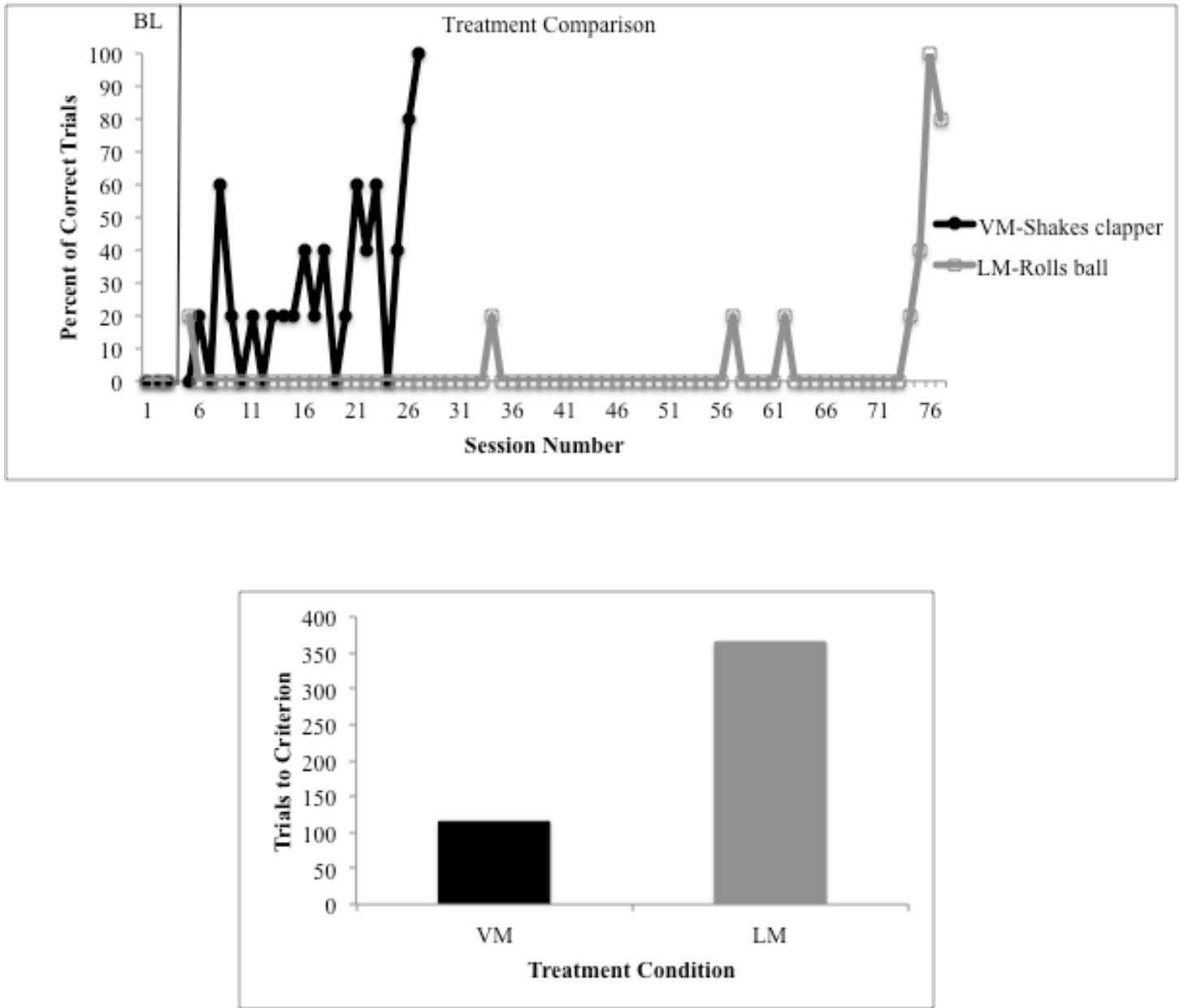
Figure 5. Line Graph of Treatment Mastery and Trials to Criterion Chart for Edgar
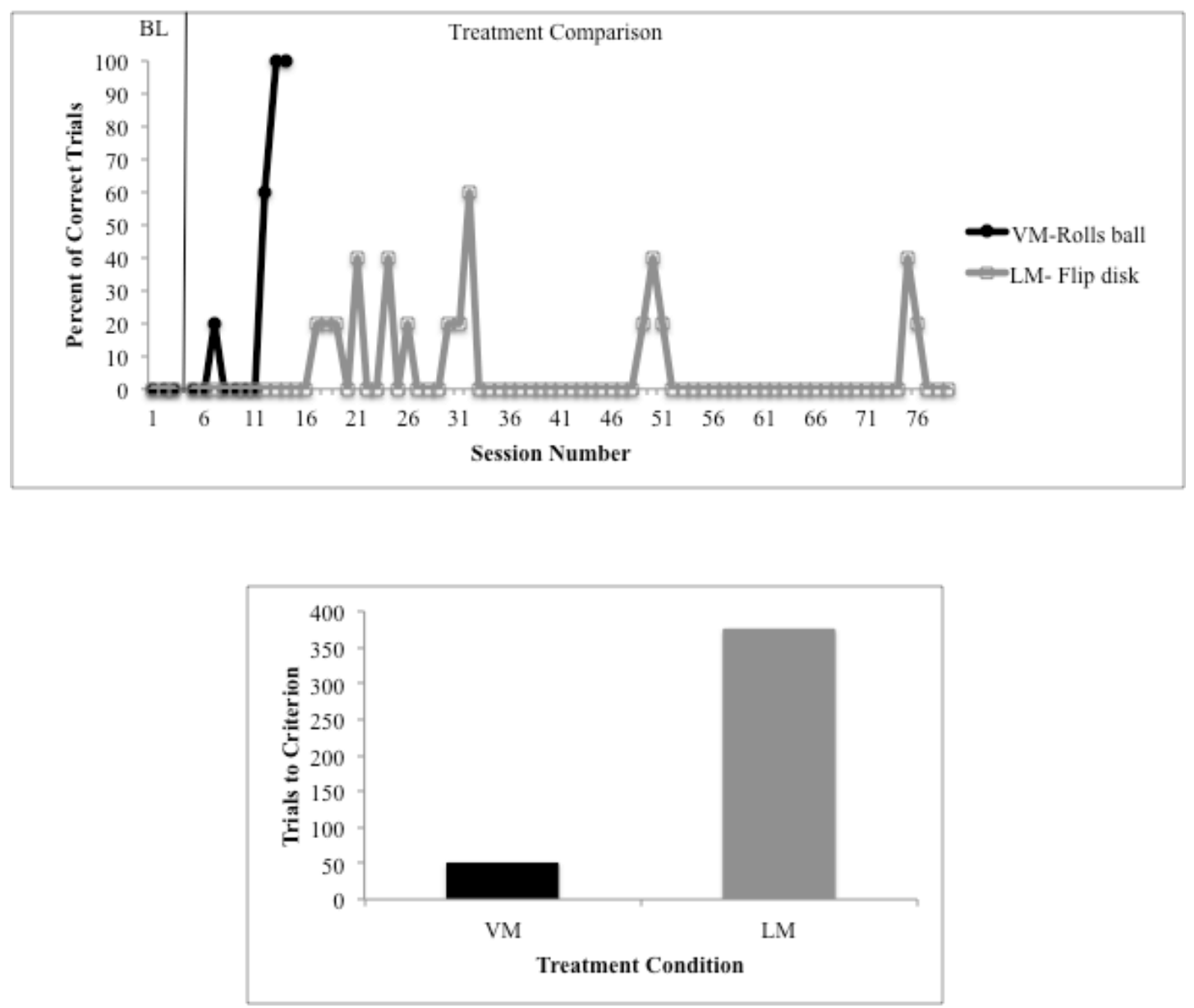
Figure 6. Line Graph of Treatment Mastery and Trials to Criterion Chart for Fiona
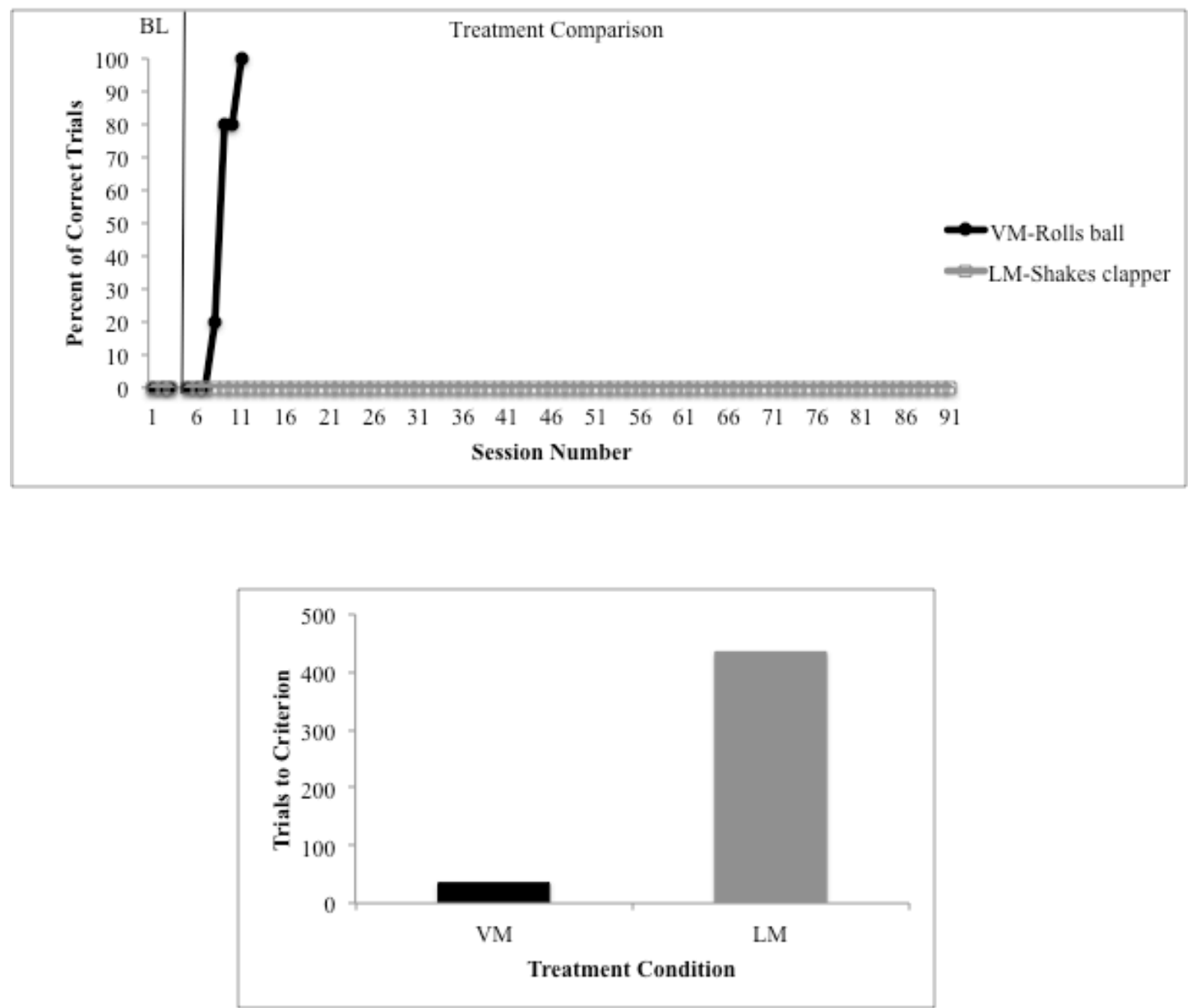
Figure 7. Line Graph of Treatment Mastery and Trials to Criterion Chart for Pedro
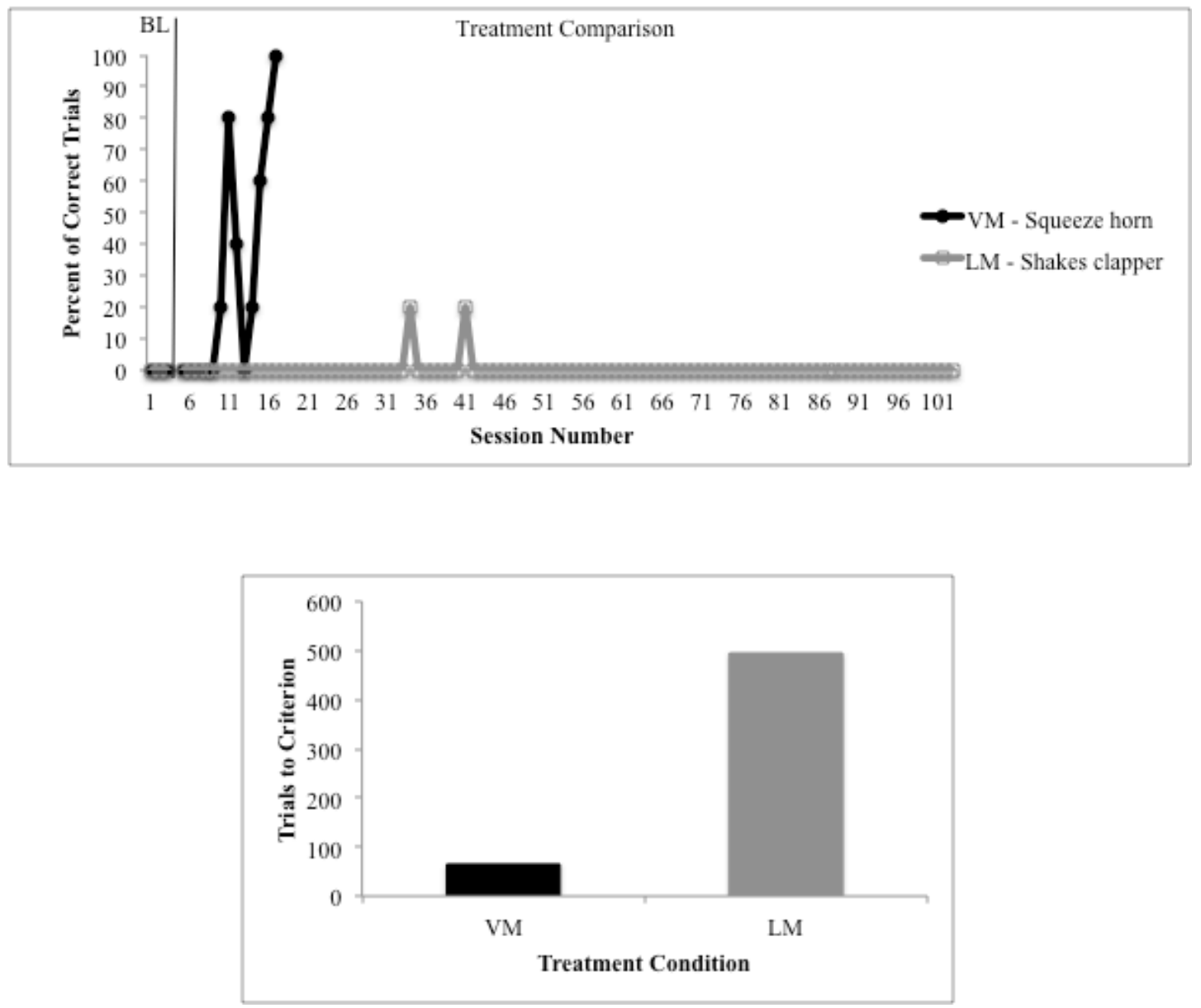
Figure 8. Line Graph of Treatment Mastery and Trials to criterion Chart for Samantha
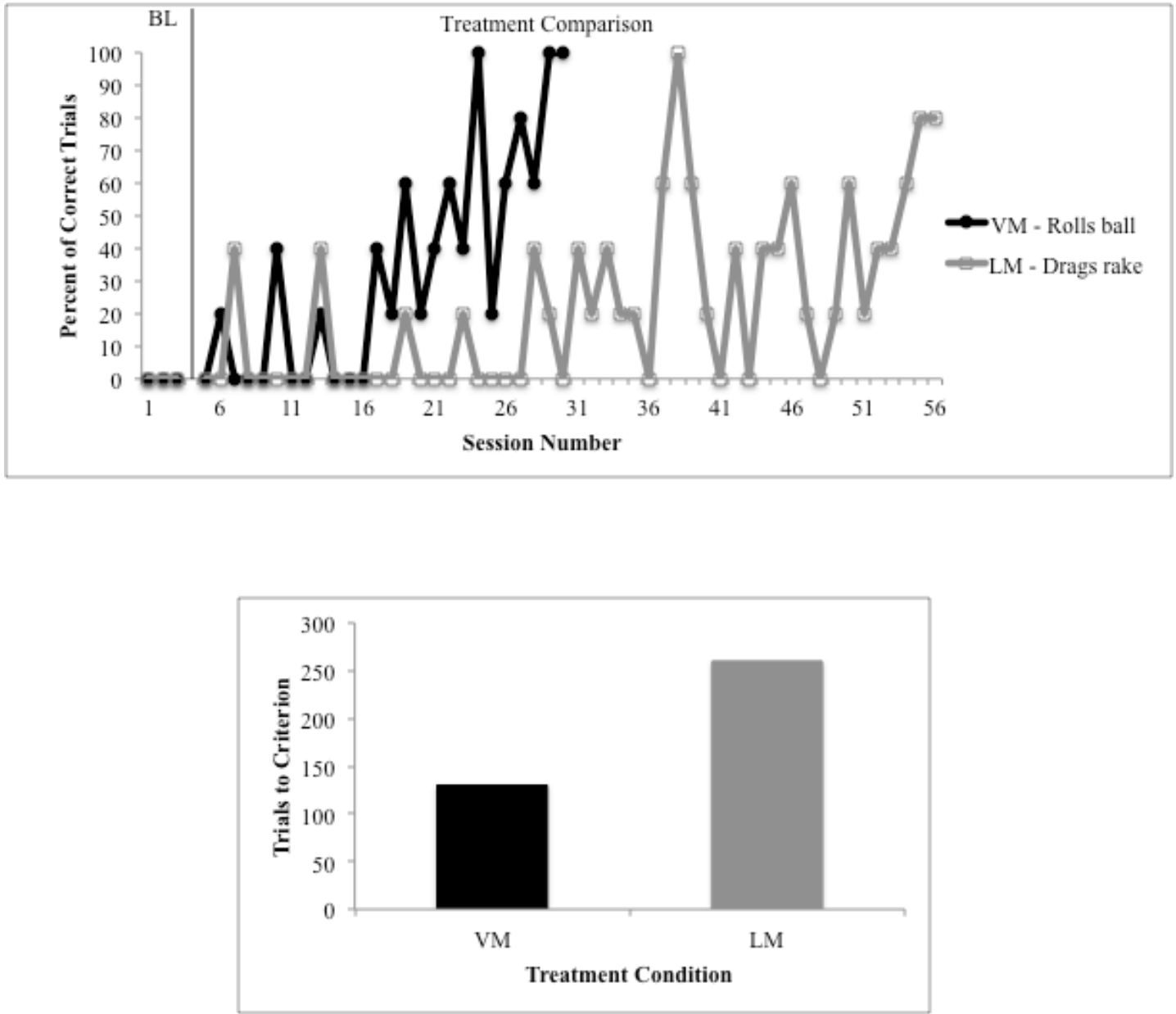
Figure 9. Line Graph of Treatment Mastery and Trials to Criterion Chart for Adam
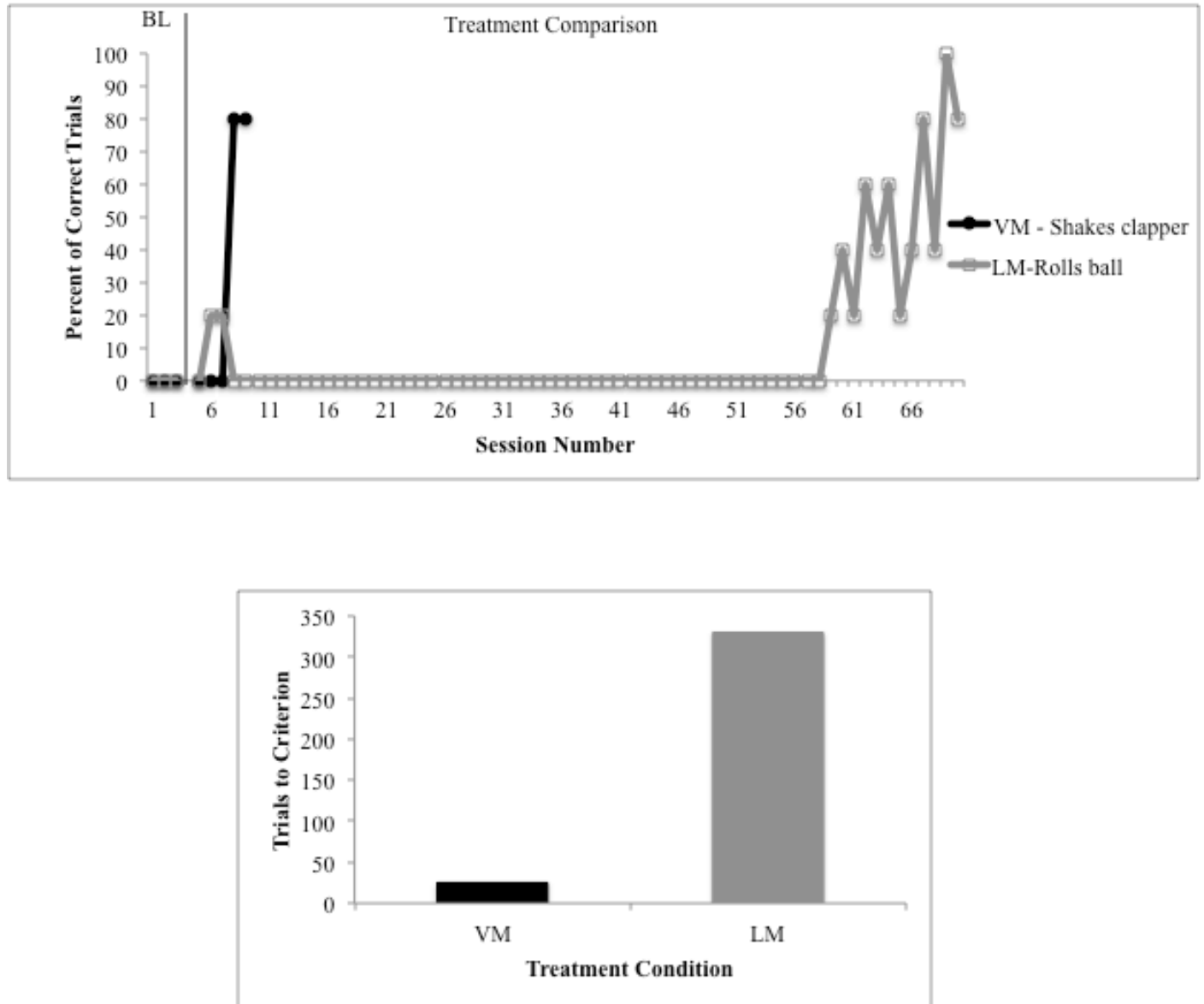
Figure 10. Line Graph of Treatment Mastery and Trials to criterion Chart for Arnie
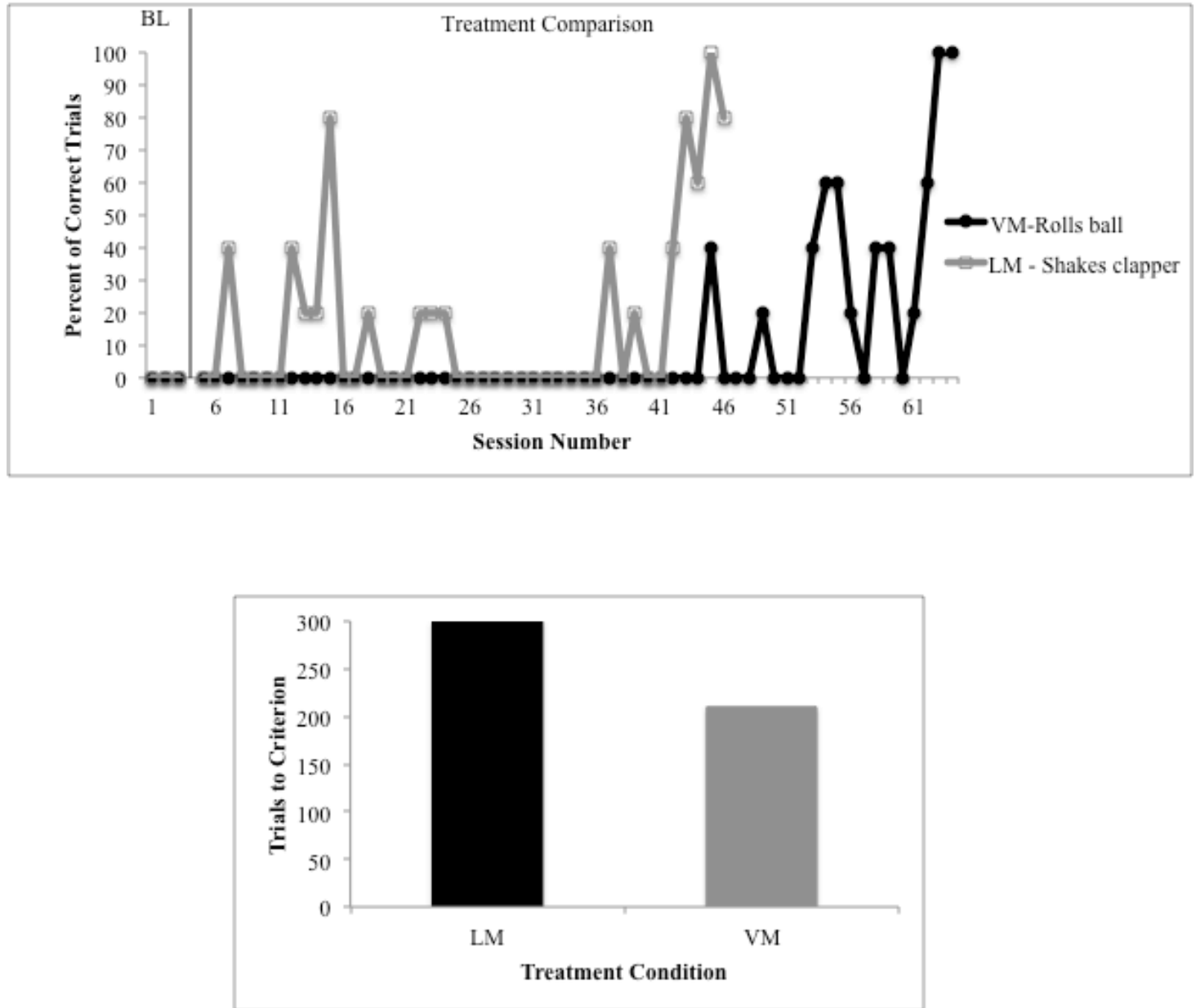
Figure 11. Line Graph of Treatment Mastery and Trials to Criterion Chart for Leo
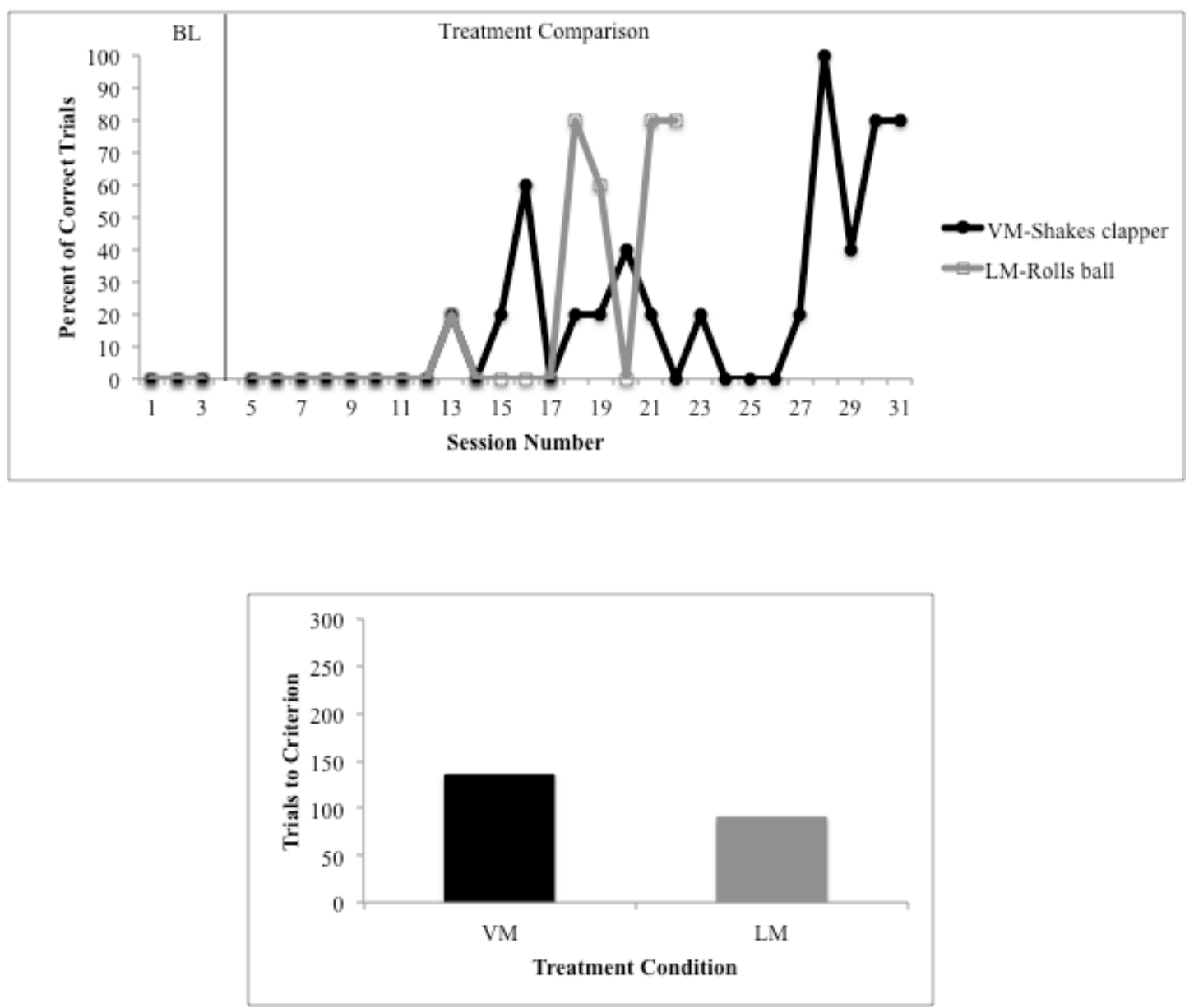
Results

Part 1 of Study 2

Study 2 involved analyzing data from a subset of children from study 1 who were selected to participate in the intervention portion of the current project. Participants were selected using a cut-off score of 16 or below on the MIS, as this score was considered a sufficient indication of low levels of pre-treatment imitation skills. All children were given pretreatment MIS assessments, ADOS assessments, and Parent and Family Technology surveys. Furthermore, all participated in both treatments types (LM and VM). In the first part of study 2, I conducted a difference test to whether a significant difference existed between the two treatment groups, VM and LM. This was done as there is a dearth of evidence in the field supporting VM as a superior intervention to LM. The test was also used to identify any characteristics of the sample that might have influenced further analyses. Normality tests were conducted on trials-to-criterion for VM and LM. While the K-S tests showed that both variables were normally distributed $(D>$ $.05)$, the Q-Q plots indicated conflicting results both before and after natural log transformations were applied (See Figures $12 \& 13$ ). Therefore, both a parametric paired samples t-test and a non-parametric Wilcoxon Signed Rank test were performed. Results of both tests revealed that there was a significant difference between the groups, therefore parametric results are reported because of increased power $[t(7)=-3.07, p<.05]$ (See Table 4). These results indicate that there was a significant difference in the number of trials-to-criterion required to learn to imitate using VM and the number of trials-tocriterion required to learn to imitate using LM. While some participants acquired behaviors more rapidly when exposed to the VM treatment, others acquired behaviors 
more rapidly in the LM treatments, and for all participants there was a difference between the two.

Figure 12. Q-Q Plot of Trials to Criterion for VM

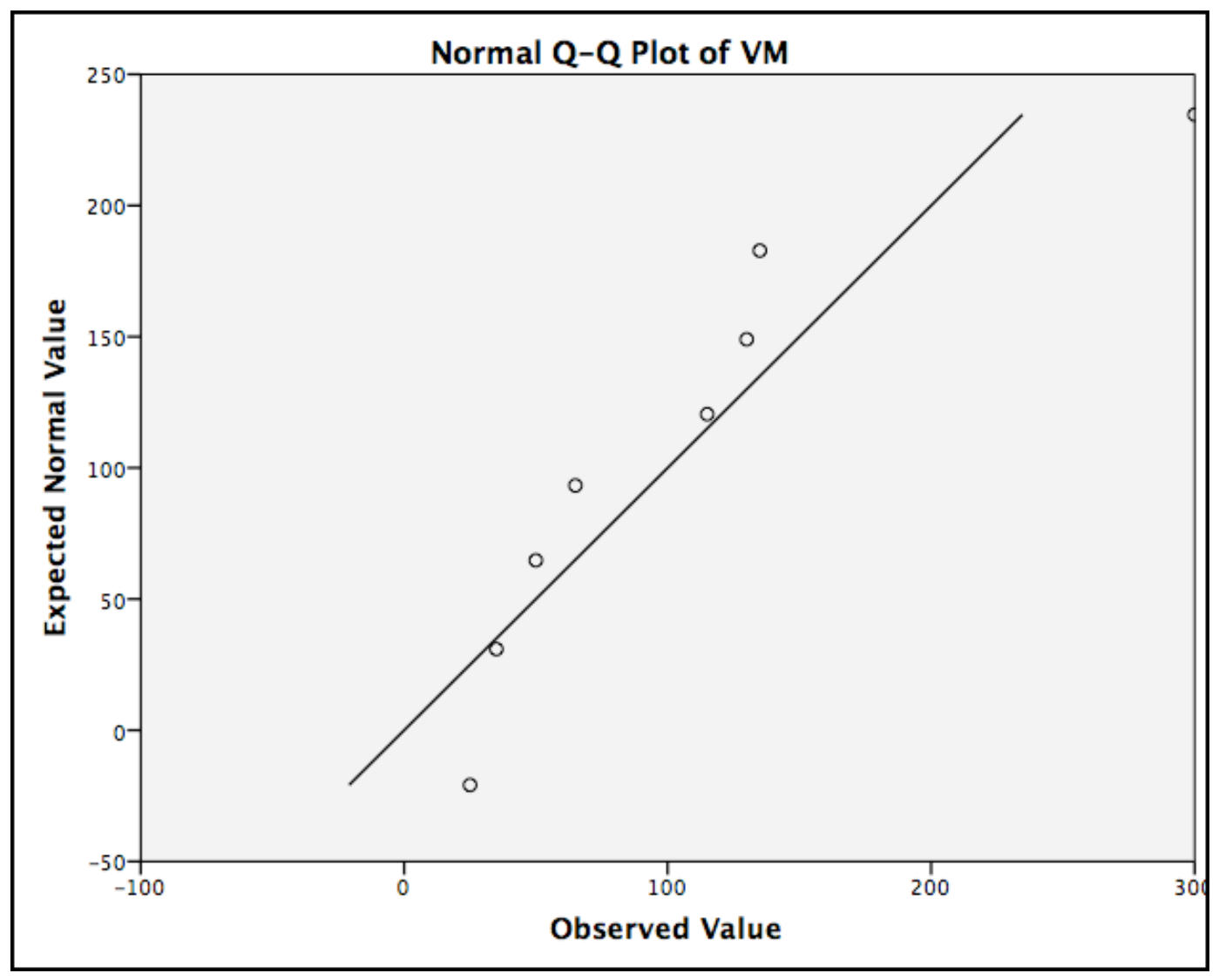


Figure 13. Q-Q Plot of Trials to Criterion for LM

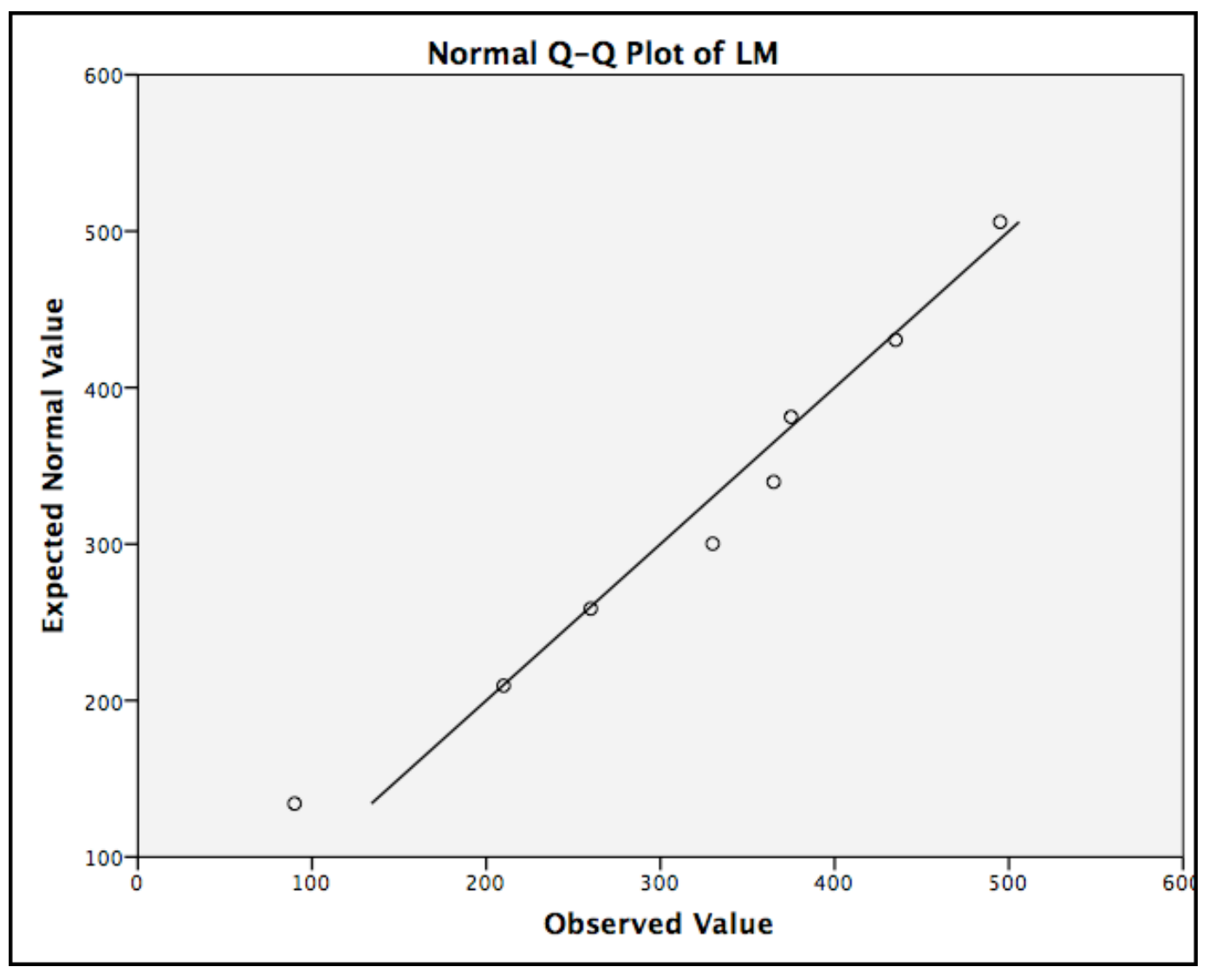

Table 4. t-test for Difference Between Treatment Groups

\begin{tabular}{|c|c|c|c|c|c|c|c|c|c|}
\hline & \multicolumn{6}{|c|}{ Treatment Type } & \multirow{3}{*}{$\begin{array}{l}95 \% \text { CI for } \\
\text { Mean } \\
\text { Difference }\end{array}$} & \multirow[b]{3}{*}{$\mathrm{t}$} & \multirow[b]{3}{*}{$\mathrm{df}$} \\
\hline & \multicolumn{3}{|c|}{ VM } & \multicolumn{3}{|c|}{ LM } & & & \\
\hline & $\mathrm{M}$ & SD & $\bar{n}$ & $\mathrm{M}$ & SD & $\mathrm{n}$ & & & \\
\hline $\begin{array}{c}\text { Trials to } \\
\text { Criterio } \\
\text { n }\end{array}$ & 106.88 & 89.08 & 8 & 320 & 129.61 & 8 & $-377.22,-49.03$ & $*-3.07$ & 7 \\
\hline
\end{tabular}




\section{Part 2 of Study 2}

Following the difference test, the sample was separated into two groups based on success with either treatment. Line graphs of individual participant data were analyzed to identify trends for each participant in order to detect possible inter-subject differences (See Figures 4-11). A selection criterion was used to determine success with either intervention modality based on clinically determined relevance. The selection criterion mandated that in order to represent a difference between the effectiveness of the two treatments, one treatment must have required at least 15 additional trials to criterion. This benchmark was selected because it is representative of one additional day of treatment. Once the two groups were identified, scores on the ADOS, MIS and Parent and Family Technology Survey were examined for their predictive validity with reference to success in either the VM or LM conditions. Owing to the small sample size, exact logistic regression was conducted to evaluate a subset of the aforementioned hypothesized relationships (Zamar et al., 2009).

Results indicated that six children were more successful with the VM treatment condition, with a mean number of trials to criterion for the VM condition of $70(S D=$ 43.13), and a mean number of trials to criterion for the LM condition of 376.67 ( $S D=$ 81.65). The two remaining participants were more successful with the LM treatment modality, with a mean number of trials to criterion for the LM condition of 150 ( $S D=$ 84.85), and a mean number of trials to criterion for the VM condition of $217.5(S D=$ 116.67). Differences in trials to criterion between the two treatment types for each participant ranged from 45 to $430(M=246.75, S D=144.17)$, with a minimum 
difference of 15 trials considered necessary to display a clinically significant difference in the effectiveness of the two treatments (See Figure 14).

Figure 14. Trials to Criterion for Each Participant and Treatment Type

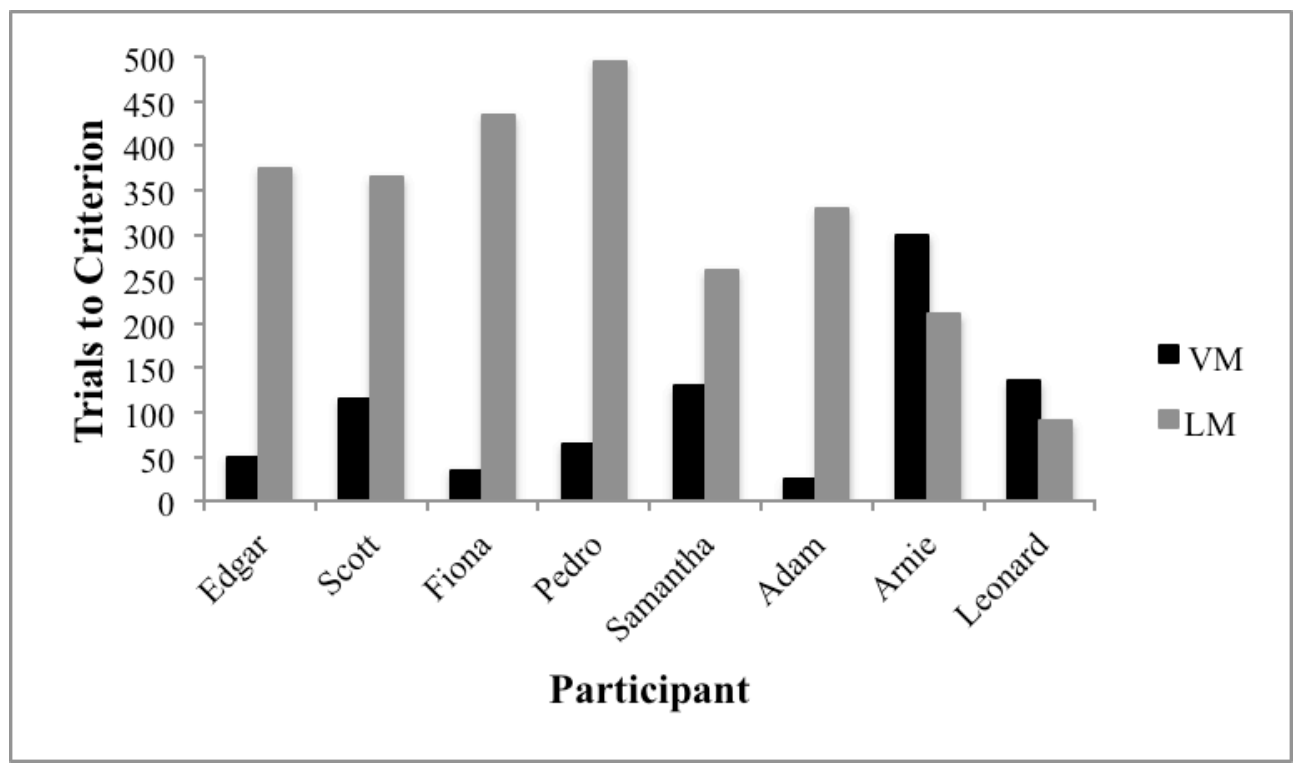

Additionally, when separated into treatment success groups the range in trials-tocriterion became strongly differentiated, with the participants who were more successful with the LM condition demonstrating a distinctly smaller difference in trials to criterion between the two treatment types $(M=67.5, S D=31.82)$, than those who were more successful with the VM treatment type $(M=306.5, S D=31.82)$ (See Figure 15). This difference may be related to the fact that participants who were more successful with the LM treatment type demonstrated more advanced imitation skills, and were therefore able to learn to imitate behaviors regardless of the presentation modality, but simply learned faster using LM. This may suggest that because as they can learn to imitate via both VM and LM, there is no need to resort to VM-based interventions for initial training for these participants. 
Figure 15. Differences in Trials to Criterion Between Treatments

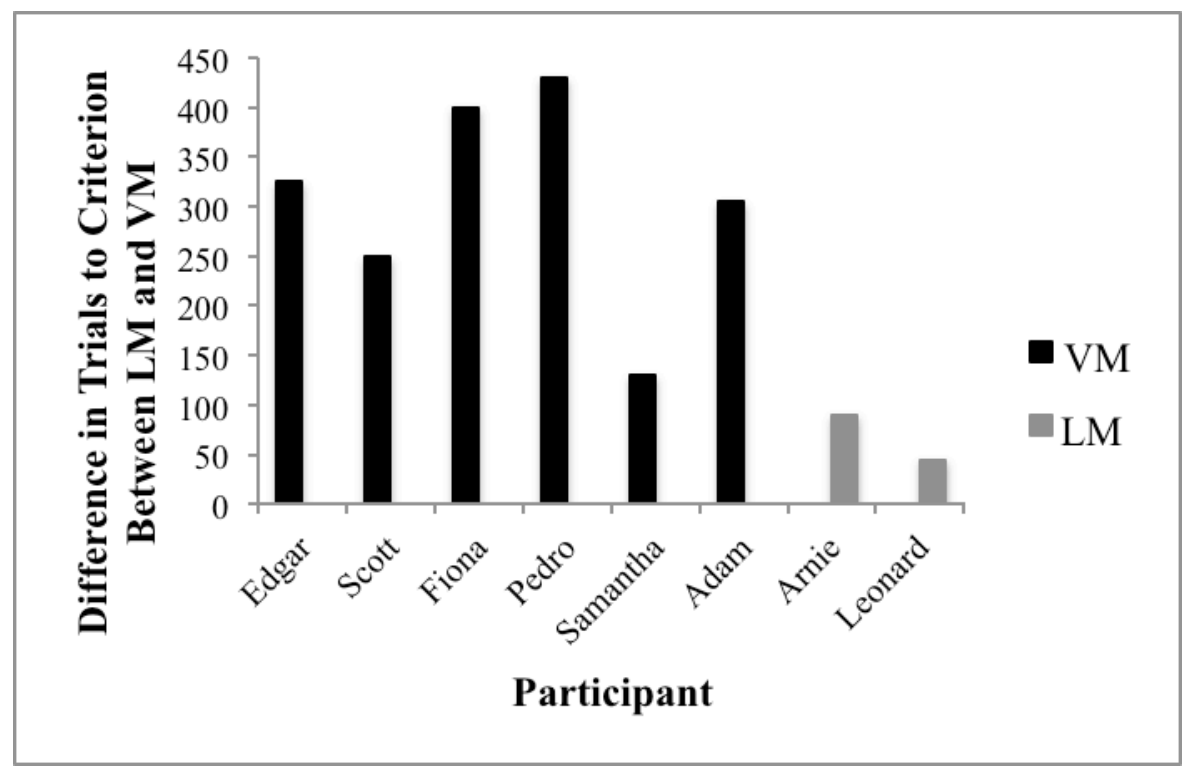

It is to be noted that three of the participants who were more successful with the VM treatment type did not acquire the behaviors placed into the LM condition during the course of treatment. Thus, for these three individuals, trials-to-criterion is in fact trials completed without achieving mastery in the LM condition. If these participants are removed from the analyses, however, the difference between the participants in the LM group and those in the VM group remains, with the VM group continuing to demonstrate a much larger difference in trials-to-criterion than the LM group $(M=318.33, S D=$ 53.46).

\section{Predictor Analysis}

Three potential predictors were identified: (1) SA totals on the ADOS, (2) MIS scores, and (3) scores on a Parent and Family Technology survey designed for the present study. The K-S test was performed for each of these variables in order to examine the underlying structure of the data and determine whether or not it conformed to a normal 
distribution. Results indicated that SA totals from the ADOS failed to demonstrate normality $(D<.05)$. However, both Technology Survey scores and MIS scores did demonstrate normality $(D>.05)$. Visual inspection of Q-Q plots for MIS scores and Technology Survey scores further confirmed the results of the K-S test (See Figures 16 \& 17). ADOS scores ranged from 14 to 19 , with a mean of $17.38(S D=1.77)$, while MIS scores showed a range of 5 to $15(M=9, S D=3.29)$, and Technology scores ranged from 79 to $118(M=99.00, S D=12.34)$.

Figure 16. Q-Q Plot for MIS (Study 2)

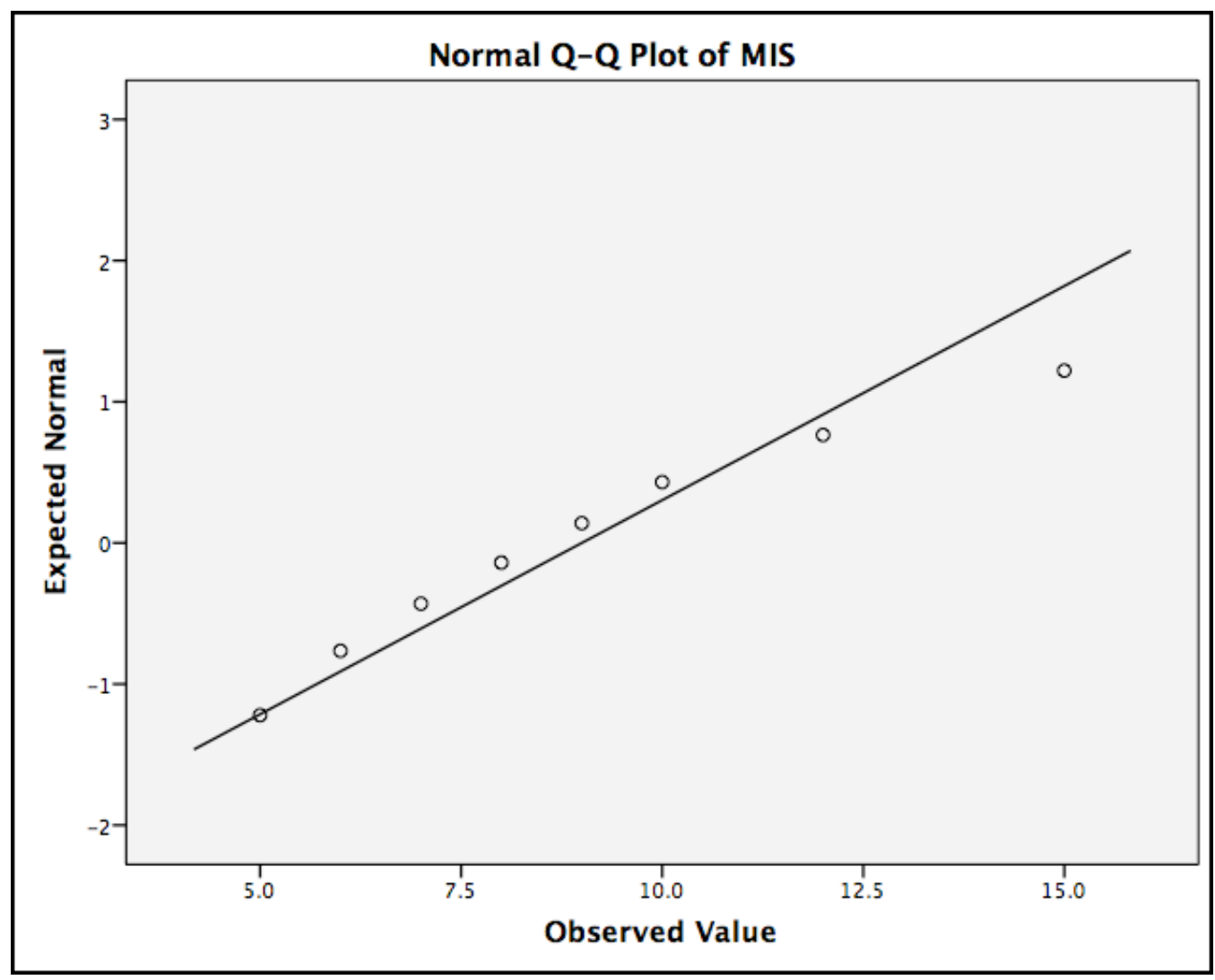


Figure 17. Q-Q Plot for Parent and Family Technology Survey

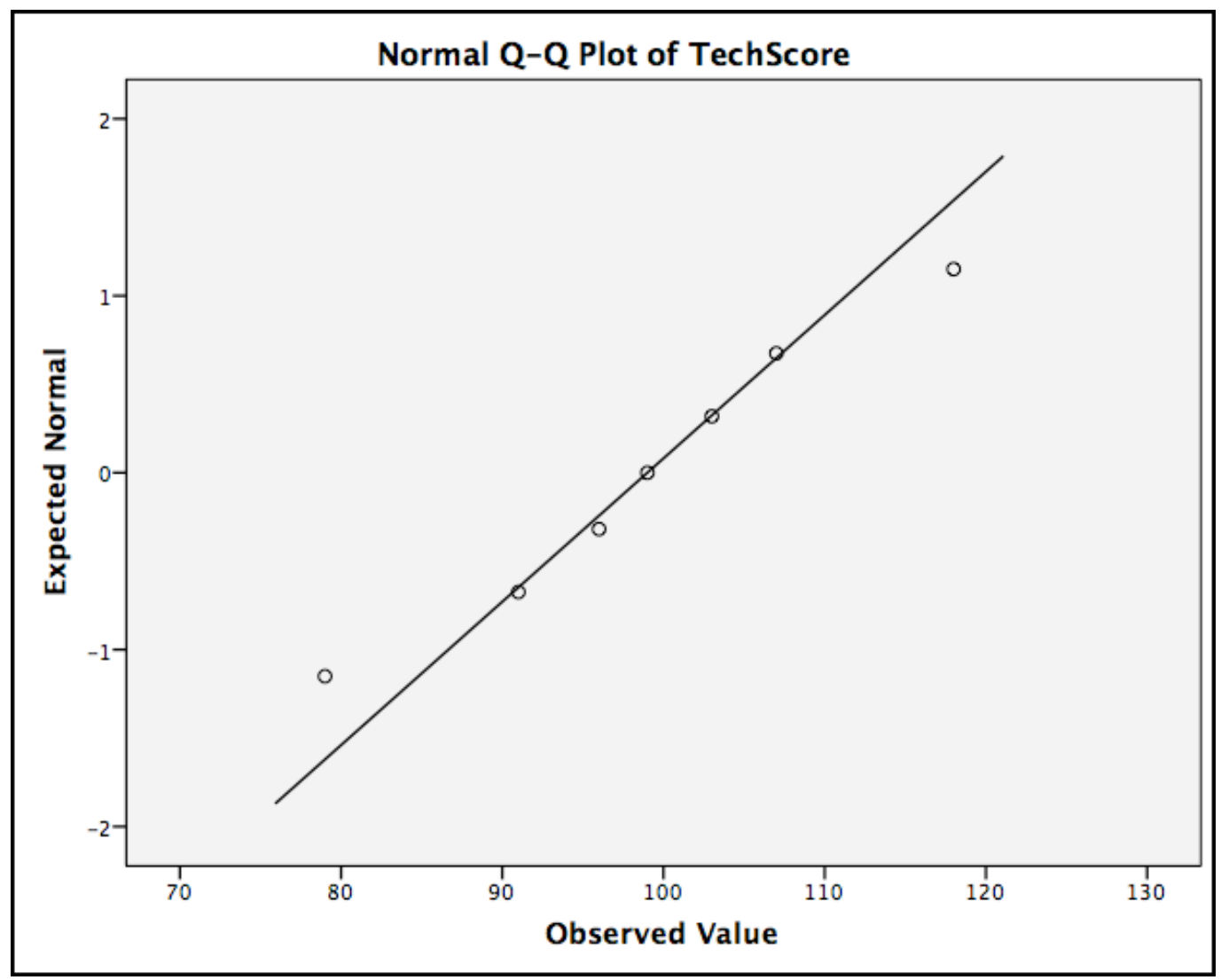

Owing to the fact that MIS scores were normally distributed and were selected from a larger sample of participants whose scores also demonstrated a normal distribution, in addition to the presence of a binary outcome variable, a logistic regression was used to evaluate a predictive relationship between MIS scores and success with either the VM or LM intervention modality. Correlational analyses among Treatment Group and MIS variables revealed a significant relationship $(r=0.84, n=8, p<0.05)$. A logistic regression was conducted to evaluate a potential predictive relationship. Results indicated that MIS scores significantly predicted group membership in either the LM or VM treatment condition, $X^{2}(1)=8.99, p<.01$. The model correctly classified $100 \%$ of 
cases. These results demonstrate that pre-treatment imitative abilities were a significant predictor of treatment success within this sample.

Figure 18. Graph of Each Participant's MIS Score

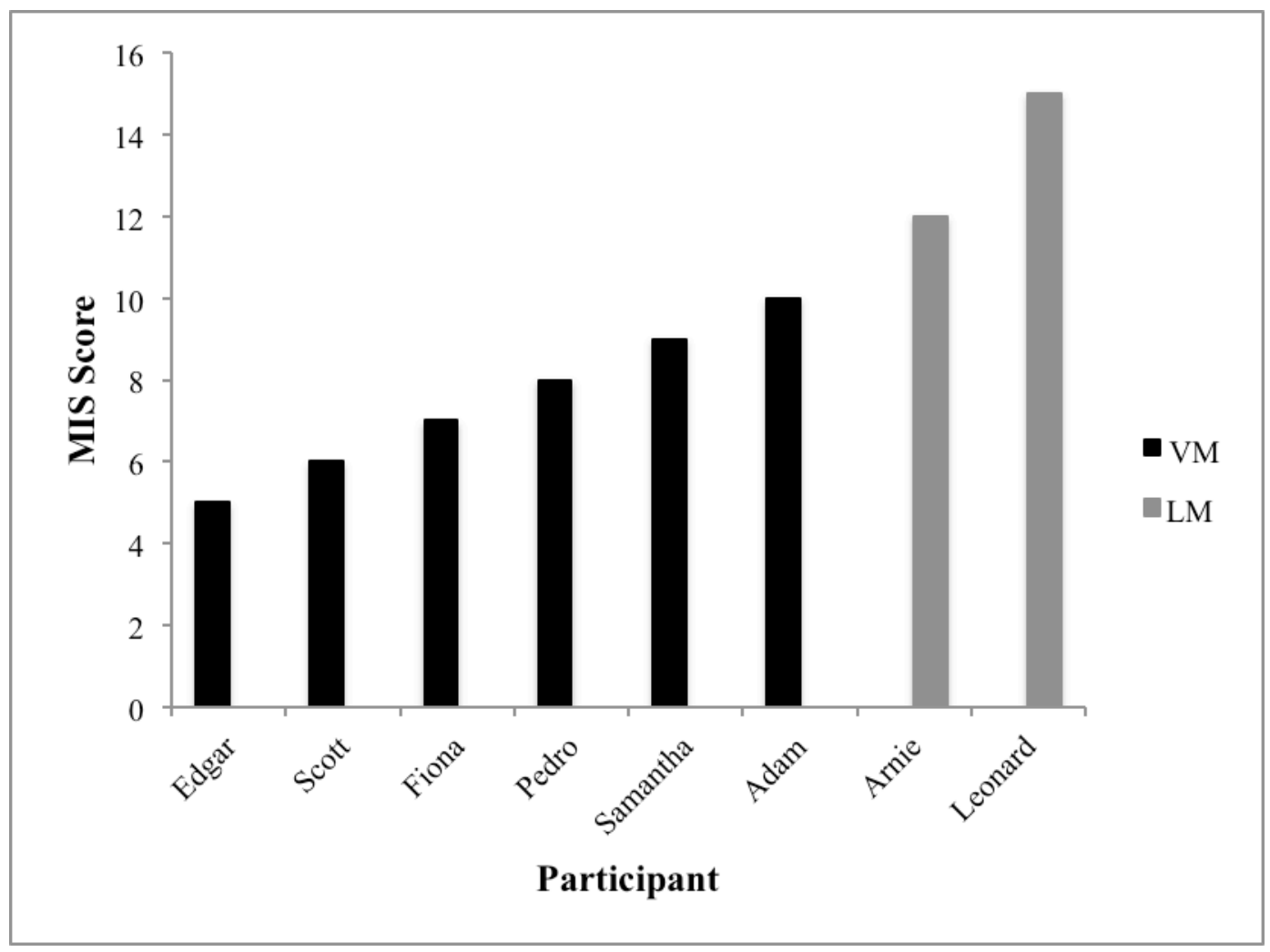

Additionally, based on previous observations regarding group differences in trials-to-criterion and the assumption that this difference may be related to imitative abilities, a linear regression was conducted to evaluate a potential predictive relationship between MIS scores and differences in trials-to-criterion between the two treatment types (LM and VM). Correlational analyses among difference in trials-to-criterion and MIS variables revealed a significant relationship $(r=0.73, n=8, p<0.05)$. Results indicated that MIS scores significantly predicted the differences in trials-to-criterion, $b=-.73, t()=$ $-2.6, p<.05$. MIS scores also explained a significant proportion of variance in group 
membership, $R^{2}=.535, F(1,6)=6.90, p<0.05$ (See Table 6). These results demonstrate that pre-treatment imitative abilities were a significant predictor of the degree of difference in trials-to-criterion between VM and LM within the current sample, and add support to the theory that children with slightly more advanced imitation skills were able to learn successfully with both presentation modalities, while children with fewer to no imitative abilities were consistently more successful with VM.

As SA totals from the ADOS failed to demonstrate a normal distribution, and the sample size was small $(n<30)$, an exact logistic regression model (Zamar et al., 2007) was fit to the data in order to determine the validity of SA totals from the ADOS as a predictor of treatment success. The use of this type of regression is further validated given the dichotomous nature of the outcome variable. The results for the ADOS $(\beta=$ $0.08, p>.05$, CI $[-0.89,1.06])$ indicate that this measure did not successfully predict group membership.

As Technology Survey scores were normally distributed, a logistic regression was used to evaluate a predictive relationship between these scores and success with either the VM or LM intervention modality. Correlational analyses among Treatment Group and Technology score variables failed to reveal a significant relationship $(r=0.03, n=7, p>$ 0.05). Results indicated that Technology scores did not significantly predict group membership in either the LM or VM treatment condition, $X^{2}(1)=.005, p>.05$. Because of the small sample size $(n=7)$, an exact logistic regression model was fit to the data. This model also failed to produce a significant result $(\beta=-0.01, p>0.05$, CI $[-0.16$, 0.13]) indicating that Technology scores did not successfully predict treatment success. 
Children were not significantly more likely to demonstrate success with either the VM or LM condition based on their ADOS scores, or Technology Survey scores alone (See Figures $19 \& 20$ ). This suggests that neither social skills nor technological literacy are directly related to intervention type preference, however results indicated that scores on the MIS did significantly predict group membership. This supports the assumption that the strength of an individual's pre-existing imitative repertoire may directly relate to success with a VM based intervention, and, more specifically, that children with the least developed imitative repertoires appear to be consistently more successful with VM based interventions. Additionally, since the sample size was small $(n=8)$, it is conceivable that social skills and technological literacy may have more predictive validity than was demonstrated as a result of these analyses and thus further research into each of these variables is recommended.

Figure 19. Graph of Each Participant's SA Total from the ADOS

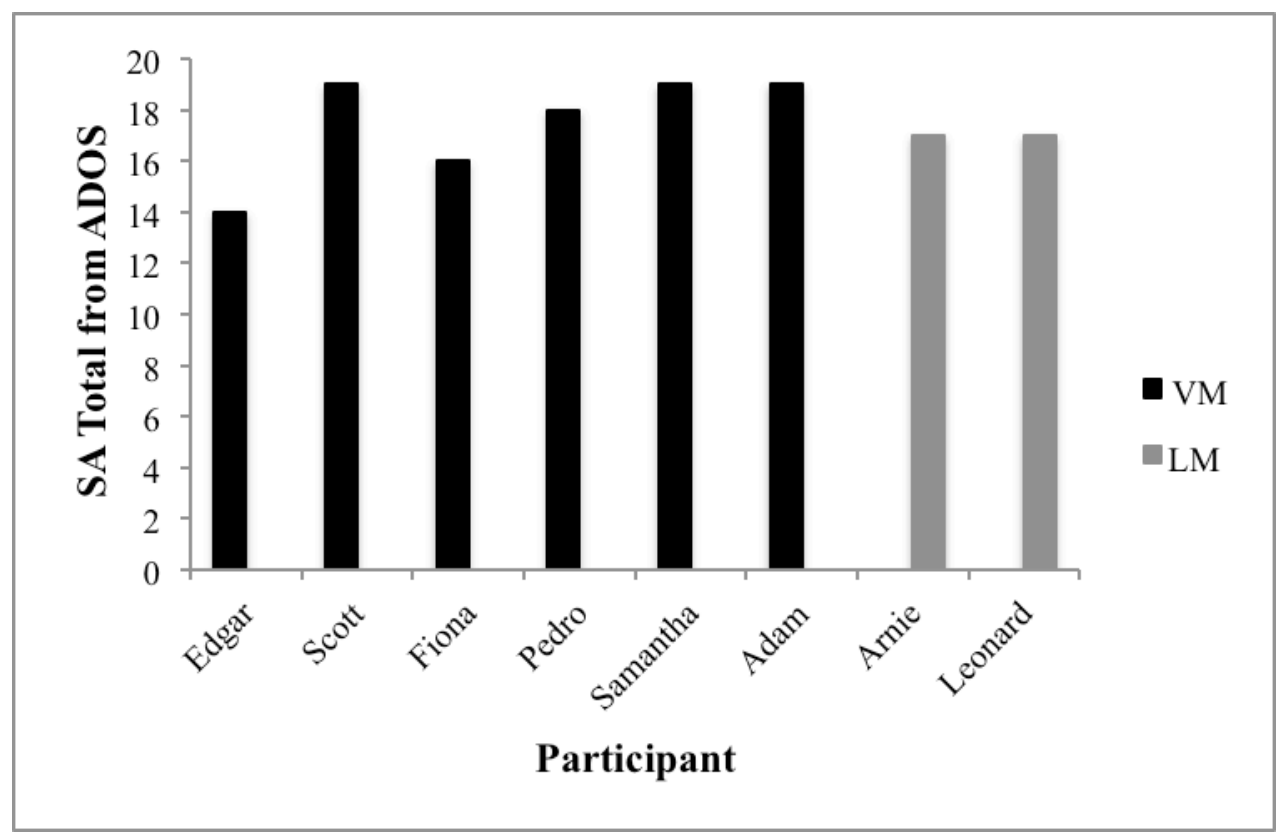


Figure 20. Graph of Each Participant's Parent and Family Technology Survey Score

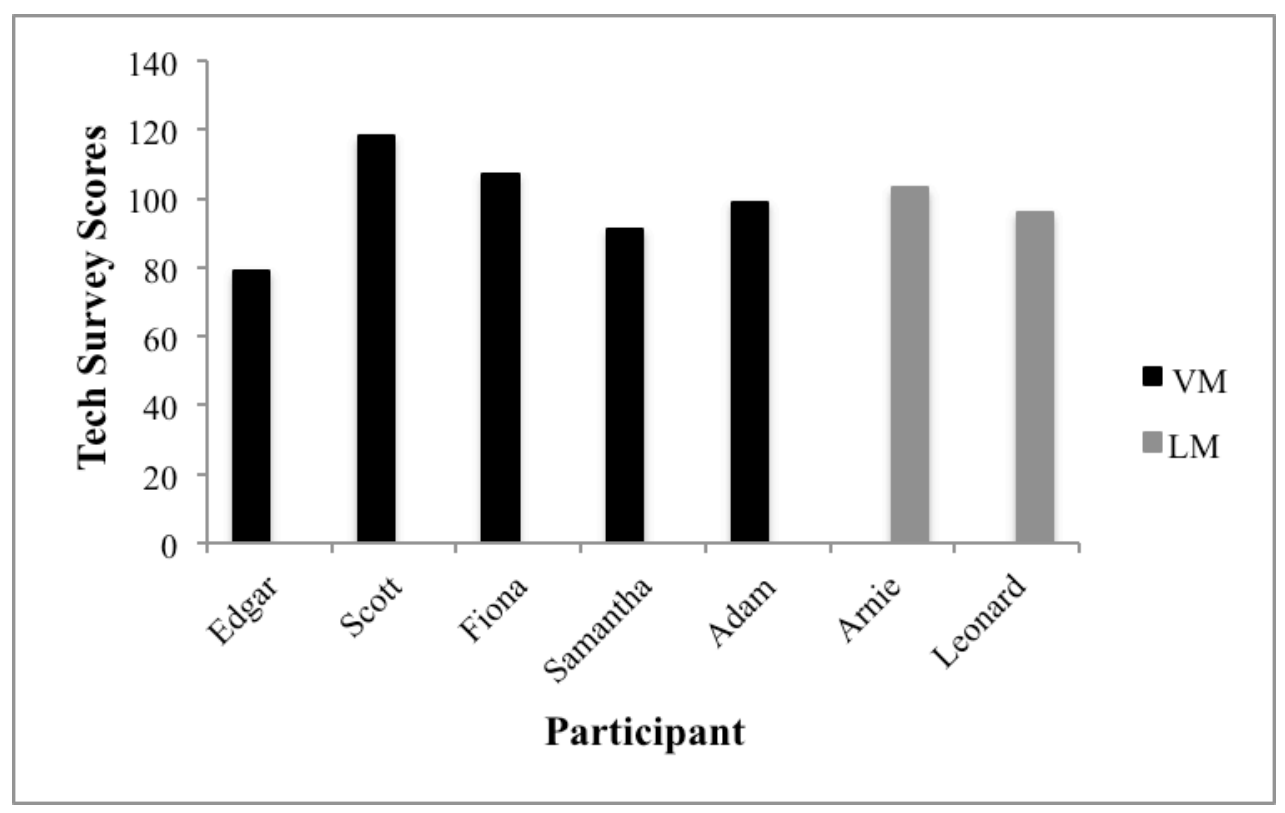

While statistical analyses indicated that the MIS is the only significant predictor of group membership in either the VM or LM category, there may be some additional interesting information regarding ADOS scores. While the sample size may be too small for the difference to be noted statistically as only two participants ended up in the LM treatment category, both of the participants who were more successful with the LM technique received scores of 17 on their ADOS SA totals. This might indicate that these children were neither the most social (these were Edgar and Fiona, who received scores of 14 and 16, respectively), nor the least social (Scott, Pedro, Samantha, and Adam all received scores of either 18 or 19), but rather were those whose social scores fell somewhere in the middle. Although this information is cursory at best, it may indicate the necessity for further research into this relationship. 


\section{DISCUSSION}

The present study supports previous research demonstrating a strong relationship between social skills and imitation, and adds new evidence to the literature on imitation regarding the relationship between VM and treatment success.

\section{Study 1}

While a significant amount of previous research has been conducted regarding the relationship between imitation and social skills, and while this research is frequently cited throughout the literature on imitation interventions, no studies have yet been published directly comparing SA totals from ADOS assessments to scores on the MIS (Ingersoll, 2008; Ledford \& Wolery, 2010; Rogers \& Vismara, 2008). This is particularly surprising given that the ADOS is highly pervasive and considered to be the "gold standard" in diagnostic tools for ASD (Sikora et al., 2008). Similarly, though lacking this degree of reputability, the MIS is one of a relatively small number of demonstrably effective motor imitation assessments available (Stone at al., 1997). For these reasons, I analyzed the results of these two assessments to determine whether the hypothesized predictive relationship between the two would remain. The results of my analysis demonstrated a significant predictive relationship between the two assessments, indicating that my hypothesis was accurate, and MIS scores did predict SA totals. These results contribute to the large body of literature on both imitation and social skills within the ASD population and add concrete evidence to affirm the frequently cited relationship between the two.

Additionally, the directed nature of this relationship (that MIS scores predicted SA totals), may add new evidence to the debate about the nature of the deficit in imitation in children with ASD, and why this deficit is so much more prominent in this population 
than in that of other children with developmental delays (Dawson \& Adams, 1984).

Imitation is considered to be directly related to the development of typical social skills as it allows children access to myriad social experiences and learning opportunities in which they are able to interact with others (Meltzoff \& Gopnick, 1994). These data additionally suggest that social skills may be directly related to the development of typical imitation repertoires, and may demonstrate the type of "cascading effects" noted elsewhere in the autism literature (Mundy, Gwaltney \& Henderson, 2010). Perhaps this relationship is the result of atypical social development stifling opportunities to gain a generalized imitative repertoire through lack of typical social behaviors, such as eye contact and positive affect, when interacting with others. It is possible that infants and very young children with ASD may display fewer of these behaviors than typically developing infants when interacting with caregivers, and may therefore effectively punish the caregiver's attempts at imitative play by failing to respond in the expected manner. This may result in decreased attempts by the caregiver to engage in these interactions and therefore decreased opportunities for the child to learn to imitate others. While the details of this relationship have yet to be fully explicated, the results of the current analysis contribute to the available literature and add evidence to the need for further exploration into this area.

\section{Study 2}

Study 2 was designed to analyze the effectiveness of VM interventions as compared to LM interventions for imitation training, and to begin to explore what individual differences may influence success with VM. VM based intervention are becoming progressively more popular within the field of $\mathrm{ABA}$ for treating individuals 
with ASD (Paterson \& Arco, 2007). These interventions have been used to teach a variety of different skills, and in recent years have begun to be used for teaching imitation (Cardon, 2012; Cardon \& Wilcox, 2010; Kleeberger \& Mirenda, 2010). Although the body of literature exploring this particular application of the VM methodology has grown in recent years, several questions about when, why, and for whom these methods are most effective remain (Buggey \& Ogle, 2012; Rayner, 2011). The present study began by directly comparing VM to LM for teaching imitation to young children with ASD who presented with limited to no imitative repertoires. While several articles have incorporated or compared VM and other teaching methodologies, none have directly compared LM to VM for teaching this particular skill. In order to facilitate as direct a comparison as possible between the two methodologies, all aspects of treatment in the current study were identical between the two with the exception of the medium through which the compound $\mathrm{S}^{\mathrm{D}}$ ("do this" and the demonstration of the behavior) was presented. Results of this analysis indicated that several of the participants were distinctly more successful with the VM procedure (six out of eight), while the remaining two were more successful with the LM procedure. The results of the current study contradict several other studies, which state that VM may be an ineffective treatment for children under the age of four, by demonstrating that VM was effective for several participants in this age bracket (Buggey, 2011, Buggey et al., 2011, Buggey \& Ogle, 2012). Of the six participants who were more successful with the VM based intervention, five were under the age of four. Additionally, all the participants (seven out of eight of whom were under four), achieved eventual success with the VM intervention. However, this difference in 
findings may be related to the fact that the previous studies were specifically looking at VSM, rather than VM.

The results of the current study indicate that the medium of presentation itself was the distinguishing feature between the two treatment types for the individual participants. Although all other aspects of treatment remained identical, one or the other method was distinctly more effective for each participant. All eight participants exhibited results indicating a difference between the two treatments. The implications of this finding are broad in that they may provide much needed insight into why VM techniques are becoming popular for this population. Even when exposed to the relatively standard DTT procedures used in this study, certain individuals were significantly more successful when those trials were presented in part by a therapist behind an iPad screen rather than one sitting across from them.

In order to further explore this difference and attempt to discern what some of the contributing factors may be, I identified three factors that might function as predictors of success with one or the other intervention modality. The MIS was selected as a measure of motor imitation, and it was predicted, based on the results of my previous research which demonstrated that children with very few imitative skills were frequently successful with VM imitation training, that those individuals with the fewest imitative skills would likely perform better with the VM based intervention (McDowell, 2014). The SA total from the ADOS was selected as a measure of social skills and it was predicted that those individuals with the most advanced social skills would be more successful with the LM intervention. Finally, a Parent and Family Technology Survey was designed for the purposes of the present study and it was predicted that those 
individuals with the highest scores of this survey would be more successful with the VM based intervention.

MIS

MIS scores indicating the level of pre-treatment imitative abilities were found to predict both with which treatment participants would be more successful (VM or LM) $(\beta=-.84, t(7)=-3.84, p<.01)$ and the difference in number of trials-to-criterion between the two treatments $(\beta=-.73, t(7)=-2.6, p<.05)$. At first, these results appear to be in agreement with the theory put forth in the literature that pre-treatment imitation is a factor in success with VM based interventions. However, many of the researchers who have made this claim have done so based on the assumption the VM procedures are unlikely to be effective in the absence of a pre-existing imitative repertoire (Rayner, 2011). The current study has demonstrated that the opposite may in fact be true. Within the present sample, participants with the fewest imitative abilities (those who scored the lowest on the MIS assessment) were found to be more successful with the VM treatment, while participants with slightly more advanced imitative skills were found to be more successful with the LM procedure. These results support my hypothesis that children with the fewest imitative abilities would be more successful with VM than with LM. SA Totals from the ADOS

SA totals were not found to predict success with either LM or VM. This contradicts my hypothesis that participants with more advanced social skills would be more successful with the LM treatment. Additionally, these results contradict other researchers who have theorized that aspects of social development such as language may directly influence success with VM based interventions (Delano, 2007). Finally, although 
social skills have been linked to imitation (Rogers \& Vismara, 2008), and imitation was shown in the current study to be predictive of success with one or the other intervention modality, social skills were not shown to replicate this relationship.

There are multiple potential reasons for this disagreement, the most obvious of which may be the small sample size. Another potential explanation might be that the aspects of imitative abilities that are directly related to social skills may vary from those aspects of imitation that predict membership in either treatment group. However, while this explanation is plausible, it is also conceivable that a more complex relationship might exist between social skills and treatment success, that was not detected by the present analyses because of various limitations such as sample size.

While the original hypothesis predicted that children with more advanced social skills would be more successful with the LM treatment, the data appear to indicate that it is instead the group with moderate social skills who were more successful with this treatment type. Participants with both the most advanced social skills (scores of 14 and 16 on their SA totals) and those with the fewest social skills (scores of 18 and 19 on their SA totals) were all more successful with the VM procedure. The two participants who were more successful with the LM treatment both received scores of 18 , which falls in the middle of the other group's scores. Although this information is based on a markedly small group of participants and was not determined based on statistical analyses, it may provide an interesting backdrop for future research into the relationship between social skills and VM based treatments. 


\section{Parent and Family Technology Survey}

Similarly, scores from the technology survey were not found to significantly predict which treatment paradigm would lead to greater success. This contradicts the hypotheses of previous researchers, who have stated that a preference for television and other electronic devices may contribute to success with VM interventions (Nikopoulos \& Keenan, 2003). However, this contradiction may be the result of myriad factors including the small sample size and the possibility that the survey itself may not have adequately represented the construct for which it was intended. It is also possible that including the technological literacy of the parent and family into this assessment rather than only that of the child, while presumed to be relevant based on the young age of the sample, may have confounded the results in such a way that the child's technological literacy was obscured. Further research into the relationship between technological literacy and success with VM based interventions is needed prior to drawing conclusions.

\section{Implications}

The implications of the findings of the current study are substantial. The results indicate that the most effective means of determining which children should be taught to imitate using a video model may be through their pre-treatment imitation scores as determined by the MIS. They also convey, albeit with some room for doubt, that neither social skills nor technological literacy will provide as effective a measure. In terms of practical implications, these data demonstrate a potential answer to the question of which strategies should be implemented by practitioners when attempting to determine the most ideal treatment paradigm for individual children. The findings imply that implementing an assessment as simple as the MIS, and using the results of that assessment to determine 
whether to begin imitation treatment with an LM or VM based intervention, may potentially save therapists and children weeks of effort trying to learn a new behavior with a potentially less effective treatment. More specifically, these results suggest that VM based interventions for teaching early imitation may be more effective and efficient treatments than LM interventions for children with few to no pre-treatment imitation skills.

Based on my results, I can see that the six participants who were more successful with the VM intervention took anywhere from 130 and 365 extra trials to learn the behaviors placed into the LM treatment, and three of these participants did not acquire these behaviors after as many as 430 extra trials. In a practical setting those numbers are quite considerable. Not only could choosing the right treatment potentially save impressive amounts of time, but it could also save the child from experiencing boredom, frustration, and treatment fatigue as a result of repeated failures to acquire a new behavior (MacDuff et al., 2001). When working with a population as diverse as that of people with a diagnosis of ASD, any data that might indicate a least-restrictive treatment design based on individual differences is considered valuable.

Finally, it is also worth noting that the differences in trials-to-criterion between the two treatment types also varied in relation to group membership. Those who showed the greatest difference between treatment types $(M=306.5, S D=108.44)$ all belonged to the VM category, while those for whom the difference was more subtle $(M=67.5, S D=$ 31.82 ), fell into the LM category. This may be a result of the children in the LM category demonstrating more advanced imitation skills, and thus being more able to learn to imitate regardless of model type. 
A regression based on this relationship demonstrated that MIS scores were significant predictors of the difference in trials-to-criterion between treatment types. This result adds evidence to the observation that it is the children who have the greatest difficulty with pre-treatment imitation that benefit most from the VM-based intervention. Those children with the lowest MIS scores were not only more successful with the VM intervention but also showed a larger difference between treatment types than those who were slightly more imitative. That is, children who were slightly more imitative were able to learn more successfully from a live model, but were also able to learn from a video model within a reasonable period of time. This was not the case for the children who were more successful with VM, instead these children were universally much more successful with VM than LM and, furthermore, half of the participants in the VM group did not successfully acquire the behaviors placed into the LM condition during the allotted treatment period. The implications of this observation adds further support to the idea that basing treatment assignment off imitation scores may improve outcomes for individuals with the fewest imitative abilities.

Finally, these results demonstrate that even those children who are able to learn from a live model, and may not require a video based intervention for acquiring basic motor imitation, are likely able to learn to imitate video models as well. This information could prove to be extremely useful in designing interventions for acquiring more advanced or complicated skills. VM-based interventions have been demonstrated to provide several benefits such as improved generalization and ease of implementation (Kleeberger \& Mirenda, 2010). Therefore, the implication that children who are able to 
learn to imitate from a live model are also able to learn via VM may open the door to improved interventions for this group as well.

\section{Limitations}

The results of the present study, although promising, must be considered with a degree skepticism in light of certain limitations of the research design. In the first study, all participants ADOS scores were coded as Module 1 assessments because of variations in age and the time at which assessments were administered, While this was standard procedure for the ADOS assessment, age requirements changed with the creation of the ADOS-2 (Lord, 2012), dictating that the newly developed toddler module should be administered to children under the age of 30 months. Owing to this change, it is possible that participants were not assessed using the most sensitive tools available. This may have had an impact on the resultant analysis. However, as the previous version of the ADOS assessment was considered one of the most effective diagnostic tools available without the addition of the toddler module, the SA totals utilized in the current study should still be considered highly accurate and effective representations of the children's social skills.

Secondly, although all analyses in study two were appropriately determined to achieve the highest possible power, the results must be interpreted with caution because of the small sample size $(n<30)$. The general rule for predictive analyses states that one should have 10-20 observations per predictor (Vittinghoff \& McCulloch, 2007). The present dataset contained only eight observations, and therefore falls short of this recommendation. However, appropriate normality testing was conducted and in each 
instance the test that provided the highest power was conducted in order to attempt to compensate for the small sample.

Another possible concern may be the adapted alternating treatments design implemented in study two. While standard alternating treatments designs attempt to apply more than one treatment to the acquisition of a single behavior (Barlow \& Hayes, 1979), I was not able to achieve this with the present design. In order to compensate for this, I implemented measures to ensure behavioral equivalency across the target tasks including: visual feedback to the performer, auditory feedback to the performer, the use of an object, a similar number of steps, and a logical analysis by the researchers (Ingersoll, Schreibmen \& Tran, 2003; Wolery et al., 2010). Additionally, behaviors were counterbalanced across participants and treatment types in order to further compensate for not teaching the same behavior within participants. However, any remaining differences between behaviors may have potentially contributed to the resultant differences between treatment types and should therefore be taken into consideration when viewing the results.

Additionally, the length of time that participants were held in apparently ineffective treatment conditions may be considered excessive. While this extended exposure contributed to the ability to differentiate between the effectiveness of the two treatments in the research design, from a clinical perspective it would have been more appropriate to stop the intervention after fewer sessions, and either intervene using a different procedure, or with a new behavior.

Finally, although errorless learning procedures have been frequently cited as appropriate teaching procedures when working with young children with ASD (MacDuff 
et al., 2001), the error correction procedure implemented during the course of this study varied in some ways from that seen in other treatment protocols. While many error correction procedures seen in typical ABA settings involve re-presenting the $\mathrm{S}^{\mathrm{D}}$ and then prompting the child to perform the target behavior, the procedure used in this study did not involve a re-presentation of the $\mathrm{S}^{\mathrm{D}}$. It is possible that this distinction may have influenced the rates at which the participants were able to acquire the target behaviors. It is to be noted, however, that this procedure was consistent across treatment types (LM and VM) and that it therefore would not likely have influenced the differentiation between treatment types that was the main focus of the present analysis.

\section{Future Directions}

Results of the current research have suggested several ways in which improvements can be made when testing future iterations of this paradigm. In order to improve the certainty of the results, a larger sample should be utilized in the treatment comparison and predictor analysis. Additionally, it may be interesting to conduct an analysis of the predictive abilities of SA totals from the ADOS in terms of MIS scores with a more uniform sample. One potential course of action might be to conduct two separate analyses: one with a large sample of individuals assessed using the toddler module $(n>30)$, and one with a sample of individuals assessed using module $1(n>30)$.

In this way, not only would the assessment methods be more specified, but it may also be possible to parse out any age related effects regarding potential differences in effect size between the younger and older groups.

In regards to the treatment comparison component, in addition to increasing the sample size, it may be interesting to alter the nature of the behavior in order to determine 
whether or not the current results would be maintained. Instead of investigating only motor imitation, it may be interesting to incorporate vocal and facial imitation, which are considered to be more difficult behaviors. It may also be valuable to explore whether the results of this study hold when analyzing behaviors other than imitation. For example, when teaching common pre-school appropriate behaviors such as following directions, would children with the fewest imitative abilities learn more quickly when the $\mathrm{S}^{\mathrm{D}}$ was presented in a video based format?

Finally, in an effort to continue the process of identifying factors relevant to success with VM based interventions, it may be useful to explore additional predictors. Some further potential factors relating to individual differences in treatment success as suggested by various researchers include: attention, age, and language skills. The paradigm implemented in the present analyses would easily lend itself to alterations, which could allow each of these factors as well as others to be tested. That analysis may then improve understanding within the field of what variables play a role in the successful implementation of VM interventions. The discovery of these additional mediating variables may have the potential to contribute to the development of an assessment through which practitioners could determine the ideal treatment medium for individual children and in so doing be able to improve treatment outcomes.

Summary

The present dissertation consisted of two studies, which explored the relationship among social skills, imitation, and VM-based interventions for children with ASD. Results of the first study indicated that social skills, as assessed by SA totals from ADOS assessments, significantly predicted motor imitation abilities as assessed by the MIS. 
These results are significant as they not only contribute to the existing body of literature highlighting the relationship between social skills and imitation within this population, but also offer a new analysis of two of the most prominent assessments of these skills sets. Importantly, this is an analysis that has heretofore been absent from the relevant body of literature.

The second portion of this study involved the selection of a subset of participants from the larger sample whose MIS scores indicated that they would meaningfully benefit from an imitation intervention. These eight children were placed into a treatment comparison study in which they were taught to imitate two equivalent behaviors, one using a VM intervention and the other using an LM intervention. The format of these interventions was identical, barring the medium through which the $\mathrm{S}^{\mathrm{D}}$ was presented. Results of this study indicated that there was a significant difference between the two treatment types and that a portion of the participants was more successful with the VM intervention while the remaining participants were more successful with the LM intervention. These findings demonstrate the presence of individual differences that contribute to success with one or the other treatment modality. Additionally, these results suggest that the medium of presentation is the differentiating factor between the two treatments, as all other potentially confounding variables were consistent between the treatments.

Three factors were identified as potential predictors of success with one or the other treatment modality and regression analyses were performed to determine their significance. Although neither SA totals from the ADOS, nor results of the Parent and Family Technology survey were found to be significant predictors, these results may be 
attributed to a number of limitations regarding sample size and the ability of the measures to correctly assess the constructs for which they were intended. MIS scores, however, were found to significantly predict both treatment success group, and differences in trialsto-criterion between the two treatment types. These results indicate that pre-treatment imitation scores may be valuable predictors of treatment success with either VM- or LMbased interventions. Additionally, they demonstrate that these scores may contribute to knowledge regarding which individuals would be more likely to benefit from VM-based interventions for early imitation, and which individuals may be more likely to be successful with either technique. Those individuals who demonstrated the fewest imitation abilities in pretreatment assessments were universally and distinctly more successful with the VM based intervention than the LM based interventions. The significance of these discoveries is widespread, and although these results must be treated cautiously, they indicate the possibility that a simple pre-treatment assessment of imitation may be relevant and valuable in order to significantly reduce treatment time, effort, and frustration when attempting to teach early imitation to young children with ASD. 


\section{REFERENCES}

Akshoomoff, N. (2006). Use of the Mullen Scales of Early Learning for the Assessment of Young Children with Autism Spectrum Disorders. Child Neuropsychology, 12(4-5), 269-277. doi: 10.1080/09297040500473714

American Psychiatric Association, Autism Spectrum Disorders. (2012). Retrieved from http://www.psychiatry.org/autism

Ayllon, T., \& Michael, J. (1959). The psychiatric nurse as a behavioral engineer. Journal of the Experimental Analysis of Behavior, 2, 323-334. doi: 10.1901/jeab.1959.2-323

Baer, D. M., Wolf, M. M., \& Risley, T. R. (1968). Some current dimensions of applied behavior analysis. Journal of Applied Behavior Analysis, 1(1), 91-97.

doi: 10.1901/jaba.1968.1-91.

Barlow, D. H., \& Hayes, S. C. (1979). Alternating treatments design: One strategy for comparing the effctes of two treatments in a single subject. Journal of Applied Behavior Analysis, 12(2), 199-210.doi: 10.1901/jaba.1979.12-199

Barlow, D. H., Nock, M. K., \& Hersen, M. (2009). Single Case Experimental Designs: Strategies for Studying Behavior Change. Boston, MA: Pearson Education, Inc.

Baron-Cohen, S. (2001). Theory of mind in normal development and autism. Prisme, 34, 174-183.

Bergman, L. R., \& Trost, K. (2006). The person-oriented versus the variable-oriented approach: Are they complementary, opposites, or exploring different worlds? MerrillPalmer Quarterly, 52(3), 601-632.doi:10.1353/mpq.2006.0023

Blundell, S.W., Shepherd, R.B., Dean, C.M., Adams, R.D. (2003). Functional strength training in cerebral palsy: A pilot study of a group circuit training class for children aged 4-8 years. Clinical Rehabilitation. 17. 48-57. doi: 10.1191/0269215503cr584oa

Bradley-Johnson, S. (2001). Cognitive Assessment for the Youngest Children: A Critical Review of Tests. Journal of Psychoeducational Assessment, 19(1), 19-44. doi: $10.1177 / 073428290101900102$

Brown, A. K., Brown, J. L., \& Poulson, C. L. (2008). Discriminating which fork to use: Teaching selective imitation to people with autism. Research in Autism Spectrum Disorders, 2(2), 199-208. doi: 10.1016/j.rasd.2007.06.001

Buggey, T., \& Ogle, L. (2013). The use of self-modeling to promote social interactions among young children. Focus on Autism and Other Developmental Disabilities, 28(4), 202-211. doi: 10.1177/1088357612464518 
Bui, L.T., Moore, D.W., Anderson, A. (2013). Using escape extinction and reinforcement to increase eating in a young child with autism. Behaviour Change, 30(1), 45-55. doi: $10.1017 /$ bec. 2013.5

Carr, J. E., Nicolson, A. C., \& Higbee, T. S. (2000). Evaluation of a brief multiplestimulus preference assessment in a naturalistic context. Journal of Applied Behavior Analysis, 33, 353-357. doi: 10.1901/jaba.2000.33-353

Casey, A.M., McWilliam, R.A., Sims, J. (2012). Contributions of incidental teaching, developmental quotient, and peer interactions to child engagement. Infants and Young Children. 25(2). 122-135. doi:10.1097/IYC.0b013e31824cbac4

Celik, S., Vuran, S. (2014). Comparison of direct instruction and simulatenoys prompting procedure on teaching concepts to indviduals with intellectual disability. Education and Training in Autism and Developmental Disabilities. 49(1). 127-122.

Centers for Disease Control and Prevention, Autism Spectrum Disorders (ASDs) Data and Statistics (2013). Retrieved from http://www.cdc.gov/ncbddd/autism/data.html

Charlop-Christy, M., \& Daneshvar, S. (2003). Using video modeling to teach perspective taking to children with autism. Journal of Positive Behavior Interventions, 5(1), 12. Retrieved from http://ezproxy.fiu.edu/login?url=http://search.proquest.com/docview/218773380?accounti $\mathrm{d}=10901$

Cooper, J. O., Heron, T. E., \& Heward, W. L. (2007). Applied behavior analysis (2nd ed.). Upper Saddle River, NJ: Prentice Hall.

Correia, C.J., Benson, T.A. (2006). The use of contingency mangaemnt ot reduce cigarette smoking among college students. Experimental and Clinical

Psychopharmacology. 14(2). 171-179. doi: 0.1037/1064-1297.14.2.171

Davis, T.N., Dacus, S., Strickland, E., Machalicek, W., Coviello, L. (2013). Reduction of automatically maintaine self-injurious behavior utilizing noncontingent matched stimuli. Developmental Neurorehabilitation, 16(3), 166-171. doi:10.3109/17518423.2013.766819

Dawson, G., \& Bernier, R. (2013). A quarter century of progress on the early detection and treatment of autism spectrum disorder. Development and Psychopathology, 25, 14551472. doi: 10.1017/S0954579413000710d

Dawson, G., Webb, S., Schellenberg, G. D., Dager, S., Friedman, S., Aylward, E., \& Richards, T. (2002). Defining the broader phenotype of autism: Genetic, brain, and behavioral perspectives. Development and Psychopathology, 14(03).

doi:10.1017/S0954579402003103 
Delano, M. E. (2007). Video Modeling Interventions for Individuals with Autism.

Remedial and Special Education, 28(1), 33-42. doi: 10.1177/07419325070280010401

DeLeon, I. G., \& Iwata, B. A. (1996). Evaluation of a multiple-stimulus presentation format for assessing reinforcer preferences. Journal of Applied Behavior Analysis, 29, 519-533. doi: 10.1901/jaba.1996.29-519

Dytham, C. (2003). Tests 1: Tests to look at differences. In Choosing and using statistics: A biologist's guide. Malden, MA: Blackwell Pub.

Ergenekon, Y., Tekin-Iftar, E., Kapan, A., \& Akmanoglu, N. (2014). Comparison of video and live modeling in teaching response chains to children with autism. Education and Training in Autism and Developmental Disabilities, 49(2), 200-213.

Farrant, B. M., Maybery, M. T., \& Fletcher, J. (2011). Socio-emotional engagement, joint attention, imitation, and conversation skill: Analysis in typical development and specific language impairment. First Language, 31(1), 23-46. doi: 10.1177/0142723710365431

Ferster, C. B. (1961). Positive reinforcement and behavioral deficits in autistic children. Child Development, 32, 347-356.

Finn, C. A., \& Sladeczek, I. E. (2001). Assessing the Social Validity of Behavioral Interventions: A Review of Treatment Acceptability Measures. School Psychology Quarterly, 16(2), 176-206. doi: 10.1521/scpq.16.2.176.18703

Ghaderi, A. (2007). Logical functional analysis in the assessment and treatment of eating disorders. Clinical Psychologist. 11(1). 1-12. doi:10.1080/13284200600957324

Green, G. (2001). Behavior analytic instruction for learners with autism: Advances in stimulus control technology. Focus on Autism and Other Developmental Disabilities, 16(2), 72-85. doi: 10.1177/108835760101600203

Hall, S.S., Hustyi, K.M., Hammond, J.L., Hirt, M.,Reiss, A.L. (2014). Using discrete trial taininf to identify specific learning impariments in boys with fragile x syndrome. Journal of Autism and Developmental Disorders, 44, 1659-1670.

doi: 10.1007/s10803-014-2037-6

Hattier, M. A., \& Matson, J. L. (2012). An examination of the relationship between communication and socialization deficits in children with autism and PDDNOS. Research in Autism Spectrum Disorders, 6(2), 871-880.

doi: 10.1016/j.rasd.2011.12.001

Herbert, M. R. (2010). Contributions of the environment and environmentally vulnerable physiology to autism spectrum disorders. Current Opinion in Neurology, 23(2), 103-110. doi: 10.1097/WCO.0b013e328336a01f 
Horne, P.J., Erjavec, M. (2007). Do infants show generalized imitation of gestures? Journal of the Experimental Analysis of Behavior. 87(1). 63-87.

doi:10.1901/jeab.2007.11-06

Ingersoll, B. (2008). The social role of imitation in autism implications for the treatment of imitation deficits. Infants and Young Children, 21(2), 107-119.

doi:10.1097/01.IYC.0000314482.24087.14

Ingersoll, B., \& Lalonde, K. (2010). The Impact of Object and Gesture Imitation Training on Language Use in Children With Autism Spectrum Disorder. Journal of Speech, Language, and Hearing Research, 53(4), 1040-1051. doi: 10.1044/1092-4388(2009/090043)

Ingersoll, B., Schreibman, L. (2006). Teaching reciprocal imitation skills to young children with autism using a naturalitstic behavioral approach: Effects on language, pretend play, and joint attention. Journal of Autism and Developmental Disorders. 36(4). 487- 505. doi: 10.1007/s10803-006-0089-y

Kaale, A., Fagerland, M. W., Martinsen, E. W., \& Smith, L. (2014). Preschool-based social communication treatment for children with autism: 12-month follow-up of a randomized trial. Journal of the American Academy of Child and Adolescent Psychiatry, 53(2), 188-198. doi:10.1016/j.jaac.2013.09.019

Kanner, L. (1943). Autistic disturbances of affective contact. Nervous Child, 2, 217-250.

Kasari, C., Sigman, M., Mundy, P., \& Yirmiya, N. (1990). Affective sharing in the context of joint attention interactions of normal, autistic, and mentally retarded children. Journal of Autism and Developmental Disorders, 20, 87-100. doi: 10.1007/BF02206859

Kroeger, K.A., Nelson, W.M. (2006). A language programme to increase the verbal production of a child dually diagnosed with down syndrome and autism. Journal of Intellectual Disability Research. 50(2). 101-108. doi: 10.1111/j.1365-2788.2005.00734.x

Ledford, J., \& Wolery, M. (2011). Teaching imitation to young children with disabilities: A review of the literature. Topics In Early Childhood Special Education, 30, 245-255. doi: $10.1177 / 0271121410363831$

Levin, J. R., Ferron, J. M., \& Kratochwill, T. R. (2012). Nonparametric statistical tests for single-case systematic and randomized $\mathrm{ABAB}$...AB and alternating treatment intervention designs: New developments, new directions. Journal of School Psychology, 50, 599-624. doi:10.1016/j.jsp.2012.05.001

Lickliter, R., \& Honeycutt, H. (2003). Developmental dynamics: Toward a biologically plausible evolutionary psychology. Psychological Bulletin, 129(6), 819-835.

doi:10.1037/0033-2909.129.6.819 
Locke, J. L. (2001). First communication: The emergence of vocal relationships. Social Development. 10(3). 294-308. doi: 10.1111/1467-9507.00167

Loibl, K., Rummel, N. (2014). The impact of guidance during problem-solving prior to instruction on students' inventions and learning outcomes. Instrumental Science. 42. 305326. doi: $10.1007 / \mathrm{s} 11251-013-9282-5$

Lord, C., Risi, S., Lambrecht, L., Cook, E. H., Leventhal, B. L., DiLavore, P., et al. (2000). The autism diagnostic observation schedule - generic: A standard measure of social and communication deficits associated with the spectrum of autism. Journal of Autism and Developmental Disorder, 30(3), 205-223. doi:10.1023/A:1005592401947

Lord, C., Rutter, M., DiLavore, P., Risi, S., Gotham, K., \& Bishop, S. (2012). Autism diagnostic observation schedule (2nd ed.). Los Angeles, CA: Western Psychological Services.

Lovaas, O. I., Schreibman, L., \& Koegel, R. L. (1974). A behavior modification approach to the treatment of autistic children. Journal of Autism \& Childhood Schizophrenia, 4(2), 111-129. doi: 10.1007/BF02105365

Lovaas, O. I. (2003). Teaching individuals with developmental delays: Basic intervention techniques. Austin, TX: PROED.

Luyster, R., Gotham, K., Guthrie, W., Coffing, M., Petrak, R., Pierce, K., ... Lord, C. (2009). The autism diagnostic observation schedule - toddler module: A new module for a standardized diagnostic measure for autism spectrum disorders. Journal of Autism and Developmental Disorders, 39(9), 1305-1320. doi: 10.1007/s10803-009-0746-z

MacDuff, G. S., Krantz, P. J., \& McClannahan, L. E. (2001). Prompts and prompt-fading strategies for people with autism. In C. Maurice, G. Green, \& R. M. Foxx (Eds.), Making a difference: Behavioral intervention for autism (37-50). Austin, TX: PRO-ED, Inc.

Madsen, K. M. (2004). Review of vaccines and autism. Nordic Journal of Psychiatry, 59(5) Retrieved from http://ezproxy.fiu.edu/login?url=http://search.proquest.com/docview/ 620938691 ?accountid $=10901$

Magiati, I., Wei Tay, X., \& Howlin, P. (2014). Cognitive, language, social and behavioral outcomes in adults with autism spectrum disorders: A systematic review of longitudinal follow-up studies in adulthood. Clinical Psychology Review, 34, 73-86.

doi:10.1016/j.cpr.2013.11.002

Maharaj, A.V.M. (2014). Exploring the development of social responses in chidlren with callous and unemotional traits: An examination of the impact of hypothesized reinforcing 
and aversive stimuli (Doctoral dissertation). Retrieved from FIU Electronic Theses and Dissertation. Paper 1174, http://digitalcommons.fiu.edu/etd/1174

Maione, L., Mirenda, P. (2006). Effects of video modeling and video feedback on peerdirected social language skills of a child with autism. Jounral of Positive Behavior Interventions. 8. 106-118. doi: 10.1177/10983007060080020201

Mawhood, L., Howlin, P., \& Rutter, M. (2000). Autism and developmental receptive language disorder - a comparative follow-up in early adult life. I: Cognitive and language outcomes. Journal of Child Psychology and Psychiatry, 41(5), 547-559.

doi:10.1111/1469-7610.00643

McCoy, K., \& Hermansen, E. (2007). Video modeling for individuals with autism: A review of model types and effects. Education and Treatment of Children, 30(4), 183-213. doi:10.1353/etc.2007.0029

McCrimmon, A., \& Rostad, K. (2014). Test review: Autism diagnostic observation schedule, second edition (ADOS-2) manual (part II): Toddler Module. Journal of Psychoeducational Assessment, 32(1), 88-92. doi: 10.1177/0734282913490916

McDowell, L.S., Gutierrez, A., Bennett, K.D. (in press). Analysis of live modeling plus prompting and video modeling for teaching imitation to children with autism. Behavioral Interventions. doi:10.1002/bin.1419

Moeyaert, M., Ugile, M., Ferron, J. M., Onghena, P., Heyvaert, M., Beretvas, S. N., \& Van den Noortgate, W. (2012). Estimating intervention effects across different types of single-subject experimental disgns: Empirical illustration. School Psychology Quarterly, 1-14. doi:10.1037/spq0000068

Mullen, E. (1995). Mullen scales of early learning. Circle Pines, MN: American Guidance Service, Inc.

Mundy, P., Gwaltney, M., \& Henderson, H. (2010). Self-referenced processing, neurodevelopment and joint attention in autism. Autism, 14(5), 408-429. doi:10.1177/1362361310366315

Mundy, P., Sigman, M. D., Ungerer, J., \& Sherman, T. (1986). Defining the social deficits of autism: The contribution of non-verbal communication measures. Child Psychology \& Psychiatry \& Allied Disciplines, 27(5), 657-669.

doi:10.1111/j.1469-7610.1986.tb00190.x

Nielsen, M., \& Dissanayake, C. (2004). Pretend play, mirror self-recognition and imitation: A longitudinal investigation through the second year. Infant Behavior and Development, 27, 342-365. doi:10.1016/j.infbeh.2003.12.006 
Nopprapun, M., \& Holloway, J. (2014). A comparison of fluency training and discrete trail insturction to teach letter sounds to children with asd: Acquisition and learning outcomes. Research in Autism Spectrum Disorders, 8, 788-802.

doi:10.1016/j.rasd.2014.03.015

Pavlov, I. P. (1977). Conditioned reflexes. (Trans, by GV Anrep.) London: Oxford University Press.

Peters-Scheffer, N., Didden, R., Korzilius, H., \& Sturmey, P. (2011). A meta-analytic study on the effectiveness of comprehensive ABA-based early intervention programs for children with Autism Spectrum Disorders. Research in Autism Spectrum Disorders, 5(1), 60-69. doi:10.1016/j.rasd.2010.03.011

Radley, K. C., O'Handley, R. D., Ness, E. J., Ford, W. B., Battaglia, A. A., McHugh, M. B., \& McLemore, C. E. (2014). Promoting social skill use and generalization in children ith autism spectrum disorder. Research in Autism Spectrum Disorders, 8, 669-680. doi:10.1016/j.rasd.2014.03.012

Rayner, C. (2011). Sibling and adult video modeling to teach a student with autism: Imitation skills and intervention suitability. Developmental Neurorehabilitation, 14(6), 331-338. doi:10.3109/17518423.2011.603369

Rayner, C., Denholm, C., \& Sigafoos, J. (2009). Video-based intervention for individuals with autism: Key questions that remain unanswered. Research in Autism Spectrum Disorders, 3(2), 291-303. doi: 10.1016/j.rasd.2008.09.001

Rogers, S. J. (2004). Developmental regression in autism spectrum disorders. Mental Retardation and Developmental Disabilities Research Reviews, 10(2), 139-143. doi:10.1002/mrdd.20027

Rogers, S. J., \& Vismara, L. A. (2008). Evidence-based comprehensive treatments for early autism. Journal of Clinical Child and Adolescent Psychology, 37, 8-38. doi:10.1080/15374410701817808

Schreibman, L., Dufek, S., \& Cunningham, A. B. (2011). Identifying moderators of treatment outcome for children with autism. New York, NY: Springer Science + Business Media.

Shukla-Mehta, S., Miller, T., \& Callahan, K. J. (2010). Evaluating the Effectiveness of Video Instruction on Social and Communication Skills Training for Children With Autism Spectrum Disorders: A Review of the Literature. Focus on Autism and Other Developmental Disabilities, 25(1), 23-36. doi:10.1177/1088357609352901

Smith, T. (2001). Discrete Trial Training in the Treatment of Autism. Focus on Autism and Other Developmental Disabilities, 16(2), 86-92. doi:10.1177/108835760101600204 
Spreckley, M., \& Boyd, R. (2009). Efficacy of Applied Behavioral Intervention in Preschool Children with Autism for Improving Cognitive, Language, and Adaptive Behavior: A Systematic Review and Meta-analysis. The Journal of Pediatrics, 154(3), 338-344. doi:10.1016/j.jpeds.2008.09.012

Stone, W. L., Ousley, O. Y., \& Littleford, C. D. (1997). Motor imitation in young children with autism: What's the object? Journal of abnormal child psychology, 25(6), 475-485. doi:10.1023/A:1022685731726

Stone, W. L., \& Yoder, P. J. (2001). Predicting spoken language level in children with autism spectrum disorders. Autism, 5(4), 341-361. doi:10.1177/1362361301005004002

Stokes, T.F, \& Baer, D.M. (1977). An implicit technology of generalization. Journal of Applied Behavior Analysis, 10(2), 349-367. doi:10.1901/jaba.1977.10-349

Tereshko, L., MacDonald, R., \& Ahearn, W. H. (2010). Strategies for teaching children with autism to imitate response chains using video modeling. Research in Autism Spectrum Disorders, 4(3), 479-489. doi:10.1016/j.rasd.2009.11.005

Tsiouri, I., Schoen Simmons, E., \& Paul, R. (2012). Enhancing the application and evaluation of a discrete trial intervention package for eliciting first words in preverbal preschoolers with asd. Journal of Autism and Developmental Disorders, 42, 1281-1293. doi:10.1007/s10803-011-1358

Virués-Ortega, J. (2010). Applied behavior analytic intervention for autism in early childhood: Meta-analysis, meta-regression and dose-response meta-analysis of multiple outcomes. Clinical Psychology Review, 30(4), 387-399. doi:10.1016/j.cpr.2010.01.008

Vittinghoff, E., \& McCulloch, C. E. (2007). Relaxing the rule of ten events per variable in logistic and Cox regression. American journal of epidemiology, 165(6), 710-718. doi:10.1093/aje/kwk052

Watkins, M. W., \& Pacheco, M. (2001). Interobserver agreement in behavioral researcher: Importance and calculation. Journal of Behavioral Education, 10(4), 205-212. doi: $10530819 / 00 / 12000205$

Watson, J. B. (1925). Behaviorism. Transaction Publishers.

Young, J.M., Krantz, P.J., McClannahan, L.E., Poulson, C.L. (1994). Generalized imitation and response-class formation in children with autism. Journal of Applied Behavior Analysis. 27(4). 685-697. doi:10.1901/jaba.1994.27-685 
Young, G. S., Rogers, S. J., Hutman, T., Rozga, A., Sigman, M., \& Ozonoff, S. (2011). Imitation from 12 to 24 months in autism and typical development: A longitudinal Rasch analysis. Developmental Psychology. doi:10.1037/a0025418 


\section{APPENDICES}
A. MIS Data Collection Sheet
B. Parent and Family Technology Survey Form
C. List of target behaviors 
Appendix A: MIS Data Collection Sheet

Name:

Motor Imitation

Skills Assessment

Date:

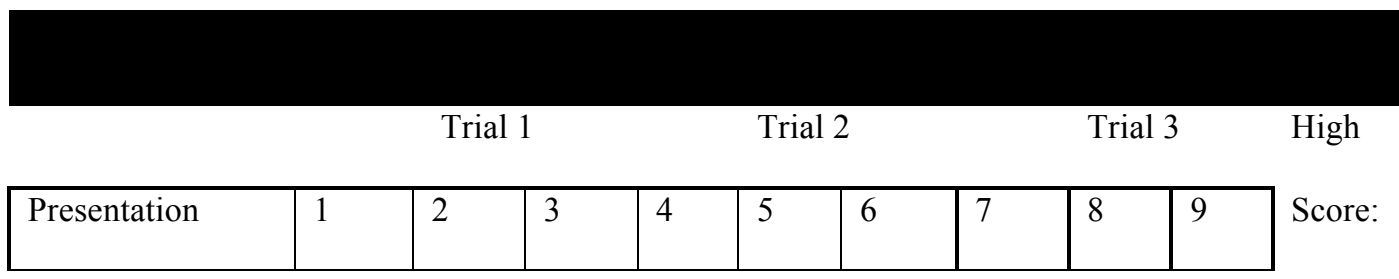

\begin{tabular}{|l|l|l|l|l|l|l|l|l|l|l|}
\hline Shake Egg & & & & & & & & & & \\
\hline Push Car & & & & & & & & & & \\
\hline Walk Lion & & & & & & & & & & \\
\hline Hold Beads & & & & & & & & & & \\
\hline Bang Spoon & & & & & & & & & & \\
\hline Push Teacup & & & & & & & & & & \\
\hline Walk Hairbrush & & & & & & & & & & \\
\hline Block on Head & & & & & & & & & & \\
\hline Clap & & & & & & & & & & \\
\hline Wave & & & & & & & & & & \\
\hline Bend Finger & & & & & & & & & & \\
\hline Scratch Table & & & & & & & & & & \\
\hline Open \& Close \\
Fist
\end{tabular}


Total:

\title{
Appendix B: Parent and Family Technology Survey Form
}

\section{Parent and Family Technology Survey}

\author{
Parent/Caregiver Name: \\ Child Name: \\ Date:
}

\section{TECHNOLOGY AT HOME}

Which of the following devices, if any, do you have in your household? Which of the devices in your home is your child allowed to use? (Mark al mat agpiy.

a. Televiaion est

b. Cable or saselles TV

c. Paid video subscription (such as Huru, Neeflix, Amazon Prime)

c. DVD or VHS playar

e. Laptop or desktop computer

f. Smart phone (Whe an (Fhane ar Andraid phano)

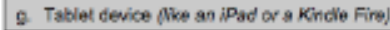

h. Ereader (Whe a Nock or Kindle)

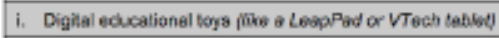

i. Music Player inclueing mp3 players (the an Fod) or stereos

k. Console Caming Devios (Whe an Xbax, Playstiotion, or wi]

l. Hanoheid Gaming Device (Whe a GameBoy, Nintendo DS or PSP)

\section{YOUR USE OF TECHNOLOGY}

On average, how often do YOU do the following activities on a technology device (at home, work or in another location)? (Merk ane for each row)

\begin{tabular}{|c|c|c|c|c|c|}
\hline & Every day & $\begin{array}{l}\text { Several fimes } \\
\text { a week }\end{array}$ & $\begin{array}{l}\text { Once or (wice } \\
\text { os week }\end{array}$ & $\begin{array}{c}\text { Once or twice } \\
\text { a manth }\end{array}$ & Never \\
\hline a. Watch TV & $\square$ & $\square$ & $\square$ & $\square$ & $\square$ \\
\hline b. Wateh DVDs or videotapes & $\square$ & $\square$ & $\square$ & $\square$ & $\square$ \\
\hline c. Sand ar rescive email & $\square$ & $\square$ & $\square$ & $\square$ & $\square$ \\
\hline $\begin{array}{l}\text { d. Sand ar recolva taxt mossages or } \\
\text { instent messeges }\end{array}$ & $\square$ & $\square$ & $\square$ & $\square$ & $\square$ \\
\hline 6. Listen to masic & $\square$ & $\square$ & $\square$ & $\square$ & $\square$ \\
\hline $\begin{array}{l}\text { 1. Do school-sistaled work (for yoursalt, } \\
\text { not your chid's school] }\end{array}$ & $\square$ & $\square$ & $\square$ & $\square$ & $\square$ \\
\hline 2. Do job-related work & $\square$ & $\square$ & $\square$ & $\square$ & $\square$ \\
\hline $\begin{array}{l}\text { h. Regd books, nemspespers of } \\
\text { megazines on a tablet or e-reader } \\
\text { (such se Kinde or Nooth) }\end{array}$ & $\square$ & $\square$ & $\square$ & $\square$ & $\square$ \\
\hline 1. Watch anine vidoos ch a computor & $\square$ & $\square$ & $\square$ & $\square$ & $\square$ \\
\hline $\begin{array}{l}\text { i. Watch online videcs on mobile devices } \\
\text { (such as ced phane, i Pod, or Pad) }\end{array}$ & $\square$ & $\square$ & $\square$ & $\square$ & $\square$ \\
\hline 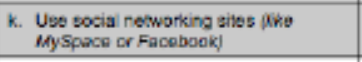 & $\square$ & $\square$ & $\square$ & $\square$ & $\square$ \\
\hline $\begin{array}{l}\text { 1. Pay games on a cansele pleyer (such } \\
\text { as Xbax, Playstation, or Wi) }\end{array}$ & $\square$ & $\square$ & $\square$ & $\square$ & $\square$ \\
\hline $\begin{array}{l}\text { m. Pay games an a computar (laptop ar } \\
\text { deshtiop) }\end{array}$ & $\square$ & $\square$ & $\square$ & $\square$ & $\square$ \\
\hline $\begin{array}{l}\text { n. Pay games an mobile devices (such } \\
\text { as coll phane, Pod, or Pod) }\end{array}$ & $\square$ & $\square$ & $\square$ & $\square$ & $\square$ \\
\hline $\begin{array}{l}\text { 0. Uso mabile device for purposa ohor } \\
\text { than games (ffor example, using } \\
\text { apps to acosss tho local waather, } \\
\text { news, ar maps) }\end{array}$ & $\square$ & $\square$ & $\square$ & $\square$ & $\square$ \\
\hline
\end{tabular}




\section{Parent and Family Technology Survey}

\section{MAKING DECISIONS ABOUT TECHNOLOGY USE}

Where do you get information about technology that can help your child learn? imark al that apaly.

$\square$ a. From my inends, relaives, or ether parents

$\square$ b. Fram the media (Whe TV, magazines, nowspopars, anlhe nows sires!

$\square$ c. Fram my chlld's school (toachers or adiministrators)

$\square$ d. Fram community arganizations (such as abrary, community confor, roligious contorf)

$\square$ a. Fram chidran (my own ar othars)

$\square$ f. Ofhar (clasase spocty).

How much do you agree or disagree with the following statements? (Mork ane for asch row.)

\begin{tabular}{|c|c|c|c|c|}
\hline 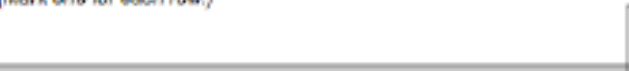 & $\begin{array}{l}\text { Strongly } \\
\text { disegree }\end{array}$ & Disagres & Agres & $\begin{array}{l}\text { STrongly } \\
\text { sgreo }\end{array}$ \\
\hline $\begin{array}{l}\text { a. Most of tha time, I [or anather adult) docida what shows, channats, } \\
\text { websites, or wideo gomes my child may view or play. }\end{array}$ & $\square$ & $\square$ & $\square$ & $\square$ \\
\hline $\begin{array}{l}\text { b. Most of tha time, I (or another adult) docida what fochoology } \\
\text { devices (compuler, iPad, phone, atc.) my child may use. }\end{array}$ & $\square$ & $\square$ & $\square$ & $\square$ \\
\hline $\begin{array}{l}\text { c. Most of the time, I (or another adult) decide when my child may } \\
\text { wase vethndegy. }\end{array}$ & $\square$ & 口 & $\square$ & $\square$ \\
\hline $\begin{array}{l}\text { d. Most of the time, I (or another aduli) decide how muoh time my } \\
\text { child may apend using tochnology. }\end{array}$ & $\square$ & $\square$ & $\square$ & $\square$ \\
\hline
\end{tabular}

Please tell us how YOU use technology (watch television, use the computer, play video games, etc.) with your child. (Mork av that sppy.)

$\square$ 8. Encourage my child to use technology

$\square$ b. Set up shows, cipital games, apps, or ather technology for my child

$\square$ c. Help with technology probloms whila my child is watchinglpleying fifor oxampio, if the game "freezes" or the camputer needs to be restarled

$\square$ d. Answer questions my child has abou: the contert he or she is watchinglalaying

$\square$ e. Set limis an my child's use of lechnology

$\square$ r. Aak questions to check that my child is leaming

$\square$ g. Talk with my child about what he or she is watchingldaing wth the technology

$\square$ h. Watch TY shows, movies or videos with my child

$\square$ i. Pley digtal games or spps with my child

$\square$ j. Make connectons between the showe/gamee my child watcheejplays and things wo do in our daily life flor example, falk about how we are using a fecipe for beking cookies, just hine Curicus George used a frcipe)

$\square k$. Mlske connectons between the showelgamee rry child watches/plays and things I krow he or she is learning at schood for exampie, taik sbout how Big Bird is sending a letter, just fike you child sant valentine cards to his chassonatos at schoou

How do your children interact with one another when they are using technology (watching TV, using the computer, etc.)? (Mark all thet acply.

$\square$ a. I anly have one child

$\square$ b. They watch TV or videos iogether

$\square$ c. They play digital games together (e.g. an a computer, movie device, or ganing console)

口id. Mly older childifen) help my preschocler with tectnology

$\square$ e. My preschooler helps my other childfren] with technelogy

$\square$ f. Other (please specify): 


\title{
Parent and Family Technology Survey
}

What kind of Internet access do you have at home? (Mark ane only.)

\author{
$\square$ a. I dont have intamet access at home \\ $\square$ b. Dial-up telephone sccess (Trrough a modem) \\ $\square$ c. High-spead (such as hroadband, cable modam ar DSL) \\ $\square$ d. I have Internet access at home, but only on a cell phone \\ $\square$ e. I have Internet access at home, but I dont know what kind \\ f. I domt know if I have Intemet access at hame
}

Please describe how and why you control your child's technology use.

8. HOW do you control your chid's sectroliogy use?

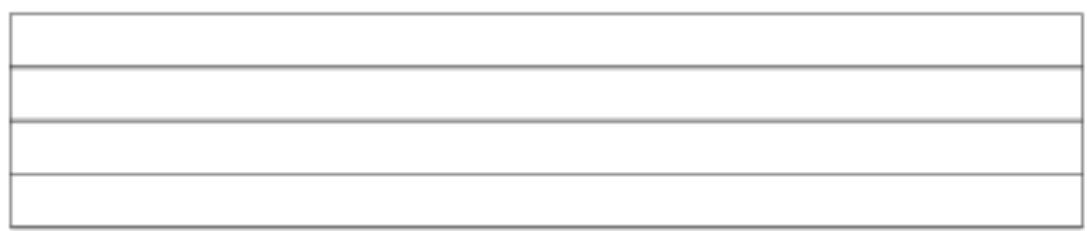

b. WHY do you cortrol your chile's tectholicgy use?

\begin{tabular}{|l|}
\hline \\
\hline \\
\hline \\
\hline
\end{tabular}

If your child uses technology (watches TV, uses the computer, plays video games, etc.) OUTSIDE OF YOUR HOME, where does this occur? (Mark all that apply.)
$\square$ a. At a daycare or childeare certer
$\square$ b. As the library
$\square$ c. Al a relative's house
$\square$ d. At a friend's house
De. in the car
$\square$ r. On a bus or train
口. Al a community center
$\square$ h. At church or other religious institution
$\square$ i. Other (plosese specty).

During the week (Monday-Friday), about how much time does your child spend using technology (watching TV, using the computer, playing video games, etc.) each day? (Mark ane any.)

$\square$ a. Lees than half an hour a day

$\square$ b. Half an hour to 1 hour a day

$\square$ c. 1-2 hours a day

$\square$ d. $2-3$ hours a day

$\square$ e. $3-4$ hours a day

D. More ban 4 hours a day 


\section{Parent and Family Technology Survey}

\section{YOUR CHILD'S USE OF TECHNOLOGY}

How often does your child do the following activities at home?

\begin{tabular}{|c|c|c|c|c|c|c|}
\hline & \multicolumn{5}{|c|}{ How of en your chivd does this activity: } & \multirow{2}{*}{$\begin{array}{l}\text { sctivity help } \\
\text { your chadd } \\
\text { leam math? } \\
\text { Nyss, } \\
\text { check heve: }\end{array}$} \\
\hline & $\begin{array}{l}\text { Every } \\
\text { day }\end{array}$ & $\begin{array}{c}3 \propto 4 \text { limi6s } \\
\text { a week }\end{array}$ & $\begin{array}{c}\text { Ones or mitos } \\
\text { a week }\end{array}$ & $\begin{array}{c}\text { Onse ar Wics } \\
\text { a month }\end{array}$ & Never & \\
\hline 8. Watch TV & $\square$ & 0 & $\square$ & 0 & $\square$ & $\square$ \\
\hline b. Watch OVDs of videctapess & $\square$ & $\square$ & $\square$ & $\square$ & $\square$ & $\square$ \\
\hline $\begin{array}{l}\text { c. Sand or rocolve messages (Mhe } \\
\text { text, email or instant messages) }\end{array}$ & $\square$ & $\square$ & $\square$ & $\square$ & $\square$ & $\square$ \\
\hline d. Listen to music & $\square$ & $\square$ & $\square$ & $\square$ & $\square$ & $\square$ \\
\hline a. Do school-ralatad work & $\square$ & $\square$ & $\square$ & $\square$ & $\square$ & $\square$ \\
\hline $\begin{array}{l}\text { f. Read or look at books on an } \\
\text { erfeader (such) \&s Kinclite or Nook) }\end{array}$ & $\square$ & $\square$ & $\square$ & $\square$ & $\square$ & $\square$ \\
\hline $\begin{array}{l}\text { g. Watch orline videcs on a } \\
\text { computer }\end{array}$ & $\square$ & $\square$ & $\square$ & $\square$ & $\square$ & $\square$ \\
\hline $\begin{array}{l}\text { h. Watch orline videcs on mobile } \\
\text { devices (such es cel phore, } \\
\text { Pad, or IPad) }\end{array}$ & $\square$ & $\square$ & $\square$ & $\square$ & $\square$ & $\square$ \\
\hline $\begin{array}{l}\text { 1. Pay video gamas on a consola } \\
\text { player (such as Xbar, } \\
\text { Playstation, or Wi) }\end{array}$ & $\square$ & $\square$ & $\square$ & $\square$ & $\square$ & $\square$ \\
\hline $\begin{array}{l}\text { 1. Pley games an a compuler } \\
\text { (faptop ar deshitiop) }\end{array}$ & $\square$ & $\square$ & $\square$ & $\square$ & $\square$ & $\square$ \\
\hline $\begin{array}{l}\text { k. Pay games an mobile devices } \\
\text { (such as ced phone, ifod. } \\
\text { or Pad] }\end{array}$ & $\square$ & $\square$ & $\square$ & $\square$ & $\square$ & $\square$ \\
\hline $\begin{array}{l}\text { L. Use appes on mabile dovices } \\
\text { other than games }\end{array}$ & $\square$ & $\square$ & $\square$ & $\square$ & $\square$ & $\square$ \\
\hline
\end{tabular}

When your child uses technology at home (watches TV, uses the computer, plays video games, ete.), how does he or she use it? (Mark av that agply)

a. On hisher own

$\square$ b. With me or another parant ar guardiar

$\square$ c. With brothers of sisters

$\square$ d. With other childen (for exsmple, friends or cousine)

$\square$ 6. With grandparents

$\square$ r. With ather adull relatives for exsmple, acunts or uncles;

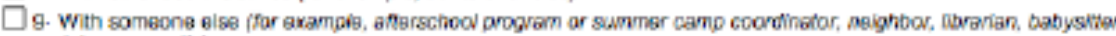
(please specilify).

While your child uses technology at home (watehing TV, using the computer, playing video games, etc.), what are you typically doing? (Mork al that apply.)

$\square$ 8. Cooking of doing household chores of tasks the cleaning or peying bells:

$\square$ b. Caring tor other chitdren

$\square$ c. Working

$\square$ d. Taking with friends of family

$\square$ e. Taking with my child about shat he or she is watching or plsying

$\square$ f. Watching TV or videos together with my child

$\square$ 9. Playing digital games together with my child (on any device)

$\square$ h. Watching or playing seperately from my child (on ancther device)

$\square$ L. Other (plesses specily). 
Appendix C: List of Behaviors

Imitation Tasks

1. Squeeze horn

2. Shake clapper

3. Roll ball

4. Scratch rake

5. Flip disk

6. Lift slinky

\section{Instructions}

- If child performs a task during baseline move to the next on the list until all tasks have been attempted

- Begin second station (VM or LM) with task following the one used during the first station (VM or LM) 
VITA

\section{LOGAN MCDOWELL}

2009

2014

2014

2015

Bachelor of Arts, Political Studies, Bard College.

Annandale-On-Hudson, NY.

Master in Science, Psychology. Florida International University. Miami, FL.

Board Certified Behavior Analyst

Doctoral Candidate, Psychology, Florida International University. Miami, Florida.

\section{PUBLICATIONS AND PRESENTATIONS}

Further Comparison of Video Prompting with and Without Voiceover Narration. Kyle D. Bennett, Anibal Gutierrez Jr., Logan S. McDowell, Elizabeth D. Cramer and Christina Crocco. FABA (2014).

Evaluating a Video-Modeling Procedure for Teaching Imitation to Young Children with ASD. Logan McDowell and Anibal Gutierrez. FABA (2013)

A core deficits centered curriculum for early intervention. Logan McDowell and Anibal Gutierrez. CARD (2014)

Evaluating a gum-chewing procedure for decreasing post-meal rumination in a young child with autism. Logan McDowell and Anibal Gutierrez. ABAI (2014)

Analyzing predictors of success with a video-modeling intervention technique. Logan McDowell and Anibal Gutierrez, Jr. FABA (2014)

Using Video-Modeling to Teach Imitation to a Young Child with Autism. Logan McDowell and Anibal Gutierrez. ABAI (2013)

Analyzing the relationship between social skills and success with a video-modeling intervention technique. Logan McDowell, Anibal Gutierrez, Jr. ABAI (2015) [Accepted]

McDowell, L.S., Gutierrez, A., Bennett, K.D. (in press). Analysis of live modeling plus prompting and video modeling for teaching imitation to children with autism. 
Behavioral Interventions. doi:10.1002/bin.1419 